\title{
Revisão das espécies de Ceroplastinae Atkinson (Hemiptera, Coccoidea, Coccidae) do Estado de São Paulo, Brasil
}

\author{
Ana Lúcia Benfatti Gonzalez Peronti ${ }^{1}$, Carlos Roberto Sousa-Silva ${ }^{1} \&$ Maria Cristina Granara de Willink ${ }^{2}$
}

\begin{abstract}
${ }^{1}$ Departamento de Ecologia e Biologia Evolutiva, UFSCar, Caixa Postal 676, 13. 565-905 São Carlos-SP. anaperonti@hotmail.com.br ${ }^{2}$ Consejo Nacional de Investigaciones Científicas y Técnicas (CONICET), Fundación Miguel Lillo e Instituto Superior de Entomologia "Dr. Abraham Willink" (ISUE), Faculdad de Ciências Naturales e Instituto Miguel Lillo, Universidad Nacional de Tucumán, Miguel Lillo 205, 4000 San Miguel de Tucumán, Argentina.
\end{abstract}

\begin{abstract}
Revision of the species of Ceroplastinae Atkinson (Hemiptera, Coccoidea, Coccidae) from the state of São Paulo, Brazil. The species of Ceroplastinae (Hemiptera, Coccoidea, Coccidae) from the state of São Paulo are revised. Thirty-six species are studied, 9 are synonymyzed, 8 new species are described and 19 known species are redescribed. Ceroplastes campinensis Hempel, 1901, C. bicolor Hempel, 1901, C. excaericae Hempel, 1912 and C. farmairii (Signoret, 1866) were not studied because the type material or other specimens were not found. Our studies indicate that C. albolineatus Cockerell, 1894 and C. confluens Cockerell \& Tinsley, 1898 were erroneously cited by Hempel, 1900 as occurruing in the state of São Paulo. Coccus stellifer Westwood, 1871, currently Vinsonia stellifera (Westwood, 1871), is transferred to Ceroplastes as Ceroplastes stellifer (Westwood, 1871) n. comb. Ceroplastes flosculoides Matile-Ferrero, 1993 is recorded for the first time in Brazil and Ceroplastes cassiae (Chavannes, 1848), C. deodorensis Hempel, 1937, C. formosus Hempel, 1900 and C. quadratus Green, 1935 are recorded for the first time for state of São Paulo. The Ceroplastinae is now represented by 31 species in the state of São Paulo, all included in the genus Ceroplastes. Identification key and illustrations for species are included. New synonyms are proposed: $C$. formicarius Hempel = Ceroplastes communis Hempel, 1900 n. syn.; C. janeirensis Gray, $1828=$ Ceroplastes psidii $($ Chavannes, 1848) n. syn. $=$ C. simplex Hempel, 1900 n. syn.; C. cirripediformis Comstock, $1881=$ C. cultus Hempel, 1900 n. syn. = C. cuneatus Hempel, 1900 n. syn. $=$ C. rarus Hempel, 1900 n. syn and C. rotundus Hempel, 1900 n. syn.; C. lucidus Hempel, $1900=C$. novaesi Hempel, 1900 n. syn.; C. grandis Hempel, $1900=$ C. rhizophorae Hempel, 1918 n. syn. New species described are: $C$. acutus sp. nov.; $C$. bragai sp. nov.; $C$. coronatus sp. nov; $C$. glomeratus sp. nov; C. jordanensis sp. nov.; $C$. minimus sp. nov.; $C$. solanaceus sp. nov.; $C$. willinkae sp. nov. Redescribed species are: C. agrestis Hempel, $1932 ; C$. cassiae; C. cirripediformis; C. deodorensis; C. diospyros Hempel, 1928; C. floridensis Comstock, 1881; C. flosculoides; C. formicarius Hempel, 1900; C. formosus Hempel, 1900; C. grandis; C. gregarius Hempel, 1932; C. iheringi Cockerell, 1895; C. janeirensis; C. lucidus; C. purpureus Hempel, 1900; C. quadratus; C. speciosus Hempel, 1900; C. stellifer $\mathbf{n}$. comb. and C. variegatus Hempel, 1900. Lectotypes and paralectotypes of $C$. agrestis, C. deodorensis, C. diospyros, $C$. purpureus, C. formosus, C. speciosus and C. variegatus and a neotype for $C$. cassiae are designated.
\end{abstract}

KEYWORDS. Ceroplastes; Ceroplastidia; Vinsonia; Waxiella; revision.

RESUMO. Revisão das espécies de Ceroplastinae Atkinson (Hemiptera, Coccoidea, Coccidae) do Estado de São Paulo, Brasil. As espécies de Ceroplastinae (Hemiptera, Coccoidea, Coccidae) que ocorrem no Estado de São Paulo são revisadas. São estudadas 36 espécies de Ceroplastinae, das quais 9 são sinonimizadas, 8 espécies novas são descritas e 19 são redescritas. Ceroplastes campinensis Hempel, 1901, C. bicolor Hempel, 1901, C. excaericae Hempel, 1912 e C. farmairii (Signoret, 1866), mencionadas para o Estado de São Paulo, não foram examinadas, devido a não localização do material tipo ou de outros exemplares. Nossos estudos indicaram que C. albolineatus Cockerell, 1894 e C. confluens Cockerell \& Tinsley, 1898 foram erroneamente citadas por Hempel, 1900 para o estado de São Paulo. Coccus stellifer Westwood, 1871, atualmente Vinsonia stellifera (Westwood, 1871), é transferida para gênero Ceroplastes como Ceroplastes stellifer (Westwood, 1871) n. comb. C. flosculoides Matile-Ferrero, 1993 é registrada pela primeira vez para o país e $C$. cassiae (Chavannes, 1848), C. deodorensis Hempel, 1937, C. formosus Hempel, 1900 e C. quadratus Green, 1935 são registradas pela primeira vez no Estado de São Paulo. Ceroplastinae é agora representada por 31 espécies no Estado de São Paulo, todas incluídas no gênero Ceroplastes. Ilustrações e uma chave para espécies são incluídas. Novos sinônimos: C. formicarius Hempel = Ceroplastes communis Hempel, 1900 n. sin.; C. janeirensis Gray, $1828=$ Ceroplastes psidii (Chavannes, 1848) n. sin. $=$ C. simplex Hempel, 1900 n. sin.; . cirripediformis Comstock, $1881=$ C. cultus Hempel, 1900 n. sin. = C. cuneatus Hempel, 1900 n. sin. = C. rarus Hempel, 1900 n. sin e C. rotundus Hempel, 1900 n. sin.; C. lucidus Hempel, $1900=$ C. novaesi Hempel, 1900 n. sin.; C. grandis Hempel, $1900=$ C. rhizophorae Hempel, 1918 n. sin. Novas espécies descritas: $C$. acutus sp. nov.; C. bragai sp. nov.; C. coronatus sp. nov; C. glomeratus sp. nov; $C$. jordanensis sp. nov.; $C$. minimus sp. nov.; $C$. solanaceus sp. nov.; $C$. willinkae sp. nov. Espécies redescritas: $C$. agrestis Hempel, 1932; C. cassiae (Chavannes, 1848); C. cirripediformis; C. deodorensis Hempel, 1900; C. diospyros Hempel, 1928; C. floridensis Comstock, 1881; C. flosculoides Matile-Ferrero, 1993; C. formicarius Hempel, $1900 ; C$. formosus Hempel, 1900; C. grandis Hempel, 1900; C. gregarius Hempel, 1932; C. iheringi Cockerell, $1895 ;$ C. janeirensis; C. lucidus; C. purpureus Hempel, 1900; C. quadratus Green, 1935; C. speciosus Hempel, 1900; C. stellifer e C. variegatus Hempel, 1900. São designados lectótipos e paralectótipos para C. agrestis, C. deodorensis, C. diospyros, C. formosus, C. purpureus, C. speciosus e C. variegatus e um neótipo para C. cassiae.

PALAVRAS-CHAVE. Ceroplastes; Ceroplastidia; Vinsonia; Waxiella; revisão. 
Conhecidos popularmente por cochonilhas cerosas, os Ceroplastinae (Hemiptera, Coccoidea, Coccidae) são separados dos demais cocóideos por apresentarem espessa carapaça cerosa que recobre o corpo das fêmeas adultas. A cera geralmente apresenta-se dividida em placas que se desenvolvem ao redor de núcleos centrais, variando conforme a espécie, na forma, consistência, cor e tamanho.

As cochonilhas cerosas encontram-se distribuídas por todas as regiões zoogeográficas, especialmente na África e na América do Sul que concentram 36,1\% e 36,8\% dos registros dos espécimes-tipo, respectivamente (Ben-Dov 1993).

Os Ceroplastinae tem como espécie-tipo, Coccus janeirensis Gray, 1828, por subseqüente designação de Fernald (1903), coletada no Brasil sobre Solanum sp. (Solanaceae) (Gimpel et al. 1974). Com uma única tribo, Ceroplastini, possui 149 espécies e 7 subespécies (Ben-Dov 1993; Matile-Ferrero \& Couturier, 1993; Ben-Dov et al. 2000; Granara de Willink 1999) distribuídas em sete gêneros. Ceroplastidia Cockerell, 1910, Cerostegia De Lotto, 1969, Gascardia Targioni Tozzetti, 1893 e Paracerostegia Tang, 1991 tem seu status controvertido e Ceroplastes Gray, 1828, Vinsonia Signoret, 1872 e Waxiella De Lotto, 1971 são considerados gêneros válidos pela maioria dos autores (De Lotto 1965; Gimpel et al. 1974, Ben-Dov 1993; Hodgson 1994).

A revisão da história taxonômica da subfamília e uma nova classificação do grupo baseada em análise cladística foram apresentadas por Qin \& Gullan (1995). Esses autores concluíram que as cochonilhas cerosas podem constituir um grupo monofilético dentro do gênero Ceroplastes.

As chaves de identificação de gênero e espécie do grupo são baseadas principalmente nas fêmeas adultas (Hodgson 1994); os machos são raros e, até o momento, apenas os de Ceroplastes ceriferus (Fabricius, 1798), C. cirripedifornis Comstock, 1881 e Waxiella berliniae Hall, 1931 foram adequadamente descritos (Giliomee 1967; Gimpel et al. 1974).

Vários autores contribuíram para o conhecimento da subfamília, em diversas partes do mundo (Ben-Dov 1993). Entre os mais recentes destacam-se, Pellizzari \& Camporese (1994) para a região Paleártica (Zona Mediterrânea) e Qin \& Gullan (1994) e Hodgson \& Henderson (2000) para a região Australiana.

A região Neotropical, apesar de reunir um grande número de espécies do grupo, é carente de estudos de revisão. Na América do Sul, Mosquera $(1979,1984)$ revisou as espécies de Ceroplastes que ocorrem na Colômbia e descreveu C. bicolor, C. boyacensis, C. cundinamarcensis, C. martinae, C. ocreus e C. trochezi, redescreveu C. floridensis Comstock, $1881 \mathrm{e}$ apresentou uma chave para as 7 espécies presentes na região; Marín-Loayza \& Cisneros-Vera $(1994,1995)$ registraram $C$. utilis Cockerell, 1893, C. brachyurus Cockerell, 1903 e C. rusci (Linnaeus, 1758) para o Peru, redescreveram C. flosculoides que havia sido descrita por Matile-Ferrero \& Couturier (1993) para a Amazônia Peruana, e estudaram o ciclo de desenvolvimento de $C$. cirripediformis Comstock, 1881 e $C$. floridensis sobre plantas de laranja e maracujá, respectivamente. Granara de Willink (1999) fez a revisão das espécies de Coccidae da Argentina, propôs nova combinação para C. argentinus Brethes, 1921, C. bruneri Cockerell \& Cockerell, 1902, C. deciduosus Morrison, 1919, C. grandis Hempel, 1900, C. leonardianus Lizer \& Trelles, 1911, C. longiseta Leonardi, 1911, C. lucidus Hempel, 1900 e C. novaesi Hempel, 1900, agrupando-as no gênero Ceroplastidia; reconheceu 4 espécies de Ceroplastes para o país, $C$. cirripediformis, C. formicarius Hempel, 1900, C. janeirensis Gray, 1828 e C. rusci, apresentando chaves e redescrições para as mesmas.

Para o Brasil, até o momento, 41 espécies haviam sido registradas, 40 de Ceroplastes e 1 de Vinsonia (Gray 1828; Chavanes 1848; Targioni Tozzetti 1866; Cockerell 1895; Cockerell \& Tinsley 1898; Hempel 1900a, b, 1901a, b, 1912, 1918, 1920, 1928, 1932, 1937 e 1938; Green 1935 e Costa Lima 1940). Entre essas, 29 espécies foram mencionadas para o Estado de São Paulo, sendo 16 exclusivas para essa região, 10 distribuídas principalmente em alguns países da América do Sul, e 4 com distribuição ampla (Ben-Dov 1993).

As descrições e redescrições de espécies para o Estado de São Paulo foram feitas por Hempel entre 1900 e 1932. Após esse período, as referências às espécies dessa subfamília estão relacionadas a novas ocorrências, principalmente em plantas cultivadas (Silva et al. 1968; Zucchi et al. 1993; Caloba \& Silva 1995; Peña \& Bennett 1995; Peronti et al. 2001; Borges et al. 2003). Tendo em vista o registro de novas espécies e a necessidade de descrições atualizadas fez-se a presente revisão para o Estado de São Paulo.

\section{MATERIALE MÉTODOS}

Amostra de Ceroplastinae foram coletadas entre março de 2000 a setembro de 2002 em áreas preservadas, áreas urbanas e áreas cultivadas de várias localidades do Estado de São Paulo. Foram também analisados exemplares das coleções entomológicas do Instituto Biológico de São Paulo (IBSP), Museu de Zoologia da Universidade de São Paulo (MZSP), Departamento de Zoologia, Universidade Federal do Paraná (DZUP), Coleção Entomológica do Instituto Oswaldo Cruz, Fundação Oswaldo Cruz (FOCB), do Departamento de Ecologia e Biologia Evolutiva da Universidade Federal de São Carlos (DCBU), The Natural History Museum (BMNH), Londres; National Museum of Natural History (USNM), Washington, D.C. e Zoölogisch Museum (ZMAN), Amsterdam. As cochonilhas, coletadas sobre ramos e folhas de plantas infestadas, assim como parte dos exemplares provenientes do IBSP, FOCB e DZUP, preservados a seco, foram fixados em álcool a $70 \%$ e posteriormente, preparados e montados em lâminas permanentes, utilizando-se a técnica descrita por Granara de Willink (1990).

Todos os exemplares estudados foram identificados ou agrupados em morfo-espécies, principalmente com base na observação dos espécimes-tipo e caracteres morfológicos mencionados na literatura (Costa Lima 1940; De Lotto 1965, 1970, 1971; Gimpel et al. 1974); Gomes Costa \& Redaelli 1949; Hempel 1900a, 1901a, 1912, 1918, 1920, 1928, 1932, 1937, 1938; 
Granara De Willink 1999; Ihering 1897; Matile-Ferrero \& Couturier 1993; Mosquera 1979, 1984 e Reyne 1964).

Entre as espécies provenientes de outros estados ou países, tiveram os espécime-tipo analisados: Ceroplastes actiniformis Green, 1896 (BMNH), C. albolineatus Cockerell, 1894 (USNM), C. albolineatus vulcanicus Cockerell, 1903 (BMNH, USNM), C. amazonicus Hempel, 1900 (MZSP), C. avicenniae Newstead, 1917 (BMNH), C. brachyurus Cockerell, 1903 (USNM), C. bruneri Cockerell \& Cockerell, 1902, C. caesalpiniae Reyne, 1964 (ZMAN), C. circundatus Green, 1923 (BMNH), C. cistudiformis Cockerell, 1893 (USNM), C. coloratus Cockerell, 1898 (BMNH, USNM), C. combreti Brain, 1920 (USNM), C. confluens Cockerell \& Tinsley, 1898 (USNM), C. deceptrix (De Lotto, 1965), C. dugesii Lichtenstein, 1885 (BMNH), C. eugeniae Hall, 1931 (BMNH), C. eucleae Brain, 1920 (USNM), C. giganteus Dozier, 1931 (USNM), C. itatiayensis Hempel, 1938 (MZSP), C. lepagei Costa Lima, 1940 (FOCB), C. magnicauda Reyne, 1964 (ZMAN), C. japonicus Green, 1921 (USNM), C. parvus Green, 1935 (BMNH), C. quadratus Green, 1935 (BMNH) e C. rusci (Linnaeus, 1758) (USNM). Outras espécies foram comparadas com base na literatura.

As dimensões da cera e do corpo dos insetos foram tomadas sob microscópico estereoscópico e microscópio biológico. As magnitudes foram dadas em milímetros para o comprimento e largura do corpo e do processo caudal e em mícrons para as demais estruturas tratadas. As ilustrações foram realizadas por A.L.B.G. Peronti com uso de microscópio óptico, equipado com câmara-clara e a finalização artística por G. Marconato.

As descrições e redescrições seguem a teminologia adotada por Gimpel et al. (1974) e Granara de Willink (1995; 1999), com algumas adaptações.

As plantas hospedeiras foram identificadas utilizando-se as obras de Lorenzi (1994, 1997, 1998, 2000), Lorenzi \& Souza (1999) ou enviadas a especialistas.

\section{CEROPLASTINAEAtkinson}

Ceroplastaria Atkinson, 1886: 276

Ceroplastinae Atkinson; Bodenheimer, 1952: 317; Hodgson, 1994: 43 Gênero-tipo: Ceroplastes Gray, 1828

Descrição: Cera: varia na cor, consistência e espessura; geralmente apresenta-se dividida em 7 a 9 placas, uma dorsal, 2 ou três pares laterais, uma anterior e uma ou duas posteriores; as placas, posterior, anterior e laterais possuem um núcleo central, e a posterior pode apresentar um ou dois núcleos; as placas laterais apresentam ainda duas bandas estigmáticas, geralmente de cor branca (Fig.1a, b).

Corpo: com contorno oval, circular, ou semicircular; geralmente com um tubérculo dorsal, dois ou três laterais e um anterior. Processo caudal esclerotizado e cônico, alongado e dirigido para trás; ou curto, podendo, em algumas espécies, apresentar a área esclerotizada estendendo-se sobre o dorso na região mediana do corpo (Fig. 2).

Superfície dorsal: poros com contorno circular (Fig. 3: A1-
A2, A9, A11-A12), oval (Fig. 3: A3-A6), triangular (Fig. 3: A7A8), quadrangular (Fig. 3: A10) ou irregular (Fig. 3: A13); com 1 a 5 lóculos (Fig. 3: A1-A11, A13), raramente com 6 ou mais (Fig. 3: A12); poros monolculares podem apresentar condutos simples (Fig. 3: A1) ou ramificados (Fig. 3: A2) e em algumas espécies como em Ceroplastes rusci podem ter aparência de biloculares (Fig. 3: A3), como observado por Pellizzari \& Camporese (1994) e aqui denominados de poros monoloculares "tipo rusci"; poros biloculares e triloculares com contorno triangular de dois tipos, com lóculos de tamanhos distintos, aqui designados: bilocular "tipo I", quando um dos lóculos é bem maior que o outro (Fig. 3: A4); bilocular "tipo II", quando os lóculos são de tamanhos aproximados, (Fig. 3: A5); trilocular "tipo I", quando apresenta dois lóculos menores de mesmo tamanho nos vértices da base do triângulo e um lóculo maior central (Fig 3: A7) e, trilocular "tipo II", quando apresenta três lóculos de igual tamanho (Fig. 3: A8). O bilocular "tipo I" geralmente é encontrado em toda a superfície dorsal e o bilocular "tipo II" encontra-se mais concentrado na região submarginal da superfície dorsal. Setas cônicas ou cilíndricas com ápices variáveis (Fig. 3: B1-B15). Áreas claras (correspondentes aos tubérculos) desprovidas de poros e setas (Fig. 2). Placas anais do processo caudal, geralmente muito esclerotizadas, localizadas na extremidade do processo caudal, com 3 ou 4 setas dorsais e 2 ou 3 ventrais (Fig. 2). Poros pré-operculares geralmente com uma única abertura, podendo ser crivados em algumas espécies (Fig. 3: E). Ápice do processo caudal geralmente desprovido de setas, podendo estar presente, em algumas espécies, 2 ou 3 pares (Figs. 80, 95, 104, 105, 107).

Margem: setas estigmáticas distribuídas em toda a margem do corpo (Figs. 83, 89, 94); em parte da margem do corpo (Figs. $80,82,84,90,92,95,99,103,104,106,107,109,110)$ ou agrupadas no ápice dos canais estigmáticos (Figs. 81, 91, 93, 96, 97, 98, $101,102,105)$ que variam no número, forma e comprimento (Fig. 3: C1-C26), podendo ocorrer mais de um tipo na mesma espécie. Setas marginais (Fig. 2) mais finas que as anteriores, distribuídas em toda a margem, variam em número e comprimento.

Superfície ventral: antenas com 6 a 8 artículos; pernas geralmente pouco desenvolvidas, com ou sem esclerotização tíbio-tarsal; pernas curtas, com tíbia e tarso distintos, raramente fusionados. Sulco dos canais estigmáticos, geralmente bem definidos. Poros genitais geralmente distribuídos ao redor da vulva, podendo estar presente até os primeiros segmentos abdominais; geralmente com 10 lóculos, podendo variar entre 6 a 12; poros dos canais estigmáticos, geralmente pentaloculares, podendo variar entre 3 a 10; poros cruciformes dispersos em toda a superfície ventral, embora mais concentrados na região submarginal (Fig. 2). Condutos tubulares com formato e comprimento variáveis (Fig. 3: D1D8), podendo ser encontrados nos últimos segmentos abdominais e na região cefálica e, em um menor número de espécies, na região submarginal (Fig. 2). Setas submarginais curtas e finas acompanhando as marginais (Fig. 2); número de setas interantenais geralmente reduzido, 1 a 3 na base de cada 
antena; raramente apresentam-se numerosas, 15 a 20 (Fig. 108).

Discussão: as espécies aqui estudadas foram mantidas ou incluídas no gênero Ceroplastes como sugerido por Qin \& Gullan (1995). Esses autores demonstraram, através da análise cladística, que as cochonilhas cerosas podem formar um grupo monofilético e, que entre os gêneros analisados, Waxiella é o único que forma um agrupamento de espécies, suportado por apenas uma sinapomorfia e, portanto, sugerem que esse possa ser considerado um grupo "subenudata species-group" e não um gênero. Entre as espécies de Ceroplastinae estudadas no decorrer desse trabalho, observaram-se novas variações de caracteres como: poros dorsais, monolocular "tipo-rusci” (geralmente presente nas espécies que apresentam a carapaça cerosa dividida em 9 placas), "bilocular tipo I", "bilocular tipo II", "trilocular tipo I", "trilocular tipo II"; presença ou ausência de setas no ápice do processo caudal; presença ou ausência de poros pré-operculares dorsais crivados; diferenças entre o número de setas interantenais; além de características macroscópicas como, o número de placas da carapaça cerosa, presença de um ou dois núcleos na placa posterior, etc. que quando levadas em conta, podem indicar novos agrupamentos, mencionados no item discussão de cada espécie. A maioria dos agrupamentos aqui observados, constituem-se de espécies mencionadas para o Estado de São Paulo, para o Brasil ou que encontram-se distribuídas pela região Neotropical. Entretanto, algumas espécies como $C$. deodorensis Hempel, 1937 e C. iheringi Cockerell, 1895, registradas apenas para o Estado de São Paulo, são muito próximas de espécies mencionadas para o sul da África. Outras espécies nativas como, C. gregarius Hempel, 1900, C. variegatus Hempel, 1900, C. solanaceus Peronti sp. nov., $C$. jordanensis Peronti sp. nov. e $C$. bragai Peronti sp. nov. se aproximam de $C$. cirripediformis Comstock, 1881, amplamente distribuída, bem como, de C. sinensis Del Guercio, 1900, C. cistudiformis Cockerell, 1893 e C. irregularis Cockerell, 1893, mencionadas para América do Norte e A. Central. Devido à ampla distribuição de alguns agrupamentos, provavelmente relacionada com introduções acidentais de espécies, sugerimos que antes que novos grupos, ou até mesmo gêneros sejam propostos, estes devam ser melhor estudados, através de uma revisão geral da subfamília.

Chave de identificação das espécies de Ceroplastes que ocorrem no Estado de São Paulo, baseada nas características das fêmeas adultas.

1. Setas interantenais numerosas (15-20); tíbia e tarso fundidos (Fig. 108)

25. C. stellifer (Westwood) n.comb.

Setas interantenais em número reduzido (1-3); tíbia e tarso distintos 2

2(1). Setas estigmáticas distribuídas na margem do corpo e ventralmente no ápice dos canais estigmáticos (Figs. 80, 82, 83, 84, 89, 90, 92, 94, 95, 99, 103, 104, $106,107,109,110)$. 3

Setas estigmáticas agrupadas no ápice do canal estigmático e na superfície dorsal (Figs. 81, 91, 93, $96,97,98,101,102,105)$. 18

3(2). Setas estigmáticas distribuídas em toda a margem do corpo (Figs. 83, 89, 94) .. 4

Setas estigmáticas distribuídas em parte da margem do corpo (Figs. 80, 82, 84, 90, 92, 95, 99, 103, 104, $106,107,109,110)$

4(3). Antenas com 8 artículos; condutos tubulares presentes na região cefálica, poros pré-operculares simples; setas dorsais capitadas; garras desprovidas de dentículo; processo caudal igual ou maior que $1 / 5$ do comprimento do corpo (Fig. 83) 4. C. cassiae

Antenas geralmente com 7 segmentos; condutos tubulares na região cefálica ausentes, poros préoperculares crivados; setas dorsais cônicas ou truncadas lateralmente; garras com dentículo; processo caudal curto, inferior a 1/5 do comprimento do corpo 5

5(4). Poros dorsais com 2 a 6 lóculos (Fig. 89) 6. C. coronatus Peronti sp. nov.

Poros dorsais com 3 e 4 lóculos, biloculares, pentaloculares e hexaloculares ausentes (Fig. 94) 11. C. formicarius

6(3). Esclerotizaçao tíbio-tarsal ausente (Figs. 80, 92, 95, 104, 107); digítulos da garra geralmente diferentes, um dilatado e um delgado, exceto em Ceroplastes floridensis, que apresenta digítulos da garra iguais (Fig. 92)

Esclerotizaçao tíbio-tarsal presente; digítulos da garra iguais, ambos dilatados (Figs. 82, 84, 90, 99, 103, $106,109,110)$ 11

7(6). Condutos tubulares em toda região submarginal da superfície ventral; poros dorsais com 2 a 4 lóculos; setas dorsais cônicas truncadas (Fig. 92)

9. C.floridensis

Condutos tubulares presentes apenas na região cefálica e nos últimos segmentos abdominais; poros dorsais com 1 a 3 lóculos; setas cilíndricas, geralmente com ápice arredondado; digítulos da garra diferentes; 2 ou 3 pares de setas presentes no ápice do processo caudal .............................. 8

8(7). Processo caudal longo, 1/3-1/2 do comprimento do corpo; condutos tubulares presentes perto das coxas mesotorácicas (Fig. 80)

1. C. acutus Peronti sp. nov.

Processo caudal relativamente curto, 1/5-1/3 do comprimento do corpo; condutos tubulares ausentes nas áreas das coxas 
9(8). Setas estigmáticas distribuídas na margem da região estigmática e prolongando-se apenas um pouco além desta, não formando uma linha marginal contínua entre as regiões estigmáticas; poros da superfície dorsal monoloculares presentes (Fig. 107) 24. C. speciosus

Setas estigmáticas presentes em uma linha contínua entre as regiões estigmáticas; poros da superfície dorsal monoloculares ausentes 10

10 (9). Setas estigmáticas cilíndricas com ápice truncado, ou retangulares (38-40), dispostas em uma só linha entre a inserção das bases das antenas e das coxas posteriores; 3 ou 4 setas maiores formam uma segunda linha no centro do ápice dos canais estigmáticos; digítulos da garra pouco distintos, um pouco mais dilatado que o outro (Fig. 104)

21. C. purpureus

Setas estigmáticas cônicas (80-110) inseridas na margem do corpo entre a altura das antenas até um pouco além da inserção das pernas posteriores; no ápice dos canais estigmáticos estão dispostas em duas ou três linhas; 3 a 4 setas maiores, cilíndricas com ápice truncado ou retangulares estão dispostas no centro; digítulos da garra diferentes, um delgado e outro dilatado (Fig. 95)

12. C. formosus.

11(6). Antenas com 6 segmentos; poros da superfície dorsal monoloculares "tipo rusci" (com aparência de biloculares) e triloculares de contorno triangular (Fig. 90) 7. C. deodorensis

Antenas com 7 segmentos; poros monoculares, quando presentes, não do "tipo rusci" ... 12

12(11). Setas estigmáticas cônicas e cônicas com ápice truncado; poros triloculares com contorno triangular tipo II ausentes (Fig. 99)

17. C. janeirensis

Setas estigmáticas cônicas ou cônicas com ápice obtuso; exceto em C. bragai (Fig. 82) que apresenta uma seta retangular ou cilíndrica com ápice truncado no centro do ápice do canal estigmático; poros triloculares com contorno triangular tipo II presentes ... 13

13 (12). Processo caudal longo e afilado, medindo $2 / 5-1 / 2$ do comprimento do corpo (Fig. 110)

27. C. willinkae Peronti sp. nov.

Processo caudal não ultrapassando $1 / 3$ do comprimento do corpo ............................................ 14

14(13). Setas dorsais cônicas com ápices levemente truncados; condutos tubulares com filamento curto e dilatado (Fig. 103) .

20. C. minimus Peronti sp. nov.
Setas dorsais predominantemente capitadas; condutos tubulares com filamento delgado ......... 15

15(14). Setas estigmáticas cônicas e cônicas com ápice obtuso, sendo uma bem maior ao centro de cada região estigmática; condutos tubulares presentes apenas nos últimos segmentos abdominais, em torno da região genital (Fig. 109) .. 26. C. variegatus

Setas estigmáticas cônicas em sua maioria; condutos tubulares presentes na região cefálica 16

16(15). Setas estigmáticas cônicas, sendo apenas uma retangular no centro de cada região estigmática; condutos tubulares presentes entre a inserção do segundo par de coxas e a margem do corpo; poros dorsais de contorno irregular com 2 a 5 lóculos (Fig. 82) 3. C. bragai Peronti sp. nov.

Setas estigmáticas exclusivamente cônicas; condutos tubulares, entre as coxas medianas e a margem do corpo, ausentes; poros dorsais com contornos irregulares ausentes. 17

17 (16). Poros da superfície dorsal com 2 a 4 lóculos (Fig. 84); superfície ventral membranosa

5. C. cirripediformis

Poros da superfície dorsal com 2 a 8 lóculos; superfície ventral esclerotizada (Fig. 106)

23. C. solanaceus Peronti sp. nov.

18(2). Setas estigmáticas de dois tipos, formando grupos distintos: lanceoladas, dispostas no ápice do canal estigmático e cônicas, estendendo-se sobre a superfície dorsal do corpo do inseto; geralmente com 1 seta na base de cada antena (Fig. 98) 16 C. iheringi

Setas estigmáticas, geralmente de 1 tipo; quando de dois tipos, não formam grupos distintos, as setas de diferentes tamanhos ou formatos encontram-se mescladas (Figs. 81, 91, 93, 96, 97, 101, 102, 105) . 19

19 (18). Área esclerotizada do processo caudal com base ampla, estendendo-se sobre o dorso, pelo menos até a região mediana do corpo (Figs. 91, 93, 96, 101) ... 20

Área esclerotizada do processo caudal geralmente em forma circular ou alongada, não se estendendo sobre a área clara médio-dorsal (Figs. 81, 97, 102, 105) 23

20 (19). Esclerotização tíbio-tarsal presente; digítulos da garra iguais, ambos dilatados (Figs. 96) 13. C. glomeratus Peronti sp. nov.

Esclerotização tíbio-tarsal ausente; digítulos da garra diferentes; um dilatado e o outro delgado .......... 21

21 (20). Área esclerotizada entre os canais estigmáticos, formando uma banda entre os mesmos; antenas 
com 7 segmentos (Fig. 93) ........ 10. C. flosculoides Área esclerotizada ausente entre os canais estigmáticos; antenas com 6 segmentos 22

22 (21). Setas estigmáticas em grupos de 30 a 100, com ápices arredondados, denteados ou truncados; poros genitais distribuídos pela região central do corpo, até o mesotórax; condutos tubulares ausentes na região cefálica (Fig. 91) 8. C. diospyros

Setas estigmáticas de contorno irregular em número inferior a 30; poros genitais restritos aos últimos segmentos abdominais; condutos tubulares presentes na região cefálica (Fig.101)

18. C. jordanensis Peronti sp. nov.

23(19). Antenas com 8 segmentos; esclerotização tíbio tarsal presente; digítulos da garra iguais e dilatados; garras providas de dentículo (Fig. 97)

14. C. grandis

Antenas com 6 segmentos; esclerotização tíbio tarsal ausente; digítulos da garra diferentes; garras desprovidas de dentículo .24

24(23). Condutos tubulares da superfície ventral de dois tipos, os mais longos localizados na região cefálica e nos últimos segmentos abdominais, os mais curtos, distribuídos em toda a região submarginal; cerca de 200 setas estigmáticas cônicas e arredondadas agrupadas no ápice dos canais estigmáticos e estendendo-se sobre o dorso (Fig. 81) ..................................................... 2. C.agrestis

Condutos tubulares de um só tipo localizados na região cefálica e nos últimos segmentos abdominais; setas estigmáticas em menor número inferior a 100; presença de 2 pares de setas no ápice do processo caudal

25(24). Setas estigmáticas cilíndricas, com ápices arredondados ou truncados, em número aproximado de 90 (Fig. 105) ......... 22. C. quadratus

Setas estigmáticas cônicas, com ápices arredondados ou truncados, em grupos de 30 a 40 (Fig. 102) .......

19. C. lucidus

\section{Ceroplastes acutus Peronti sp. nov.}

(Figs. 4-7, 80)

Material tipo: holótipo o (exemplar localizado no centro da lâmina), Brasil, São Paulo, Gália, $N^{\circ} 385$ sobre Machaerium acutifolium (Fabaceae), 01-V-2002, A.L.B.G. Peronti col.; 2 parátipos na mesma preparação do holótipo (DCBU).

Etimologia: o nome da espécie é alusivo ao formato longo e afilado do processo caudal.

Características macroscópicas: (baseado em exemplares vivos).

Cera: rija, com coloração branca; circular em vista dorsal e semicircular em vista lateral; dividida em 1 placa dorsal, 4 laterais, 1 anterior e 1 posterior; placas laterais maiores no comprimento do que na largura; núcleo dorsal visível de coloração negra e núcleos laterais inconspícuos (Figs. 4-6); comprimento, 5mm (4,8-6,5); largura, 4,8mm (3,0-6,0); altura, 4,0 $\mathrm{mm}(3,0-5,0)$.

Corpo: oval, com coloração castanho-clara; tubérculos pouco evidentes (Fig. 7); comprimento, 2,5mm (2,2-4); largura, $1,76 \mathrm{~mm}(0,8-2)$; processo caudal longo e afilado, com $1,17 \mathrm{~mm}$ $(0,8-1,3)$ de comprimento e coloração castanho-escura.

Características microscópicas: Superfície dorsal: com 8 áreas claras, uma na região cefálica, uma na médio-dorsal e 3 pares laterais; setas cilíndricas com 2-3 $\mu \mathrm{m}$ de comprimento, 4$5 \mu \mathrm{m}$ de base e ápice arredondado; poros com 5-6 4 m de diâmetro, monoloculares, biloculares tipo I, triloculares, ovais e triangulares tipo I. Processo caudal com seis setas em seu ápice, três de cada lado, abaixo das placas anais. Placas anais com 3 setas dorsais (Fig. 80).

Margem: com 63 (61-107) setas estigmáticas cônicas dispostas em toda margem do corpo, exceto na cabeça e na região adjacente ao processo caudal; no ápice do canal estigmático estão dispostas em duas ou três linhas, com 3 ou 4 maiores ao centro, retangulares ou cilíndricas com ápice arredondado (Fig. 80).

Superfície ventral: antenas com $195 \mu \mathrm{m}(170-200)$ de

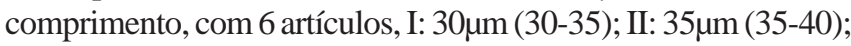

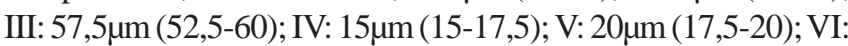
27,5 $\mu \mathrm{m}(20-27,5)$; um par de setas próximas da base de cada

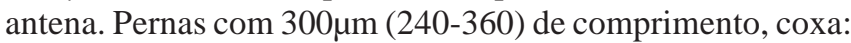
$90 \mu \mathrm{m}$ (80-90); trocanter mais fêmur: $95 \mu \mathrm{m}$ (95-120); tíbia: $80 \mu \mathrm{m}$ (70-80); tarso: $50 \mu \mathrm{m}(50-52,5)$; garra: $17,5 \mu \mathrm{m}$; digítulos tarsais delgados, com extremidades distais dilatadas com $50 \mu \mathrm{m}$ de comprimento; digítulos da garra diferentes, um dilatado e o outro delgado, ambos com 25-27,5 $\mu$ m de comprimento e extremidades distais espatuladas; esclerotização na articulação tíbio-tarsal ausente. Poros dos canais estigmáticos com 5 lóculos; poros cruciformes concentrados na região submarginal; poros genitais com 10 lóculos. Condutos tubulares com filamentos curtos na região cefálica, nos últimos segmentos abdominais e, entre o segundo par de coxas e a margem (Fig. 80).

Material examinado: BRASIL. São Paulo: Guarujá, Praia de Iporanga: (22-III-2002, hospedeiro indeterminado, A.L.B.G. Peronti col.), 1 exemplar em 1 lâmina; Santa Rita do Passa Quatro, Parque Estadual de Vassununga: (24-VII-2002, hospedeiro indeterminado, A.L.B.G. Peronti col.), 10 exemplares em 3 lâminas (DCBU).

Distribuição geográfica: Brasil (São Paulo).

Discussão: assemelham-se a $C$. acutus as espécies: $C$. formosus, C. purpureus Hempel, 1900 e C. speciosus Hempel, 1900 registradas para o Estado de São Paulo; C. itatiayensis Hempel, 1938 conhecido para o estado do Rio de Janeiro, Brasil, e C. magnicauda Reyne, 1964 conhecido para Curaçao por apresentarem antenas com 6 segmentos; ausência de esclerotização na articulação tíbio-tarsal; digítulos da garra diferentes; poros dorsais predominantemente biloculares tipo I e triloculares, ovais e triangulares tipo I; setas dorsais 

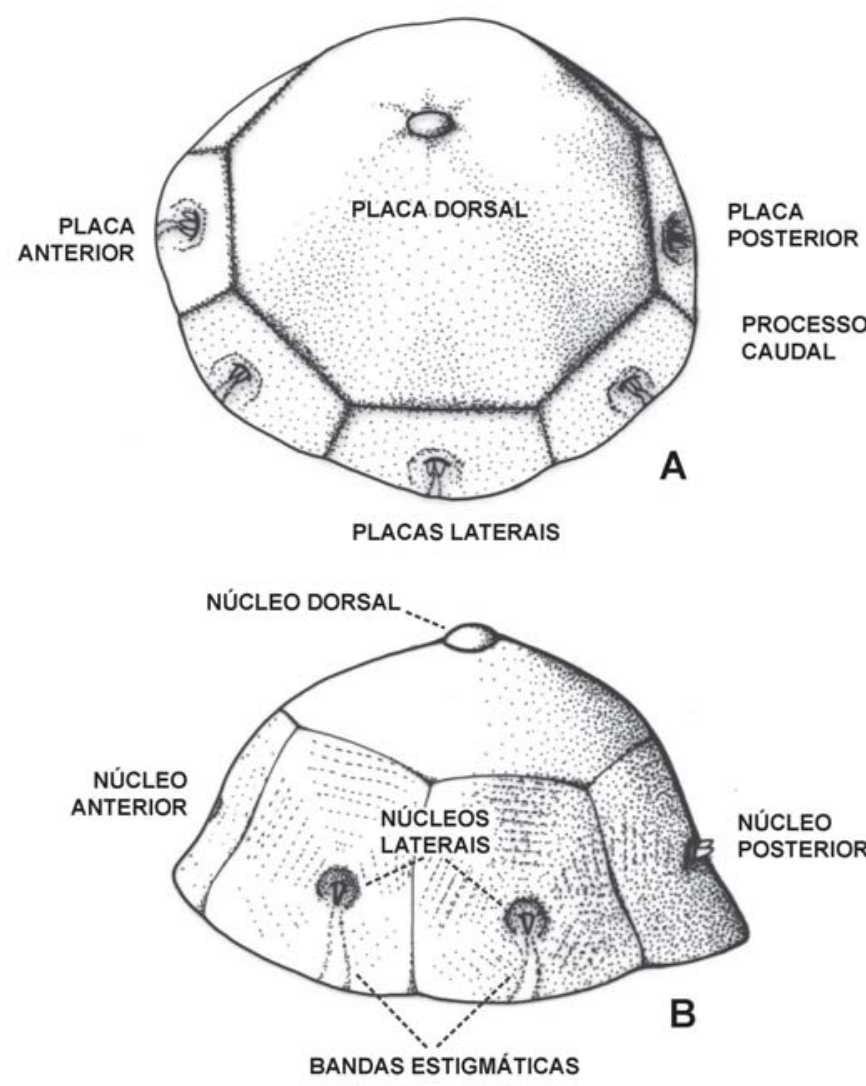

Fig. 1. Carapaça cerosa da fêmea adulta. A. Vista dorsal de um Ceroplastes com carapaça dividida em 9 placas. B. Vista lateral de um Ceroplastes com carapaça dividida em 7 placas.

cilíndricas com ápice arredondado ou truncado e, seis setas no ápice do processo caudal, três de cada lado, abaixo das placas anais. Em vista macroscópica, assemelha-se a $C$. formosus e C. itatiayensis por apresentar uma área mais clara, retangular, acima dos núcleos das placas laterais, anterior e posterior (Fig. 8). C formosus (Fig. 95) difere por apresentar processo caudal curto; ausência de condutos tubulares entre o segundo e o terceiro par de coxas e a margem do corpo e ausência de poros dorsais monoloculares. C. purpureus, difere por apresentar setas estigmáticas com formato retangular; digítulos da garra pouco diferenciados, sendo um apenas um pouco mais dilatado do que o outro; ausência de condutos tubulares entre o segundo e o terceiro par de coxas e a margem do corpo; ausência de poros dorsais monoloculares e processo caudal curto. C. speciosus difere por apresentar dois tipos de setas dorsais, ambas cilíndricas, uma com ápice arredondado e a outra com ápice truncado lateralmente; poro dorsal trilocular tipo II, com contorno circular; setas estigmáticas ausentes na região mediana do corpo; ausência de condutos tubulares entre o segundo e o terceiro par de coxas e a margem do corpo e processo caudal curto. C. itatiayensis (Fig. 8,9) difere por não apresentar condutos tubulares entre o segundo e o terceiro par de coxas e a margem do corpo. C. magnicauda difere por apresentar processo caudal com base mais larga.

\section{Ceroplastes agrestis Hempel}

(Fig. 81)

Ceroplastes agrestis Hempel, 1932: 322; Vernalha, 1953: 123 (cat.); Ben-Dov 1993: 20 (cat.). Síntipos + , Brasil, São Paulo, "Pirapitinguy", sobre planta rasteira silvestre, 31-I-1931, A. Hempel col. (IBSP). Hempel não designou holótipo na descrição original da espécie. Material tipo, preservado a seco, contendo os dados acima mencionados foram localizados no IBSP ( 2 tubos, $\left.\mathrm{N}^{\circ} 430\right)$ e no DZUP ( 1 tubo, $\mathrm{N}^{\circ} 96$ ). Foram preparados 5 exemplares em 2 lâminas do material proveniente do IBSP e aqui designados lectótipo (exemplar localizado à direita na lâmina 430a) e, 4 paralectótipos (exemplar localizado à esquerda na lâmina 430a e, exemplares da lâmina 430b) [examinado].

Características macroscópicas: (baseado em material preservado a seco).

Cera: com placas e núcleos indistintos nos exemplares mais velhos; comprimento, $13,5 \mathrm{~mm}$; largura, $9,75 \mathrm{~mm}$; altura, $9,5 \mathrm{~mm}$.

Corpo: circular, com três pares de tubérculos laterais, um dorsal e outro na extremidade anterior menos desenvolvido; comprimento: 3,4mm (2,5-3,4); largura: 2,2mm (1,75-2,55); processo caudal curto e dirigido para cima.

Características microscópicas: Superfície dorsal: setas de dois tipos, cônicas ou cônicas com ápice truncado; poros com 5-6um de diâmetro, biloculares tipo II, triloculares, com contorno oval e triangular tipo II, tetraloculares e raros pentaloculares. Placas anais com 4 setas dorsais e 1 ventral; anel anal com 6 setas (Fig. 81).

Margem: com 215-300 setas estigmáticas cônicas, algumas

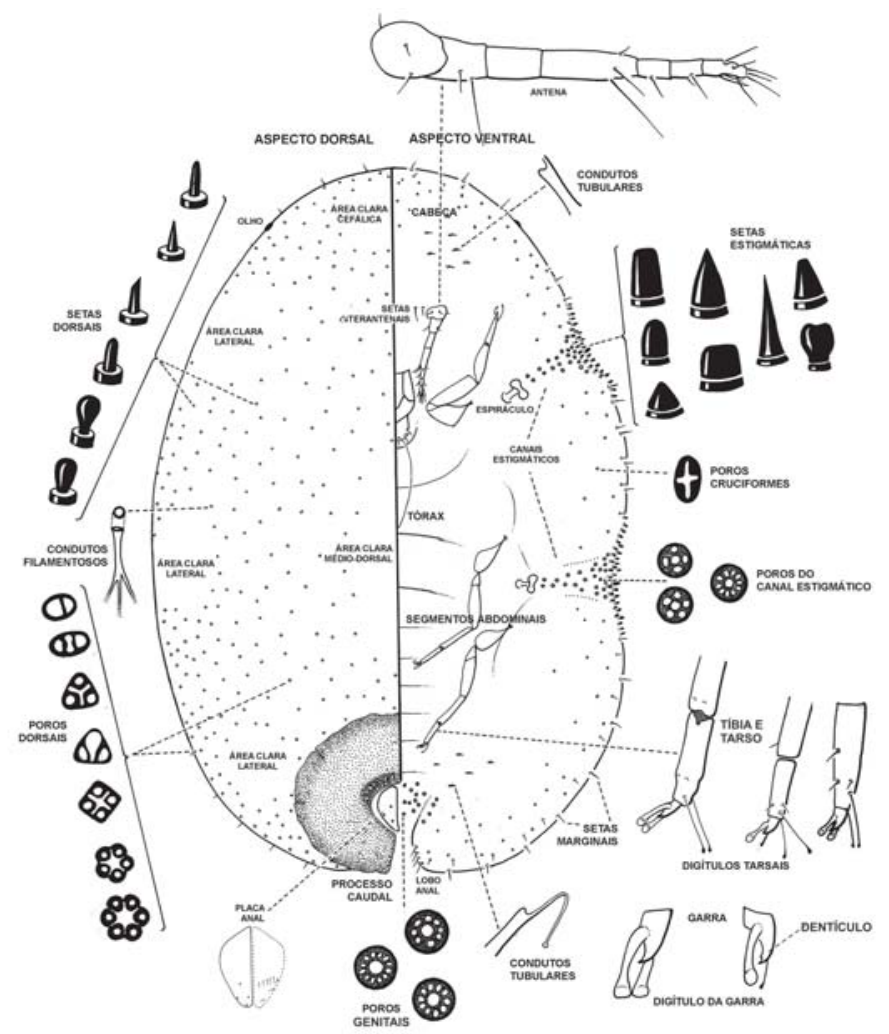

Fig. 2. Estruturas morfológicas microscópicas dos Ceroplastinae. 
com ápices arredondados; setas marginais com $35 \mu \mathrm{m}$ de comprimento (Fig. 81).

Superfície ventral: antenas com cerca de 190 $\mu \mathrm{m}(170-190)$

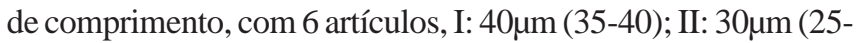

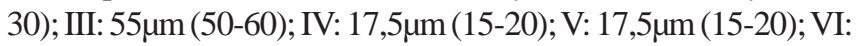

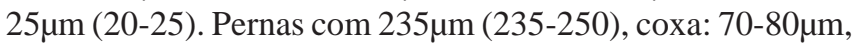

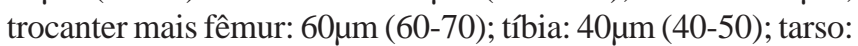
$30 \mu \mathrm{m}$ (30-40); garra: 10 $\mu \mathrm{m}$ (10-12,5); digítulos tarsais delgados com extremidades distais dilatadas e 22,5-25 $\mu \mathrm{m}$ de comprimento; digítulos da garra diferentes, um dilatado e o outro delgado, ambos com 15-17,5 $\mu \mathrm{m}$ de comprimento e extremidades distais espatuladas; esclerotização na articulação tíbio-tarsal ausente. Condutos tubulares de dois tipos, os da região cefálica e dos últimos segmentos abdominais são mais compridos, com filamentos curtos e delgados e, os da região submarginal, mais curtos e com filamentos dilatados, apresentam-se distribuídos também entre o primeiro e o segundo par de pernas (Fig. 81).

Distribuição geográfica: Brasil (São Paulo).

Discussão: assemelham-se a $C$. agrestis as espécies: $C$. floridensis, cosmopolita e C. combreti Brain, 1920, C. deceptrix (De Lotto, 1965) e C. rusticus De Lotto, 1961, conhecidos para a África do Sul, por apresentarem antenas geralmente com 6 segmentos; esclerotização tíbio-tarsal ausente e condutos tubulares formando uma banda na região submarginal da superfície ventral, embora em $C$. agrestis estes últimos difereciem-se por serem de dois tipos. Além disso, C. floridensis difere por apresentar setas estigmáticas distribuídas na margem, além do ápice dos canais estigmáticos, 3 pares de setas interantenais e digítulos da garra iguais e dilatados. $C$. combreti, C. deceptrix e C. rusticus, diferem por apresentar setas estigmáticas em menor número, setas dorsais com ápice arredondado e digítulos da garra iguais.

\section{Ceroplastes bragai Peronti sp. nov. (Figs. 82)}

Material tipo: holótipo + , Brasil, São Paulo, Campos do Jordão, $\mathrm{N}^{\circ}$ 327, hospedeiro indeterminado, 24-XI-2001, S.M.P. Braga col. (DCBU).

Etimologia: O nome da espécie é dedicado a Dra. Sandra Maria Pasenow Braga que coletou o holótipo.

Características macroscópicas: (baseado em exemplares vivos).

Cera: rija, fina, com coloração roxo-clara; oval em vista dorsal e semicircular em vista lateral; dividida em 1 placa dorsal, 4 laterais, 1 anterior e 1 posterior mais larga; núcleo dorsal grande e laterais menores; placa posterior com dois núcleos, um de cada lado da fenda do processo caudal; comprimento, $3 \mathrm{~mm}$; largura, $2,1 \mathrm{~mm}$ e altura, $2,2 \mathrm{~mm}$.

Corpo: comprimento, $2,12 \mathrm{~mm}$; largura, $1,67 \mathrm{~mm}$.

Características microscópicas: Superfície dorsal: com 8 áreas claras, uma na região cefálica, uma médio-dorsal e 3 pares laterais. Setas capitadas com 5-6 $4 \mathrm{~m}$ de comprimento; poros geralmente com contorno irregular, biloculares tipo II; triloculares, ovais e triangulares tipo II, tetraloculares e,
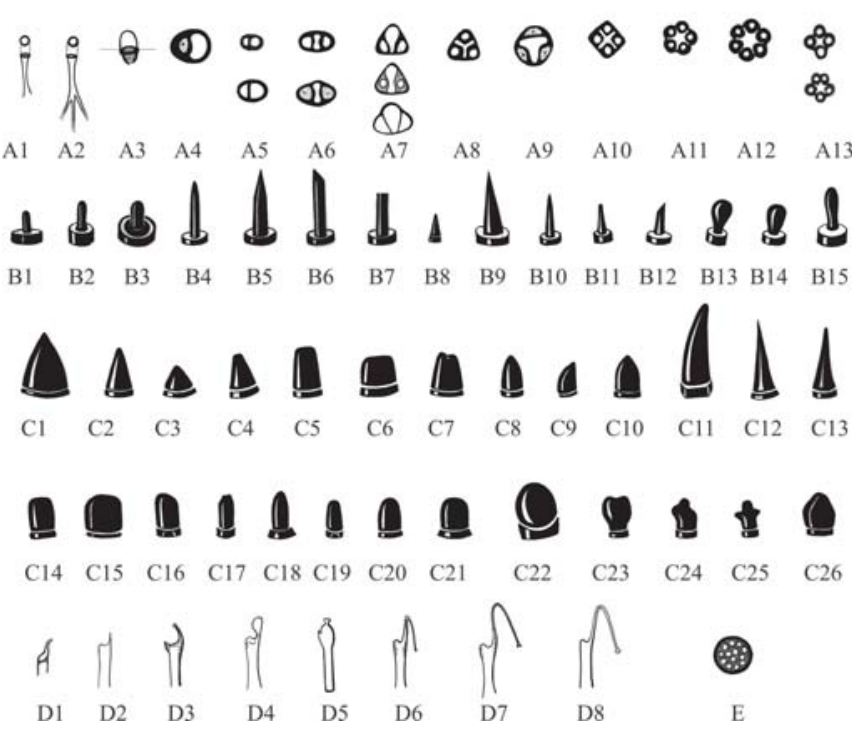

Fig. 3. Variações de alguns caracteres microscópicos de importância taxonômica. A1-A13, poros dorsais: A1, monolocular com conduto simples; A2, monolocular com conduto ramificado; A3, monolocular "tipo rusci"; A4, bilocular "tipo I"; A5, bilocular "tipo II"; A6, trilocular com contorno oval; A7, trilocular "tipo I" com contorno triangular ; A8, trilocular "tipo II" com contorno triangular ; A9, trilocular "tipo II" com contorno circular; A10, tetralocular; A11, pentalocular; A12, hexalocular; A13, tetralocular e pentalocular com contorno irregular. B1-B15, setas dorsais, B1-B3, cilíndrica com ápice arredondado; B4, B5, cilíndricas com ponta; B6, cilíndrica com ápice truncado lateralmente; B7, cilíndrica com ápice truncado; B8-B10, cônicas; B11, cônica com ápice truncado; B12, cônica com ápice truncado lateralmente; B13-B15, capitadas. C1-C26, setas estigmáticas: C1-C3, cônicas; C4-C6, cônicas com ápices truncados; C7, cônica com ápice denteado; C8-C11, cônicas com ápices obtusos; C12-C13, pontiagudas; C14, C15, cilíndricas com ápices truncados ou retangulares; C16, C17, cilíndricas com ápice truncado lateralmente; C18-C21, cilíndricas com ápices arredondados; C22, arredondada; C23-C25, com contorno irregular; C26, pentagonal. D1-D8, condutos tubulares; D1, curto com filamento dilatado; D2, com filamento curto delgado; D3, com filamento em forma de foice; D4, com filamento curto e dilatado; D5 com bulbo dilatado e filamento curto; D6, com filamento longo; D7, com filamento longo e ápice espatulado; D8, com filamento longo e ápice globoso. E1, poro pré-opercular crivado.

escassos pentaloculares. Processo caudal curto (Fig. 82).

Margem: 23-27 setas estigmáticas cônicas de diferentes tamanhos dispostas em 3 linhas na margem dos canais estigmáticos e prolongando-se em uma só linha um pouco além destes; uma seta estigmática central com ápice truncado. Cerdas marginais longas com 17,5-25 $\mu \mathrm{m}$ de comprimento (Fig. 82).

Superfície ventral: setas submarginais com 5-7,5 $\mu \mathrm{m}$ de

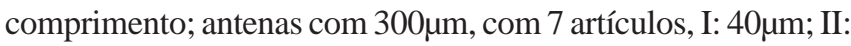

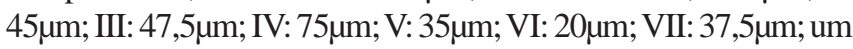
par de setas próximas da base de cada antena. Pernas com 542,5 $\mu \mathrm{m}$ de comprimento, coxa: 157,5 $\mu \mathrm{m}$; fêmur mais trocanter:

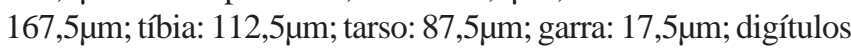
tarsais delgados com extremidades distais dilatadas com $57,5 \mu \mathrm{m}$ de comprimento; digítulos da garra iguais, dilatados, com extremidades distais espatuladas e $27,5 \mu \mathrm{m}$ de 

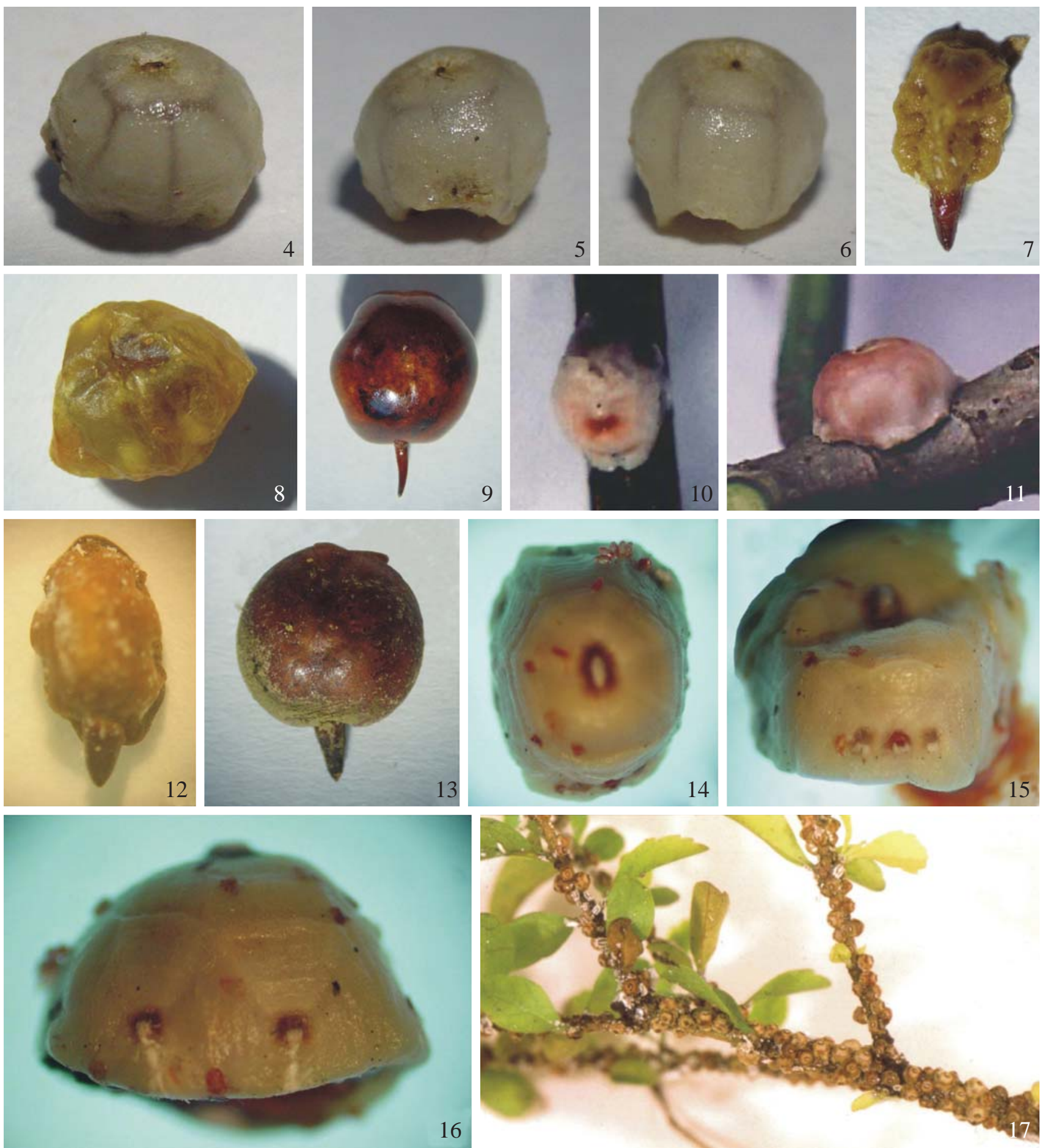

Figs. 4-17. 4-7, Ceroplastes acutus: 4, vista lateral; 5, placa posterior; 6, placa anterior; 7, corpo despido de cera. 8, 9: Ceroplastes itatiayensis: 8, vista dorsal; 9, corpo despido de cera. 10-12, Ceroplastes cassiae: 10, vista dorsal; 11, vista lateral; 12, corpo despido de cera. 13, Ceroplastes lepagei: 13, corpo despido de cera. 14-17, Ceroplastes cirripediformis: 14, vista dorsal; 15, placa posterior; 16, vista lateral; 17, infestação sobre ramo de Duranta repens var. aurea (Verbenaceae).

comprimento; esclerotização na articulação tíbio-tarsal presente. Poros dos canais estigmáticos com 5 lóculos; poros cruciformes concentrados na região submarginal; poros genitais com 10 lóculos. Condutos tubulares com filamento longo e delgado presentes na região cefálica, entre a inserção do segundo par de coxas e a margem e, nos últimos segmentos abdominais (Fig. 82).

Distribuição geográfica: Brasil (São Paulo).

Discussão: assemelham-se a C. bragai sp. nov. as espécies: C. gregarius Hempel, 1900; C. variegatus Hempel, 1900; C. 
solanaceus sp. nov. mencionadas para o Estado de São Paulo, Brasil; C. cirripediformis Comstock, 1881 e C. sinensis Del Guercio, 1900, amplamente difundidas e C. cistudiformis Cockerell, 1893, registrada para a América Central e América do Norte. Semelhanças e diferenças entre elas, ver discussão de $C$. cirripediformis.

\section{Ceroplastes cassiae (Chavannes) (Figs.10-12, 83)}

Coccus cassiae Chavannes, 1848: 141; Westwood, 1853: 484 (redescr.). Sintipos + , Brasil, Rio de Janeiro, Botafogo, sobre Cassia sp. [desaparecido]. É aqui designado Neótipo + , Brasil, São Paulo, Gália, Estação Ecológica de Caetetus No 387 sobre Machaerium acutifolium (Fabaceae), 01-V-2002, A.L.B.G. Peronti col.), 1 exemplar em 1 lâmina (DCBU).

Columnea gray Targioni Tozzetti, 1866:145 (tax., renomeação injustificada); Targioni Tozzetti 1868: 728 (sin.).

Ceroplastes gray (Targioni Tozzetti); Targioni Tozzetti 1868: 728 (sin.).

Ceroplastes cassiae (Chavannes); Signoret, 1869: 848 (tax); 1872: 43 (redescr., tax); Hempel, 1900b: 452 (redescr.); Silva et al., 1968: 137 (cat.); Ben-Dov, 1993: 24 (cat.).

Características macroscópicas: (baseado em exemplares vivos).

Cera: rija, espessa, com coloração rósea; quando branca, com uma mancha rósea na placa dorsal ou na placa posterior. Oval em vista dorsal (Fig. 10) e semicircular em vista lateral (Fig. 11); dividida em 7 placas, 1dorsal, 4 laterais, 1 anterior e, 1 posterior com subdivisão na borda inferior; apenas o núcleo dorsal é visível; placas laterais maiores no comprimento do que na largura com um rebordo fino na extremidade basal; placas anterior e posterior, projetam-se para frente e para trás, respectivamente; comprimento, $6,5 \mathrm{~mm}(6,5-9,5)$; largura, $5 \mathrm{~mm}$ (5-8); altura, 4mm (4-7).

Corpo: oval, de coloração castanho-clara e tubérculos pouco desenvolvidos; comprimento, 3,25mm (3,25-5,5); largura, $1,6 \mathrm{~mm}(1,6-3)$. Processo caudal cônico, dirigido para trás, com $0,8 \mathrm{~mm}(0,75-2)$ de comprimento e de coloração castanho-escura ou negra (Fig. 12).

Características microscópicas: Superfície dorsal: com 8 áreas claras, uma na região cefálica, uma na médio-dorsal e 3 pares laterais. Setas com cerca de $3-4 \mu \mathrm{m}$ de comprimento e ápices arredondados. Poros biloculares tipo II, triloculares, de contorno oval e de contorno triangular tipo I e, escassos monoloculares. Poros pré-operculares simples. Placas anais com 3 setas dorsais (Fig. 83).

Margem: setas estigmáticas cônicas e cônicas com ápice

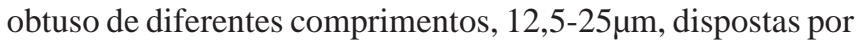
toda margem do corpo, em duas linhas, no ápice dos canais estigmáticos; setas marginais dispostas entre as setas estigmáticas com 15 a 17,5 $\mu$ m de comprimento (Fig. 83).

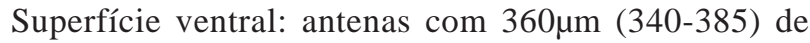

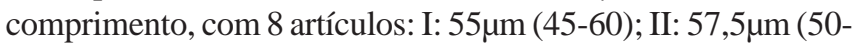

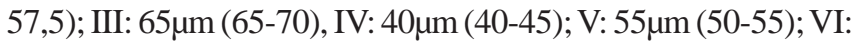

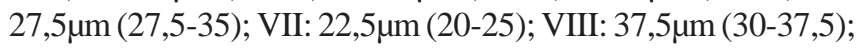
um par de setas próximas da base de cada antena. Pernas com

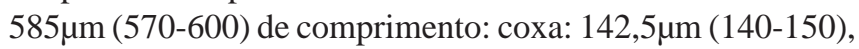

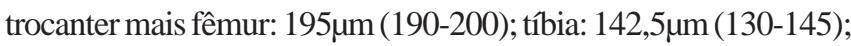

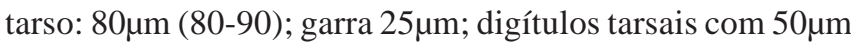
(50-60) de comprimento e extremidades distais dilatadas;

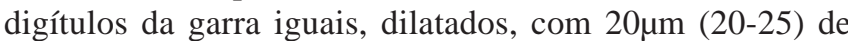
comprimento, com as extremidades distais espatuladas; esclerotização na articulação tíbio-tarsal presente. Poros do canal estigmático com 5 lóculos; poros cruciformes em toda a superfície ventral, mais concentrados na área submarginal; poros genitais com 10 lóculos distribuídos pela região central do corpo até o mesotórax. Condutos tubulares escassos, com filamento delgado e curto, presentes na região cefálica e nos últimos segmentos abdominais (Fig. 83).

Exemplares examinados: BRASIL. São Paulo: Campinas (19-XI1934, figueira-branca, E. J. Hamblenton col.), 1 exemplar em 1 lâmina; (III-1930, hospedeiro indeterminado, A. Hempel col.), 1 exemplar em 1 lâmina (IBSP); Descalvado: (15.III.2001, Croton piptocalyx, K.R.N. Cirelli col.), 1 exemplar em1 lâmina (DCBU); Gália: (11-1934, planta silvestre, O. Costa col.), 1 exemplar em 1 lâmina (IBSP); Estação Ecológica de Caetetus (01-V-2002, Ficus citrifolia, A.L.B.G. Peronti col.), 1 exemplar em 1 lâmina; (01-V-2002, Machaerium acutifolium, A.L.B.G. Peronti col.), 1 exemplar em 1 lâmina (DCBU).

Santa Rita do Passa Quatro, Parque Estadual de Vassununga (24VII-2002, hospedeiro indeterminado, A.L.B.G. Peronti col.), 1 exemplar em 1 lâmina, (DCBU).

Distribuição geográfica: Brasil (Rio de Janeiro e São Paulo).

Discussão: assemelham-se a $C$. cassiae as espécies: $C$. amazonicus Hempel registrada apenas para Manaus, Amazonia, Brasil; Ceroplastes lepagei Costa Lima, 1940, espécie registrada apenas para o estado do Rio de Janeiro, Brasil; Ceroplastes martinae Mosquera, 1984 e Ceroplastes trochezi Mosquera, 1984, conhecidos para a Colômbia, por apresentarem setas estigmáticas em toda a margem do corpo; poros da superfície dorsal predominantemente bilocular tipo II e triloculares, de contorno oval e de contorno triangular tipo I; processo caudal longo; esclerotização na articulação tíbiotarsal presente e digítulos da garra iguais e dilatados. $C$. amazonicus difere por apresentar setas estigmáticas apenas do tipo cônico. C. lepagei (Fig. 13) difere por apresentar antenas com 7 segmentos e ausência de condutos tubulares na região cefálica; $C$. martinae difere por apresentar poros tetraloculares na superfície dorsal; ausência de condutos tubulares na região cefálica e antenas com 7 segmentos. $C$. trochezi difere por apresentar antenas com 7 segmentos e setas estigmáticas de dois tipos, cônicas com ápice obtuso e cônicas com ápice truncado. Não foi encontrado, nos museus nacionais e internacionais, nenhum exemplar da série-tipo de C. cassiae. Exemplares encontrados no IBSP, com a identificação de C. cassiae, coletados por Hempel e Hamblenton, na década de 30, sobre figueira-branca ou sobre hospedeiro indeterminado, são provenientes do estado de São Paulo, localidade e hospedeiro diferentes da série-tipo, proveniente de Botafogo, Rio de Janeiro e coletada sobre Cassia sp. Outros exemplares encontrados no MZSP, com identificação da espécie, não possuem qualquer referência de hospedeiro ou localidade. A descrição da espécie feita por Chavannes, 1847, baseada principalmente nas características macroscópicas da fêmea adulta, de forma muito simplificada, 

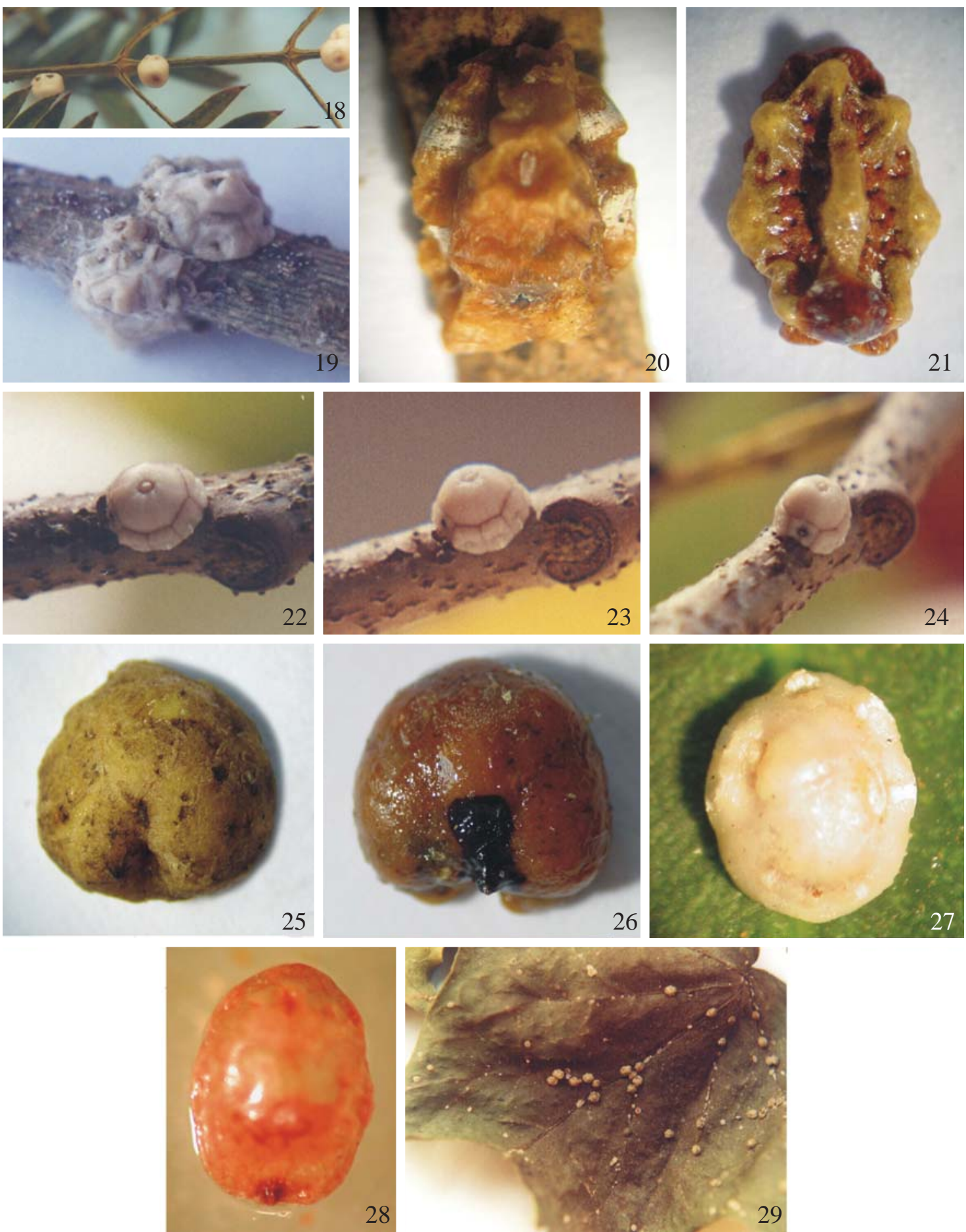

Figs. 18-29. 18, 19, Ceroplastes cirripediformis (variações na coloração e forma da carapaça cerosa): 18, sobre caule de D. repens var. aurea; 19, sobre ramos de Jacaranda sp. (Bignoniaceae). 20, 21, Ceroplastes coronatus: 20, vista dorsal; 21, corpo despido de cera. 22-24, Ceroplastes deodorensis: 22, vista dorsal; 23, vista lateral; 24, placa posterior. 25-26, Ceroplastes diospyros: 25, vista dorsal; 26, corpo despido de cera. 2729, Ceroplastes floridensis: 27, vista dorsal; 28, corpo despido de cera; 29, infestação sobre folhas de Hedera canariensis (Araliaceae).

coincide com a dos exemplares coletados no decorrer desse trabalho. Embora não tenham sido encontrados exemplares provenientes da localidade-tipo e espécie hospedeira do material-tipo original, o Neótipo aqui designado provém de epécie hospedeira da mesma família botânica e de região geográfica relativamente próxima.

\section{Ceroplastes cirripediformis Comstock}

(Figs. 14-19, 84-88)

Ceroplastes cirripediformis Comstock, 1881: 333; Silva et al., 1968: 137 (cat.); Gimpel et al., 1974: 29 (redescr. e ilustr. do $0^{\text {t }}$ e ? ); Gill, 1988: 18 (redescr. e ilustr.); Johnson \& Lion, 1988: 356 (ilustr.); 
Ben-Dov, 1993: 27 (cat.); Marín-Loayza \& Cisneros-Vera, 1994: 50 (redescr.); 1995: 52 (biol.); Peña \& Bennett, 1995: 334 (cit.). Lectótipo +, designado por Gimpel et al., U.S.A., Florida, Stanford, sobre Eupatorium sp. (USNM) [examinado].

Ceroplastes plumbaginis Cockerell, 1893: 82; Gimpel et. al., 1974: 29 (desig. sin.); Síntipos o e ninfas. Antigua, sobre Plumbago capensis (USNM) [não examinado].

Ceroplastes euphorbiae Cockerell, 1896: 17; Gimpel et. al., 1974 (desig. sin.); Síntipos \&, Jamaica: distrito Red Hill, sobre Euphorbia hypercifolia (USNM) [não examinado].

Ceroplastes mexicanus Cockerell, 1896: 20; Gimpel et. al., 1974 (desig. sin.); Síntipos + , México: San Luis Potosi, sobre Catalpa sp. (USNM) [não examinado].

Ceroplastes cerripidiformis Comstock; Houser, 1918:159 (erro de grafia).

Ceroplastes breviseta Leonardi; Granara de Willink, 1999: 49 (desig. sin.); Lectótipo e paralectótipo + , Argentina, sobre Atriplex lampa (IEAP, IFML) [examinado].

Ceroplastes cultus Hempel, 1900a: 470; Vernalha, 1953: 125 (cat.); Silva et al., 1968:138; Ben-Dov, 1993: 29. Síntipos 우, Brasil, São Paulo, Ipiranga, sobre Erigeron canadensis; 2 exemplares em 1 lâmina, (MZSP) [examinado]. n. sin.

Ceroplastes cuneatus Hempel, 1900a: 491; Vernalha, 1953: 125 (cat.); Silva et al., 1968:138; Ben-Dov, 1993: 30. Síntipos + , Brasil, São Paulo, Ipiranga, sobre Erigeron canadensis; 2 exemplares em 1 lâmina (MZSP) [examinado]. n. sin.

Ceroplastes rarus Hempel, 1900a: 469 Vernalha, 1953: 130 (cat.); Ben-Dov, 1993: 48. Síntipos + , Brasil, São Paulo, Ipiranga, sobre planta nativa; 2 exemplares em 1 lâmina (MZSP); 2 exemplares em 1 lâmina (BMNH) [examinado]. n. sin.

Ceroplastes rotundus Hempel, 1900a: 473 Vernalha, 1953: 130 (cat.); Silva et al., 1968:140; Ben-Dov, 1993: 49. Síntipos 우, Brasil, São Paulo, Ipiranga, sobre Maytenus sp.; 2 exemplares em 1 lâmina (MZSP); 1 exemplar em 1 lâmina (BMNH) [examinado]. n. sin.

Características macroscópicas: (baseado em exemplares vivos).

Cera: rija, fina, coloração branco-amarelada ou brancoacinzentada; oval em vista dorsal (Fig. 14) e semicircular ou cônica em vista lateral (Fig. 16); dividida em 1 placa dorsal, 4 laterais, 1 anterior e 1 posterior mais larga; núcleos conspícuos, sendo o dorsal o maior; placa posterior com dois núcleos, um de cada lado da fenda do processo caudal (Fig. 15); comprimento, 3,2mm (3,0-5,5); largura, 2,3mm $(2,0-4,5)$ e altura, 2,4mm (2,2-4,1).

Corpo: oval, coloração castanho-clara e com tubérculos pouco desenvolvidos; comprimento, 2,3 $\mathrm{mm}$ (2,1-3,7); largura, $1,3 \mathrm{~mm}(1,3-2,8)$; processo caudal curto, dirigido para trás e coloração castanho-escura.

Características microscópicas: Superfície dorsal: com 8 áreas claras, uma na região cefálica, uma na médio-dorsal e 3 pares laterais. Setas de dois tipos, cilíndricas com ápice arredondado ou capitado. Poros biloculares tipo II; triloculares, com contorno oval e triangular tipo II; tetraloculares, pentaloculares escassos ou ausentes. Processo caudal curto; poros pré-operculares simples; placas anais com 4 setas dorsais e 1 ventral (Fig. 84).

Margem: com 26 (16-60) setas estigmáticas cônicas, de diferentes tamanhos, dispostas em 3 a 4 linhas no ápice dos canais estigmáticos e prolongando-se lateralmente, em uma só linha, um pouco além destes; setas marginais dispostas entre as setas estigmáticas com cerca de $25 \mu \mathrm{m}$ de comprimento (Fig. 84).
Superfície ventral: antenas com 310 $\mu$ m (255-310) de

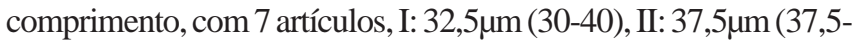
40), III: $50 \mu \mathrm{m}(50-62,5)$, IV: $60 \mu \mathrm{m}(60-80)$, V: $25 \mu \mathrm{m}$ (25-30), VI: 25 $\mu \mathrm{m}$ (25-30) e VII: $35 \mu \mathrm{m}$ (35-42,5); um par de setas próximas da base de cada antena. Pernas com 415um (410-480) de comprimento, coxa: $90 \mu \mathrm{m}$ (90-120); trocanter mais fêmur: $120 \mu \mathrm{m}$

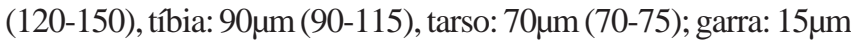
(15-25); presença de esclerotização na articulação tíbio-tarsal; digítulos tarsais delgados, com extremidades distais dilatadas, com $42,5 \mu \mathrm{m}(42,5-50)$ de comprimento e digítulos da garra iguais, dilatados com $27,5 \mu \mathrm{m}(25-27,5)$ de comprimento, com extremidades distais espatuladas. Poros dos canais estigmáticos geralmente com 5 lóculos; poros cruciformes concentrados na região submarginal; poros genitais com 10 lóculos. Condutos tubulares presentes na região cefálica e nos últimos segmentos abdominais (Fig. 84).

Material examinado: BRASIL. São Paulo: Descalvado (15-III2001, Ocotea pulchella, K.R.N. Cirelli col.), 1 exemplar em 1 lâmina; Piracicaba (15-VIII-2001, Passiflora sp., H. N. Oliveira col.), 4 exemplares em 1 lâmina; Santos (21-III-2002, Duranta repens var. aurea, A.L.B.G. Peronti col.), 6 exemplares em 2 lâminas; (21-III2002, Malpighia ilicifolia, A.L.B.G. Peronti col.), 5 exemplares em 2 lâminas; São Carlos: (11-XI-1997, 17-I-2001, 02-III-2001, 01-VIII2001, 25-III-2001, D. repens var. aurea, A.L.B.G. Peronti col.), 36 exemplares em 9 lâminas; (04-IV-2002, Byrsonima intermedia, A.L.B.G. Peronti col.), 1 exemplar em 1 lâmina; São José do Rio Preto: (20-V2001, D. repens var. aurea, A.L.B.G. Peronti col.), 9 exemplares em 3 lâminas; (20-V-2001, sobre Jacaranda cuspidifolia, A.L.B.G. Peronti col.), 5 exemplares em 2 lâminas; (20-V-2001, sobre Tabebuia sp., A.L.B.G. Peronti col.), 22 exemplares em 7 lâminas; São Paulo: (22IV-2001, D. repens var. aurea, A.L.B.G. Peronti col.), 5 exemplares em 1 lâmina (DCBU). Material proveniente de outros estados: Alagoas, Maceió: (20-V-2000, Starchitarpheta sp., J.M.M. Lima col.), 8 exemplares em 4 lâminas; (V-2000; 02-V-2000, Solanum paniculatum, J.M.M. Lima col.), 13 exemplares em 6 lâminas; (V-2000, Solanum sp., J.M.M. Lima col.); (02-V-2000, Verbenaceae, J.M.M. Lima col.), 7 exemplares em 3 lâminas (DCBU); Minas Gerais, Poços de Caldas: (06VI-2001, D. repens var. aurea, A.L.B.G. Peronti col.), 7 exemplares em 1 lâmina.

Distribuição geográfica: EUA; Itália; Filipinas; Bermudas; México; Cuba; Antígua; Jamaica; Ilhas Virgens; Porto Rico; Trinidad; Colômbia; Guiana; Brasil (Alagoas e São Paulo); Ilhas Galápagos; Argentina; Chile; Havaí; Ilhas Marshall; Ilha Wake.

Discussão: assemelham-se a $C$. cirripediformis as espécies: C. gregarius Hempel, 1900; C. variegatus Hempel, 1900; C. bragai sp. nov. e C. solanaceus sp. nov. mencionadas para o Estado de São Paulo, Brasil; C. sinensis Del Guercio, 1900, amplamente difundida, mencionada também para o Rio Grande do Sul, Brasil e C. cistudiformis Cockerell, registrada para a América Central e América do Norte por apresentarem antenas com 7 segmentos, presença de esclerotização tíbio-tarsal, digítulos da garra iguais e dilatados, setas estigmáticas predominantemente cônicas; poros da superfície dorsal predominantemente triloculares, de contornos ovais e triangulares tipo II e setas da superfície dorsal predominantemente capitadas. Ceroplastes gregarius difere, em vista macroscópica, por apresentar a carapaça de cera dividida em 8 placas; e, microscopicamente, pela ausência de 

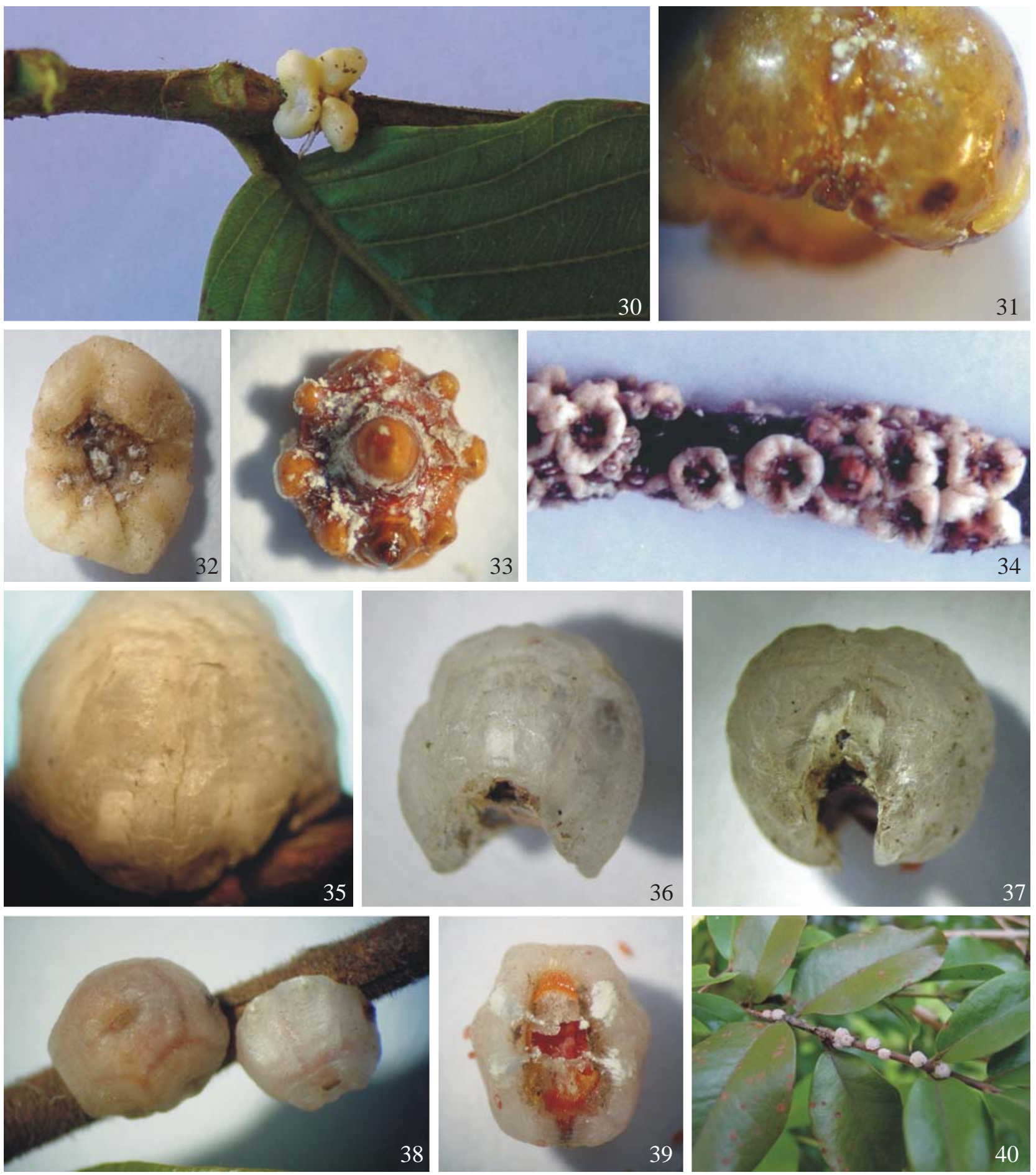

Figs. 30-40. 30-31, Ceroplastes flosculoides: 30, vista dorsal; 31, corpo despido de cera, detalhe da esclerotização entre as setas estigmáticas. $32-$ 34, Ceroplastes formicarius: 32, vista dorsal; 33, corpo despido de cera; 34, infestação sobre Banisteriopsis oxyclada (Malpighiaceae). 35-40, Ceroplastes formosus: 35, vista lateral; 36, placa anterior; 37, placa posterior; 38, vista dorsal; 39, vista ventral; 40, infestação sobre Myrciaria sp. (Myrtaceae).

condutos tubulares na região cefálica. C. variegatus difere por apresentar setas estigmáticas cônicas com ápice obtuso e ausência de condutos tubulares na região cefálica. C. bragai difere por apresentar uma seta estigmática central cônica com ápice truncado; pela presença de condutos tubulares entre o segundo par de coxas e a margem na superfície ventral e poros com contorno irregular. $C$. solanaceus, difere por apresentar poros dorsais com 4 a 6 lóculos, além dos biloculares e triloculares e ausência de condutos tubulares na região cefálica. As diferenças entre C. cistudiformis, C. sinensis e $C$. 
cirripediformis são apresentadas por Gimpel et al., 1974. Na presente revisão, Ceroplastes cultus Hempel, 1900 (Fig. 85), C. cuneatus Hempel, 1900 (Fig. 86), C rarus Hempel, 1900 (Fig. 87) e C. rotundus Hempel, 1900 (Fig. 88) são sinonimizados com C. cirripediformis. Presença de condutos tubulares na região cefálica e setas da superfície dorsal captadas foram observadas apenas em C. cuneatus e C. rotundus. C. cultus e C. rarus apresentam o material tipo muito deteriorado e esclerotizado, dificultando a visualização dessas estruturas. Algumas populações coletadas no decorrer desse trabalho apresentaram muitas variações (Figs. 18, 19), principalmente quanto a coloração, textura e formato da cera; contudo sem variações microscópicas significativas.

\section{Ceroplastes coronatus Peronti sp. nov.}

(Figs. 20, 21, 89)

Material tipo: holótipo + , Brasil, São Paulo, São Paulo, Ipiranga $\mathrm{N}^{\circ}$ 97a sobre Platanus sp. (Platanaceae), IX-1909, A. Hempel col., 1 exemplar em 1 lâmina; parátipo $\mathrm{N}^{\circ} 97$ b (DZUP).

Etimologia: o nome da espécie é alusivo a distribuição das setas estigmáticas, encontradas em toda a margem do corpo, como uma coroa.

Características macroscópicas: (baseado em exemplares preservados a seco).

Cera: oval a retangular, dividida em 7 placas com depressões ao redor dos núcleos; bandas laterais largas (Fig. 20).

Corpo: oval, coloração castanho-clara; tubérculos mais claros o corpo, sendo o dorsal maior e mais alongado que os demais; comprimento, 4,5mm; largura, 2,5 mm; processo caudal curto, dirigido para cima e coloração castanho-escura (Fig. 21).

Características microscópicas: Superfície dorsal: com 8 áreas claras, uma na região cefálica, uma na médio-dorsal e 3 pares laterais. Setas cônicas. Poros triloculares, de contorno oval e triangular tipo II, tetraloculares, pentaloculares e escassos biloculares e hexaloculares. Poros pré-operculares crivados. Placas anais com quatro setas dorsais (Fig. 89).

Margem: setas estigmáticas cônicas, de diferentes tamanhos, dispostas em toda a margem do corpo: em três ou quatro linhas no ápice dos canais estigmáticos; em duas linhas na região mediana, entre os canais estigmáticos e, em uma linha, nas regiões da cabeça e adjacentes ao processo caudal (Fig. 89).

Superfície ventral: antenas com 360um (345-365) de comprimento, com 7 ou 8 artículos, o IV podendo ser segmentado ou pseudo-segmentado, I: $62,5 \mu \mathrm{m}(60-67,5)$; II:

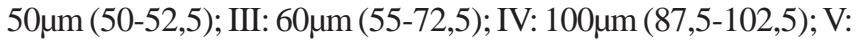

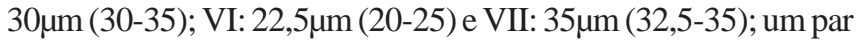
de setas próximas da base de cada antena. Pernas com 582,5 $\mu \mathrm{m}$ (575-600), coxa: $140 \mu \mathrm{m}(130-150)$, trocanter mais fêmur: $200 \mu \mathrm{m}$ (180-200), tíbia: $140 \mu \mathrm{m}(130-140)$, tarso: $80 \mu \mathrm{m}$ (80-85); garra: 22,5 $\mu \mathrm{m}$ (20-22,5), com dentículo; digítulos tarsais delgados, com extremidades distais dilatadas; digítulos da garra iguais, dilatados com extremidades distais espatuladas e 30-32,5 $\mu \mathrm{m}$ de comprimento; esclerotização na articulação tíbio-tarsal presente. Poros dos canais estigmáticos com 5, 6 e 7 lóculos; poros cruciformes dispersos na superfície ventral, mais concentrados na área submarginal; poros genitais com 10 lóculos. Condutos tubulares presentes apenas nos últimos segmentos abdominais (Fig. 89).

Distribuição geográfica: Brasil (São Paulo).

Discussão: assemelham-se a Ceroplastes coronatus as espécies: C. albolineatus var. vulcanicus Cockerell, 1903 registrada para o México; C. circundatus Green, 1923 para a Guiana; C. formicarius Hempel, 1900 para Argentina e Brasil; C. dugesii Lichtenstein, 1885 para vários países da América Central e EUA e C. ocreus Mosquera, 1984 para a Colômbia por apresentarem, setas estigmáticas ao longo de toda a margem do corpo; poros da superfície dorsal predominantemente trilocular, de contorno oval e triangular tipo II, e quadriloculares e esclerotização tíbio-tarsal. C. albolineatus var. vulcanicus, $C$. circundatus e $C$. formicarius aproximam-se ainda da espécie em questão por apresentarem poros pré-operculares crivados. C. circundatus difere por apresentar setas estigmáticas maiores e mais próximas uma das outras e setas da superfície dorsal com ápice arredondado. C. dugesii difere por apresentar setas estigmáticas dispostas em 4 ou 5 linhas na borda do canal estigmático; ausência de poros dorsais com 5 e 6 lóculos; setas da superfície dorsal com ápice arredondado; garra desprovida de dentículos e por apresentar condutos tubulares na região cefálica. $C$. formicarius difere principalmente pela ausência de poros dorsais com 2, 5 e 6 lóculos. C. ocreus difere por possuir garras desprovidas de dentículos; ausência de poros dorsais com 2, 5 e 6 lóculos; setas dorsais da parte anterior do corpo de tamanho menor e placas anais com 3 setas na superfície dorsal. C. albolineatus vulcanicus Cockerell, 1903 difere por não apresentar poros com 6 lóculos na superfície dorsal e por apresentarem setas da superfície dorsal com ápice arredondado. Os exemplares aqui estudados foram identificados por Hempel como C. albolineatus Cockerell, 1894. Entretanto, os síntipos de C. albolineatus depositados no USMN diferem destas por apresentarem, setas estigmáticas concentradas no ápice do canal estigmático, setas dorsais com ápice arredondado e ausência de poros tetraloculares e pentaloculares. Constatamos, portanto, que $C$. albolineatus não ocorre no estado de São Paulo.

\section{Ceroplastes deodorensis Hempel (Figs. 22-24, 90)}

Ceroplastes deodorensis Hempel, 1937: 9; Silva et al., 1968: 138 (cat.); Ben-Dov, 1993: 30 (cat.); Peña \& Bennett, 1995: 334 (cit.). Síntipos 우, Brasil, Rio de Janeiro, Deodoro, sobre galhos de Annonaceae, 03-VIII-1934, W. Zikán col.; (IBSP). Hempel não designou holótipo na descrição original da espécie. Material tipo, preservado a seco, contendo os dados acima mencionados foram localizados no IBSP ( 1 tubo, $\mathrm{N}^{\circ} 360$ ). Foram preparados 3 exemplares em 2 lâminas e aqui designados lectótipo (exemplar da lâmina 360a) e, 2 paralectótipos (exemplares da lâmina 360b) [examinado].

Características macroscópicas: (baseado em exemplares vivos). 

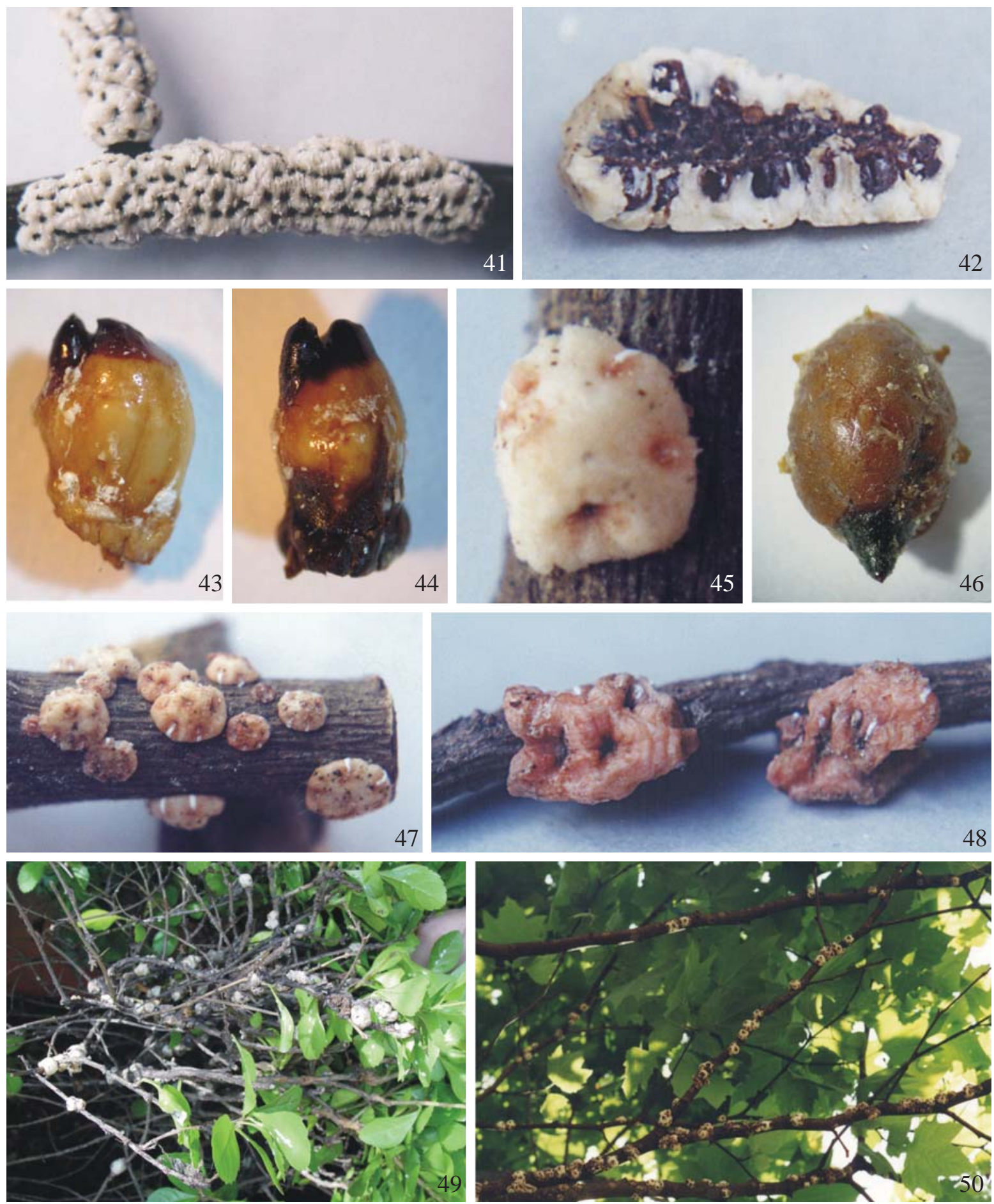

Figs. 41-50. 41-44, Ceroplastes glomeratus; 41, aglomerado, vista dorsal; 42, detalhe do interior do aglomerado; 43, 44, corpo despido de cera. 45-50, Ceroplastes grandis: 45, vista dorsal; 46, corpo despido de cera; 47, 48, variações da cera; 47, sobre Delonix regia (Caesalpinioideae); 48, sobre Schinus terebinthifolius (Anacardiaceae); 49, infestação sobre D. repens var. aurea (Verbenaceae); 50, infestação sobre Platanus sp. (Platanaceae).

Cera: rija e fina, coloração roxo-clara ou branco-acinzentada; oval em vista dorsal e, semicircular ou cônica em vista lateral (Figs. 22-24); dividida em 9 placas, 1 dorsal, maior, 6 laterais, 1 anterior e uma posterior; com placas bem definidas com contorno roxo-escuro; com núcleo dorsal grande e, os laterais, embora menores bem definidos, todos cobertos por uma secreção branca; comprimento, $3 \mathrm{~mm}$ (2,5-5,5); largura, $2 \mathrm{~mm}$ (24,5) e altura, $3 \mathrm{~mm}(2-5)$.

Corpo: oval, convexo, coloração pardo-escura com 8 pequenos tubérculos; comprimento, 2,4 $\mathrm{mm}(2,4-4,25)$; largura, 
1,5 mm (1,5-3); processo caudal curto, dirigido para trás.

Características microscópicas: Superfície dorsal: com 8 áreas claras, uma na região cefálica, uma na médio-dorsal e 3 pares laterais. Setas cilíndricas com ápice arredondado, com 4-6 $\mu \mathrm{m}$ de comprimento, mais concentradas na região submarginal; poros "tipo rusci" (monoloculares semelhantes a biloculares) em grande número e, escassos biloculares e triloculares de contorno triangular tipo I. Poros pré-operculares simples. Placas anais com 3 setas dorsais e 1 ventral (Fig. 90).

Margem: 19-23 setas estigmáticas cônicas, as maiores com ápice obtuso, dispostas em três linhas no ápice dos canais estigmáticos e, prolongando-se lateralmente um pouco além destes; os dois grupos de setas, do canal estigmático anterior e posterior, estão quase unidos na região mediana do corpo, em geral, são separados apenas por duas a três setas marginais; no centro de cada estigma, existe uma seta estigmática bem

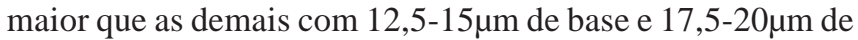
comprimento, as menores medem cerca de 5-6,75 $\mu \mathrm{m}$ de base e 7,5-12,5 $\mu \mathrm{m}$ de comprimento. Setas marginais compridas com 25 a 37,5 $\mu \mathrm{m}$, dispostas como a seguir: cerca de 10-11 entre os tubérculos dos olhos, 5-6 entre cada tubérculo do olho e a sutura estigmática anterior, 9-12 entre as suturas estigmáticas anterior e posterior e 19-25 entre a sutura estigmática posterior e a fissura anal; nos lóbulos anais estão inseridas 4 setas de 50 a $70 \mu \mathrm{m}$ de comprimento; olhos grandes e proeminentes (Fig. 90).

Superfície ventral: setas submarginais com $12,5 \mu \mathrm{m}$ de comprimento dispostas da seguinte forma: 10-11 entre os tubérculos dos olhos, 6-7 entre cada tubérculo do olho e a sutura estigmática anterior, 6-7 entre as suturas estigmáticas anterior e posterior e 25 ou mais entre a sutura estigmática posterior e a fissura anal. Antena com 227,5 $\mu \mathrm{m}(227,5-270) \mathrm{de}$

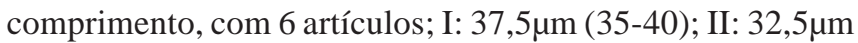
(32,5-42,5); III: $85 \mu \mathrm{m}$ (85-92,5); IV: 22,5 $\mu \mathrm{m}$ (22,5-30); V: $20 \mu \mathrm{m}$

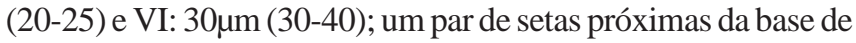
cada antena. Pernas com 450 $\mu$ m (440-470) de comprimento,

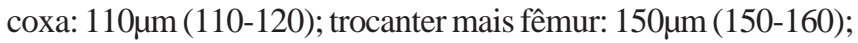
tíbia: $100 \mu \mathrm{m}$ (90-110); tarso: $70 \mu \mathrm{m}$, garra: $20 \mu \mathrm{m}(20-22,5)$, com dentículo; digítulos tarsais delgados com extremidades distais dilatadas, com 50-52,5 $\mu \mathrm{m}$ de comprimento; digítulos da garra iguais, dilatados com extremidades distais espatuladas, com 30-35 $\mu \mathrm{m}$ de comprimento; esclerotização na articulação tíbiotarsal presente. Poros dos canais estigmáticos com 5 e 6 lóculos; poros cruciformes concentrados na região submarginal; poros genitais com 10 lóculos. Condutos tubulares com filamento em forma de foice presentes na região cefálica (Fig. 90).

Material examinado: BRASIL. São Paulo: Barretos (19-X-2001, Ficus benjamina, C.R. Sousa-Silva col.,) 1 exemplar em 1 lâmina; São Carlos (17-I-2001, Annona reticulata, A.L.B.G. Peronti col.), 7 exemplares em 2 lâminas; (12-III-2001, A. muricata, A.L.B.G. Peronti col.), 4 exemplares em 1 lâmina; Votuporanga (26-X-2001, A. squamosa, A.L.B.G. Peronti col.), 5 exemplares em 2 lâminas (DCBU). Material proveniente de outros Estados: Alagoas, Maceió: (VIII-2000, A. squamosa, L.M.O. Góes col.), 7 exemplares em 3 lâminas; (04VIII-2001, A. squamosa, J.M.M. Lima col.), 10 exemplares, 2 lâminas (DCBU).
Distribuição geográfica: Brasil (Alagoas, Rio de Janeiro, São Paulo); Colômbia; Suriname.

Discussão: assemelham-se a $C$. deodorensis as espécies: Ceroplastes rusci (Linnaeus, 1758), cosmopolita, mencionada para o Brasil no Rio Grande do Sul; C. eucleae Brain, 1920, C. eugeniae Hall, 1931, C. ficus Newstead, 1910, C. spicatus Hall 1937 e C. toddaliae Hall, 1931 conhecidas para a região Africana e C. actiniformis Green, 1896 distribuída pelas regiões Oriental e Austro-Oriental. Em vista macroscópica são semelhantes por apresentarem a carapaça de cera dividida em 9 placas. Microscopicamente, caracterizam-se por apresentarem, poros monoloculares "tipo rusci" e poros triloculares; setas da superfície dorsal cilíndricas com ápice arredondado; olhos grandes, antenas com 6 segmentos; esclerotização na articulação tíbio-tarsal; digítulos da garra iguais e dilatados; garra com dentículo; condutos tubulares na região cefálica, setas estigmáticas predominantemente cônicas com ápice obtuso e setas marginais longas. $C$. rusci difere de $C$. deodorensis por apresentar os filamentos dos poros dorsais ramificados. C. eugeniae difere por apresentar um maior número de setas estigmáticas, cerca de $70 . C$. actiniformis e C. eucleae diferem por apresentar setas dorsais com base mais larga que o ápice, quase cônicas, embora com ápice arredondado. C. spicatus e $C$. toddaliae apresentam 4 setas na superfície dorsal das placas anais, diferente das demais espécies acima mencionadas, com 3 setas e, processo caudal relativamente maiores, o primeiro com cerca de $800 \mu \mathrm{m}$ e o segundo com 1,3mm de comprimento de acordo com Hodgson (1969).

\section{Ceroplastes diospyros Hempel}

(Figs. 25, 26, 91)

Ceroplastes diospyros Hempel, 1928: 236; Vernalha, 1953: 125 (cat.) Silva et al., 1968: 138 (cat.); Ben-Dov, 1993: 32 (cat.). Síntipos 우, Brasil, Sorocaba, Ituparanga, sobre Diospyros kaki, 21-VI-1926, A. Hempel. Hempel não designou holótipo na descrição original da espécie. É aqui designado lectótipo (exemplar localizado no ângulo esquerdo inferior da lâmina $\mathrm{N}^{\circ}$ 427/ Gav. 4/ Div. 48, IBSP) e, paralectótipos (três exemplares $\mathrm{N}^{\circ} 427 /$ Gav. 4/ Div. 48 e 4 exemplares da lâmina $\mathrm{N}^{\circ}$ 427/ Gav. 4/ Div. 49, IBSP) [examinado].

Características macroscópicas: (baseado em exemplares vivos).

Cera: rija, nodosa, com coloração branco-amarelada; semicircular ou cordiforme em vista dorsal e, semicircular em vista lateral; sem divisão de placas (Fig. 25); núcleos visíveis, sendo o da placa dorsal maior, e dois posteriores, um de cada lado da abertura do processo caudal; bandas estigmáticas espessas; comprimento, 7,5mm (4-10); largura, 7,4mm (5-10) e altura, $5 \mathrm{~mm}(4-5,5)$.

Corpo: semicircular ou cordiforme, de coloração castanhoclara; comprimento, 4,5mm (2,8-5,6); largura, 4,4 mm (2,5-5); processo caudal de coloração negra; área esclerotizada com base ampla, estendendo-se sobre o dorso pelo menos até a região mediana do corpo (Fig. 26).

Características microscópicas: Superfície dorsal: $\operatorname{com} 8$ áreas claras, uma na região cefálica, uma na médio-dorsal e 3 

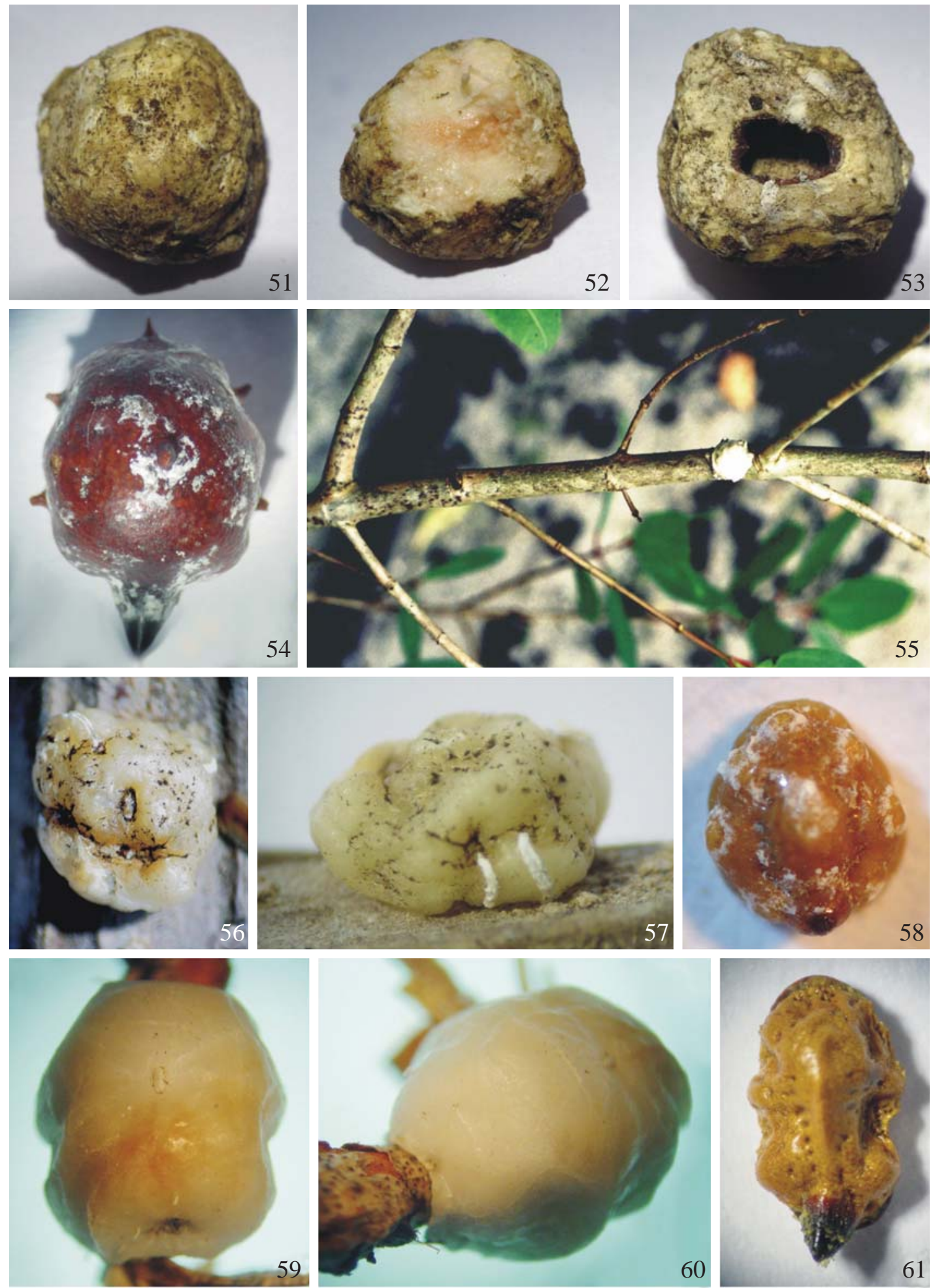

Figs. 51-61. 51-55, Ceroplastes grandis sobre Avicennia tomentosa (Verbenaceae); 51, vista dorsal; 52, coloração interna da cera; 53, vista ventral; 54, corpo despido de cera; 55, sobre a planta hospedeira. 56-58, Ceroplastes iheringi: 56, vista dorsa; 57, vista lateral; 58, corpo despido de cera. 59-61, Ceroplastes janeirensis: 59, vista dorsal; 60, vista lateral; 61, corpo despido de cera.

pares laterais. Setas de dois tipos, ambas cilíndricas, uma com ponta e outra com ápice truncado lateralmente; poros da superfície biloculares tipo I e triloculares, de contorno oval e triangular tipo I. Processo caudal com poros pré-operculares simples; placa anal com 4 setas na superfície dorsal e uma na superfície ventral; borda da prega marginal com 5 setas (Fig. 91).

Margem: com 30-70 setas estigmáticas retangulares de 
diferentes comprimentos no ápice de cada canal estigmático e estendendo-se sobre o dorso. Setas estigmáticas com ápices truncados, arredondados ou denteados (Fig. 91).

Superfície ventral: antenas com 305um (280-325) de

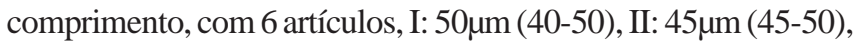

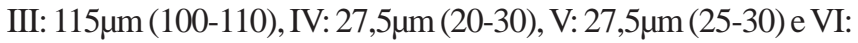
$37,5 \mu \mathrm{m}(30-37,5)$; um par de setas próximas da base de cada

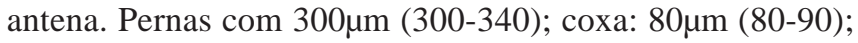

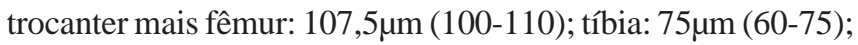

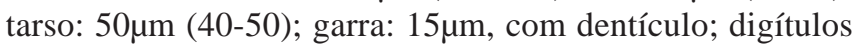
tarsais delgados, com $30 \mu \mathrm{m}$ de comprimento e extremidades distais dilatadas; digítulos da garra diferentes, um dilatado e o outro delgado, ambos com $25 \mu \mathrm{m}$ de comprimento e extremidades distais espatuladas; esclerotização tíbio-tarsal ausente. Poros dos canais estigmáticos variáveis, apresentando 5 a 10 lóculos; poros cruciformes concentrados na região submarginal; poros genitais com 10 lóculos distribuídos na região central do corpo até o mesotórax. Condutos tubulares presentes apenas nos últimos segmentos abdominais (Fig. 91).

Material examinado: BRASIL. São Paulo: São Carlos (06-VI-2001, Punica granatum, A.L.B.G. Peronti col.), 4 exemplares em 1 lâmina (DCBU); São José do Rio Preto (VII-1926, hospedeiro indeterminado, A. Hempel col.), 4 exemplares em 1 lâmina (IBSP); Valinhos (28-I2002, P. granatum, A.L.B.G. Peronti col.), 4 exemplares em 2 lâminas; (28-I-2002, Diospyros kaki, A.L.B.G. Peronti col.), 4 exemplares em 2 lâminas (DCBU). Material proveniente de outros Estados: Santa Catarina: (IX-2002, Schinus molle, A. Kussler col.), 4 exemplares em 3 lâminas (DCBU).

Distribuição geográfica: Brasil (São Paulo, Santa Catarina). Discussão: assemelham-se a $C$. diospyros as espécies: $C$. deciduosus Morrison, 1919, conhecida para a Argentina e Brasil, Rio Grande do Sul; C. giganteus Dozier, 1931, conhecida para o Haiti e $C$. jordanensis sp. nov. por apresentarem, área esclerotizada do processo caudal com base ampla, estendendo-se sobre o dorso pelo menos até a região mediana do corpo; setas estigmáticas agrupadas no ápice dos canais estigmáticos e sobre o dorso, em geral, do tipo cônica com ápice denteado; digítulos da garra diferentes e ausência de esclerotização tíbio-tarsal. C. deciduosus e $C$. jordanensis diferem principalmente por apresentarem setas estigmáticas com formato irregular, em número reduzido e poros genitais restritos aos últimos segmentos abdominais. C. giganteus difere por apresentar setas dorsais cônicas com ápice truncado e cobertura cerosa nitidamente diferente, de acordo com ilustração apresentada por Dozier (1931).

\section{Ceroplastes floridensis Comstock (Figs. 27-29, 92)}

Ceroplastes floridensis Comstock, 1881: 331; Gomes Costa, 1949: 15 (cit., fotografia); Vernalha, 1953: 127 (cat.); Silva et al., 1968: 138 (cat.); Amante \& Almeida, 1962 (cit.); Corseuil \& Barbosa, 1971: 237 (cit.); Ben-Dov, 1993: 34 (cat.); Marín-Loayza \& Cisneros-Vera, 1994: 48 (redescr.); 1995: 46 (biol.); Caloba \& Silva, 1995: 180 (cit.); Peña \& Bennett, 1995: 334 (cit.); Peronti et al., 2001: 248 (cit.). Lectótipo o designado por Gimpel et al.
(1974), U. S. A., Florida, Jacksonville, sobre "tangerine orange" (USNM) [examinado].

Cerostegia floridensis (Comstock); De Lotto, 1969: 211 (n. comb.). Paracerostegia floridensis (Comstock); Tang, 1991: 306 (n. comb.); Hodgson, 1994: 419 (redescr., ilustr.).

Características macroscópicas: (baseado em exemplares vivos).

Cera: rija e fina, coloração branco-amarelada ou rósea; retangular nos exemplares mais jovens e ovais nos mais velhos e achatada dorso-ventralmente formando um rebordo na margem; placas indefinidas; apenas o núcleo dorsal é visível (Fig. 27); comprimento, 3mm (1,9-4); largura, $2 \mathrm{~mm}(1,5-3,5)$; altura, $1,5 \mathrm{~mm}(1,2-2,0)$.

Corpo: oval em vista dorsal e achatado dorso-ventralmente e com tubérculos pouco desenvolvidos; coloração castanhoclara; comprimento, 2,5 mm (1,6-3,5); largura, 1,8 mm (1,3-2,7); processo caudal curto, dirigido para cima e coloração castanho-escura (Fig. 28).

Características microscópicas: Superfície dorsal: com 7 áreas claras, uma na região cefálica e 3 pares laterais. Setas cilíndricas com pontas; poros biloculares, triloculares de contorno oval e triangular tipo II, em maior número e, escassos tetraloculares e pentaloculares. Poros pré-operculares simples. Placas anais com 3 ou 4 setas dorsais e 1 ventral (Fig. 92).

Margem: com setas estigmáticas lanceoladas, dispostas em 3 linhas no ápice dos canais estigmáticos e, prolongandose marginalmente um pouco além destes, 24-31 setas no ápice do canal estigmático anterior e 27-38 no posterior; setas marginais com 20-25 $\mu \mathrm{m}$ de comprimento, dispostas como a seguir: cerca de 25 (23-28) entre os tubérculos dos olhos, 9 (811) entre cada tubérculo do olho e a sutura estigmática anterior, 11 (11-13) entre a suturas estigmáticas anterior e posterior e 44 (41-45) entre a sutura estigmática posterior e a fissura anal; no ápice dos lóbulos anais estão inseridas 4 cerdas mais longas em ordem crescente, com 47,5 a 82,5 $\mu$ m de comprimento (Fig. 92).

Superfície ventral: setas submarginais com aproximadamente $7,5 \mu \mathrm{m}$ de comprimento; antenas com $200 \mu \mathrm{m}$ (190-230) de comprimento, geralmente com 6 artículos: I:

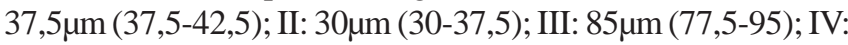

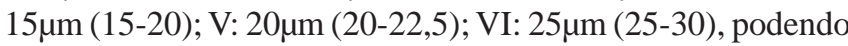
apresentar segmentação ou pseudosegmentação no terceiro segmento; três setas próximas da base de cada antena. Pernas

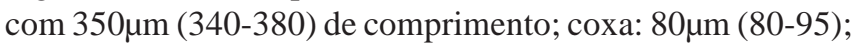

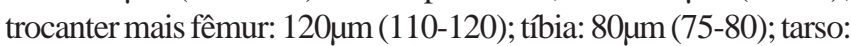

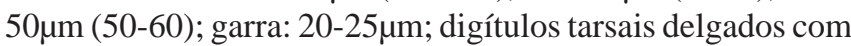
45-55 $\mu \mathrm{m}$ de comprimento e extremidades distais dilatadas; digítulos da garra iguais, dilatados, com 25-30 $\mu \mathrm{m}$ de comprimento e extremidades distais espatuladas. Poros dos canais estigmáticos com 5 lóculos; poros cruciformes concentrados na área submarginal; poros genitais com 10 lóculos. Condutos tubulares com filamento curto e base dilatada, dispostos em toda a região submarginal (Fig. 92).

Material examinado: BRASIL. São Paulo: Araras (VIII-2001, Citrus sp., A.L.B.G. Peronti col.), 3 exemplares em 1 lâmina; Botucatu (19-V- 

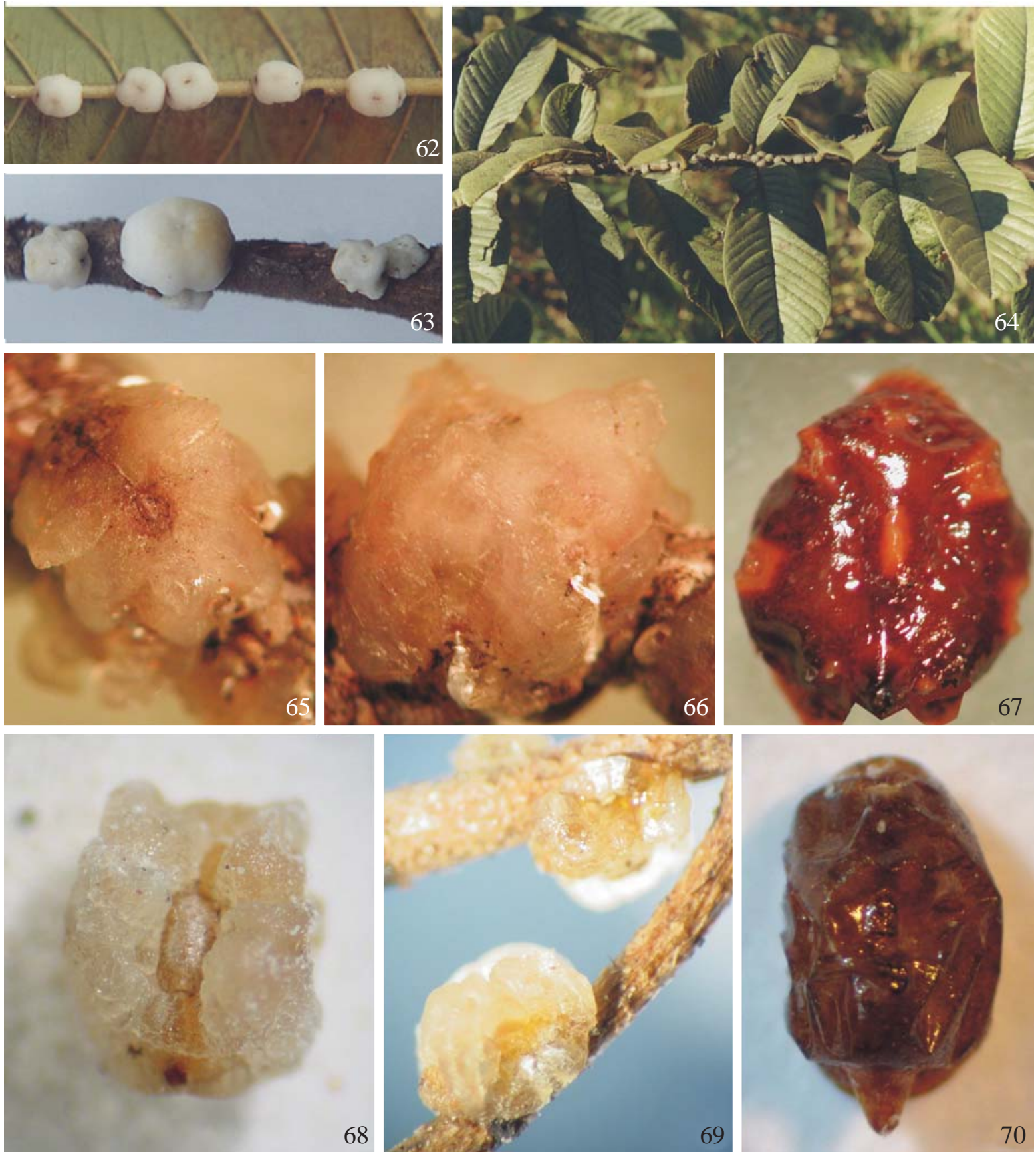

Figs. 62-70. 62-64, Ceroplastes janeirensis: 62, 63, vista dorsal, sobre ramo e folha de Psidium guajava (Myrtaceae), respectivamente; 64, infestação sobre ramos de P. guajava (Myrtaceae). 65-67, Ceroplastes lucidus: 65, vista dorsal; 66, vista lateral; 67, corpo despido de cera. 6870, Ceroplastes purpureus: 68, vista dorsal; 69, vista lateral; 70, corpo despido de cera.

2002, Schefflera arboricola, V.A. Costa col.), 2 exemplares em 1 lâmina; Santos (21-III-2002, S. actinophylla, A.L.B.G. Peronti col.), 4 exemplares em 2 lâminas; (21-III-2002, S. arboricola A.L.B.G. Peronti col.), 2 exemplares em 1 lâmina; São Carlos (26-I-1998, S. actinophylla, A.L.B.G. Peronti col.), 5 exemplares em 2 lâminas; (19-VII-2002, Eugenia americana, A.L.B.G. Peronti col.), 6 exemplares em 2 lâminas (DCBU), São José dos Campos (29-XI-1934, ameixa do Japão, H.S. Lepage col.), 13 exemplares em 3 lâminas (IBSP); São Paulo (08-III2001, Prunus domestica, A.L.B.G. Peronti col.), 5 exemplares em 1 lâmina; (22-IV-2001, Lagerstroemia indica, A.L.B.G. Peronti col.), 2 exemplares em 1 lâmina; (22-IV-2001, Hedera canariensis, A.L.B.G.
Peronti col.), 9 exemplares em 2 lâminas; (22-IV-2001, P. domestica, A.L.B.G. Peronti col.), 2 exemplares em 1 lâmina (DCBU).

Distribuição geográfica: EUA; Bermudas; França; Itália; Ilha da Madeira; Líbano; Turquia; Grécia; Chipre; Israel; Egito; China; I. Ogasawara (Bonin); Índia; Vietnã; Taiwan; Papua; Tanzânia; México; Cuba; I. Virgens; Porto Rico; Honduras; Nicarágua; Montserrat; Trinidad; Curaçao; Colômbia; Guiana; Equador; Brasil: (São Paulo, Rio Grande do Sul); Seicheles; 
Comores, Madagascar, I. Maurício, I. Reunião; I. Marianas; Palau.

Discussão: assemelham-se a $C$. floridensis as espécies: $C$. agrestis Hempel, registrada para o Estado de São Paulo; Ceroplastes combretti Brain, 1920, Ceroplastes deceptrix (De Lotto, 1965) e C. rusticus De Lotto, 1961, registradas para o Sul da África, por apresentarem uma banda submarginal de condutos tubulares; diferem da mesma principalmente por apresentarem setas estigmáticas agrupadas no ápice do canal estigmático e na superfície dorsal (ver discussão de $C$. agrestis). Outras espécies como, $C$. coronatus aqui descrita e C. formicarius, registrada para o Brasil e Argentina, assemelhan-se a $C$. floridensis, por apresentarem setas estigmáticas cônicas, setas dorsais cônicas com ápice truncado; poros dorsais do mesmo tipo e 3 setas na base de cada segmento antenal; diferem principalmente por apresentarem setas estigmáticas distribuídas em toda a margem do corpo.

\section{Ceroplastes flosculoides Matile-Ferrero} (Figs. 30, 31, 93)

Ceroplastes flosculoides Matile-Ferrero, 1993: 441; Marín-Loaysa \& Cisneros-Vera, 1994: 48 (cit., redescr.). Holótipo 오, Peru, sobre Myrciaria dubia, (MNHN) [não examinado].

Características macroscópicas: (baseado em exemplares vivos).

Cera: úmida, amarela e constituída por três lóbulos, um anterior e dois laterais; com dois longos filamentos de cor branca, provenientes dos canais estigmáticos (Fig. 30); comprimento, 4,5mm (3,4-5); largura, 3,5mm (2,7-4); altura, $3,0 \mathrm{~mm}(2,2-3,5)$.

Corpo: circular de coloração amarela; comprimento, $2,75 \mathrm{~mm}$ (2-3,2); largura, 2,5mm (1,5-3,0); processo caudal de coloração negra com área esclerotizada estendendo-se sobre o dorso (Fig. 31).

Características microscópicas: Superfície dorsal: com 7 áreas claras, uma na região médio-dorsal e 3 pares laterais. Setas cilíndricas com pontas; poros monoloculares, biloculares tipo II, triloculares, de contorno oval e triangular tipo II e tetraloculares. Esclerotização em torno da região das setas estigmáticas, anterior e posterior, unidas, formando uma faixa lateral. Área esclerotizada do processo caudal com base ampla, estendendo-se sobre o dorso, cobrindo a área clara médiodorsal; placas anais com 4 setas dorsais; anel anal com 6 setas (Fig. 93).

Margem: 60 a 70 setas estigmáticas cilíndricas com ápices arredondados agrupadas nos ápices dos canais estigmáticos e estendendo-se sobre o dorso; 5 a 7 seta cônicas com ápice truncado estão dispostas no centro do grupo (Fig. 93).

Superfície ventral: antenas com 220um (210-260) de

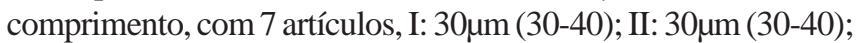

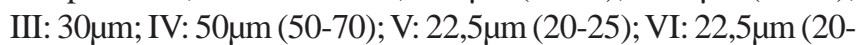
25); VII: $35 \mu \mathrm{m}$ (35-40); três setas próximas da margem da base de cada antena. Pernas com 337,5 $\mu$ m (330-350) de comprimento, coxa: $82,5 \mu \mathrm{m}(80-90)$; trocanter mais fêmur: 117,5 $\mu \mathrm{m}(115-130)$;

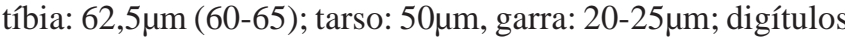
tarsais delgados com $40 \mu \mathrm{m}$ de comprimento e extremidades distais dilatadas; digítulos da garra diferentes, um dilatado e o outro delgado, ambos com $30 \mu \mathrm{m}$ de comprimento e extremidades distais espatuladas; esclerotização na articulação tíbio-tarsal presente. Poros dos canais estigmáticos com 5 lóculos; poros cruciformes dispersos em toda a superfície; poros genitais com 10 lóculos, em grande número, na região circungenital e sobre os três segmentos precedentes. Condutos tubulares com filamentos delgados e curtos na região genital e, em menor quantidade, na região cefálica, entre as antenas (Fig. 93).

Material examinado: BRASIL. São Paulo: São Carlos (10-V-2002, Psidium guajava, A.L.B.G. Peronti col.), 2 exemplares em 1 lâmina; (10-III-1989, P. guajava, M.T. Tavares col.), 4 exemplares em 1 lâmina; (25-VIII-2001, P. guajava, A.L.B.G. Peronti col.), 4 exemplares em 1 lâmina; São Simão (20-VI-1989, P. guajava, M.T. Tavares col.), 2 exemplares em 1 lâmina (DCBU). Material proveniente de outros Estados: Mato Grosso do Sul, Campo Grande (VIII-1938, A. Hempel col.), 3 exemplares em 1 lâmina; (?data, árvore silvestre, A. Hempel col.), 2 exemplares em 1 lâmina (IBSP).

Distribuição geográfica: Brasil (Mato Grosso do Sul, São Paulo); Peru.

Discussão: assemelha-se a $C$. flosculoides, $C$. coloratus Cockerell, 1898 por apresentar esclerotização em torno das setas estigmáticas na região submarginal da superfície dorsal; esclerotização do processo caudal estendendo-se sobre o dorso, cobrindo a área clara médio-dorsal; setas dorsais cilíndricas com pontas e poros dorsais biloculares, triloculares, de contorno oval e triangular, e tetraloculares. C. coloratus difere principalmente por apresentar antenas com 6 segmentos e áreas de esclerotização, em torno das setas estigmáticas, distindas, formando duas manchas, uma anterior e outra posterior.

\section{Ceroplastes formicarius Hempel}

(Figs. 32-34, 94)

Ceroplastes formicarius Hempel, 1900a: 472; 1901b: 67 (redescr.); Granara de Willink, 1999: 53 (redescr.); Vernalha, 1953: 127 (cat.) Silva et al., 1968: 138 (cat.); Foldi, 1988: 85 (cit.); Ben-Dov, 1993: 36 (cat.). Lectótipo 우 e paralectótipos designados por Granara de Willink, 1999: 54 sobre Maytenus sp. (MZSP) [examinado].

Ceroplastes scutigera Cockerell, 1902: 92; Granara de Willink, 1999: 53 (desig. sin.). Síntipos ㅇ, Argentina: Ceres, sobre arbusto (USNM) [não examinado].

Ceroplastes communis Hempel, 1900: 459; Vernalha, 1953: 124 (cat.); Silva et al., 1968: 137 (cat.); Ben-Dov, 1993: 29 (cat.). Síntipos 우, São Paulo, Ipiranga, sobre Maytenus, ?data, ?coletor; 1 lâmina, 2 exemplares (MZSP); 2 exemplares em 2 lâmina, (DZUP); exemplares preservados a seco (BMNH) [examinado]. n. sin.

Características macroscópicas: (baseado em exemplares vivos).

Cera: úmida, pastosa, com coloração rosa-clara; contorno irregular em vista dorsal (Fig. 32); oval nas fêmeas jovens; deprimida dorso-ventralmente, com placas laterais formando uma grossa bainha, rebordo com contorno irregular; nos exemplares mais jovens apresenta-se dividida em 8 placas, 1 dorsal, 4 laterais, 1 anterior e 1 posterior; a placa posterior é 

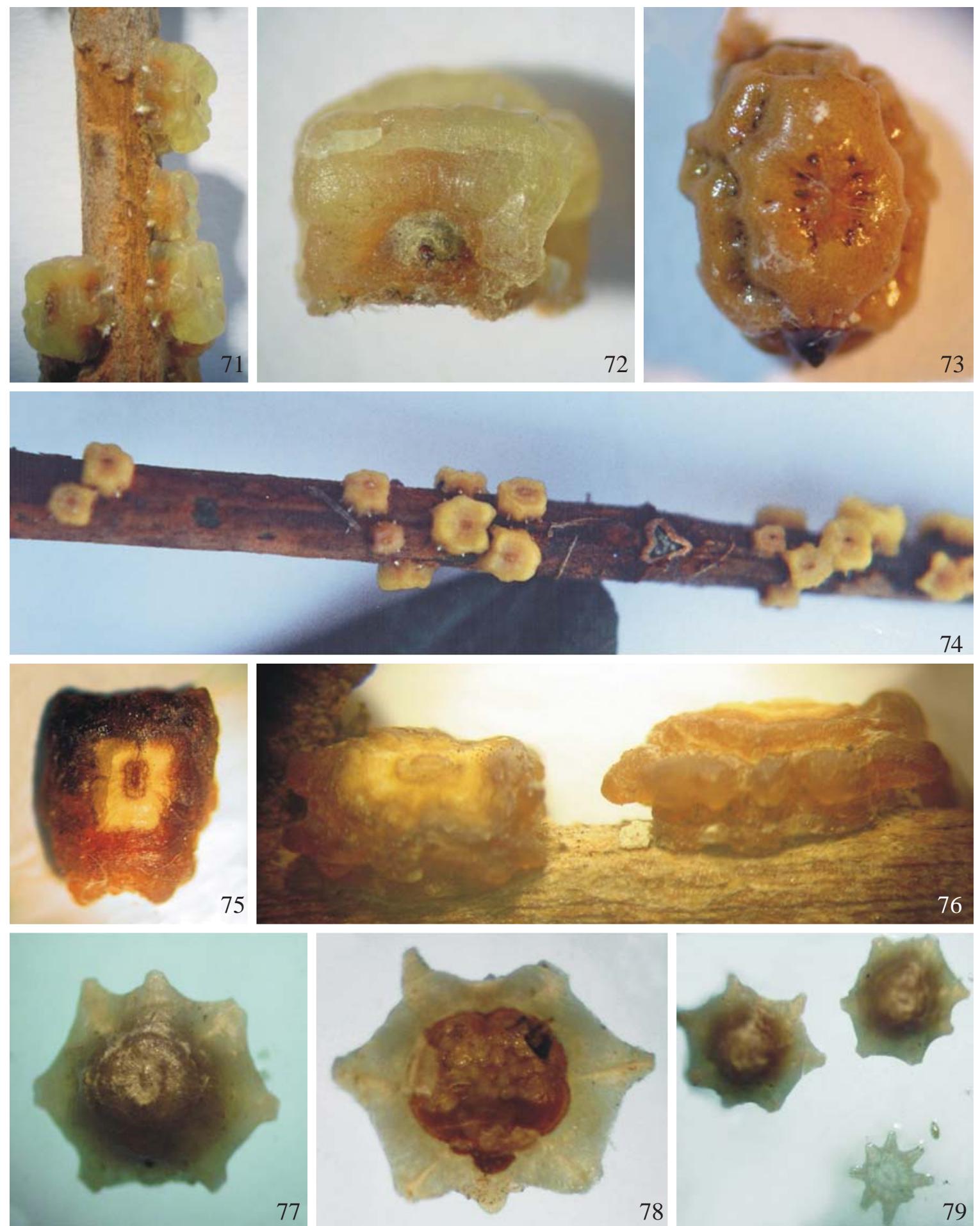

Figs. 71-79. 71-74, Ceroplastes quadratus: 71, vista dorsal; 72, placa posterior; 73, corpo despido de cera; 74, infestação sobre Myrtaceae. 75, 76, Ceroplastes speciosus: 75, vista dorsal; 76, vista lateral. 77-79, Ceroplastes stellifer: 77, vista dorsal; 78, vista ventral; 79, formas jovens.

mais larga, com dois núcleos, um de cada lado da fenda do processo caudal; núcleos cobertos por uma secreção branca, o dorsal é oval e maior, os laterais e os da placa posterior são retangulares e menores; comprimento, $4 \mathrm{~mm}$ (3-7); largura, 2,5mm (2,5-5,5) e altura, 2,0mm (1-4,75).

Corpo: circular a oval, coloração castanho-clara, com 8 tubérculos globosos, bem evidentes, 1 dorsal mais claro, 6 laterais e um anterior; comprimento, 3,5mm (2-5,3); largura, 2,0 $\mathrm{mm}(2-4 \mathrm{~mm})$; processo caudal curto com coloração castanhoescura e dirigido para cima (Fig. 33).

Características microscópicas: Superfície dorsal: com 8 áreas claras, uma na região cefálica, uma na médio-dorsal e 3 


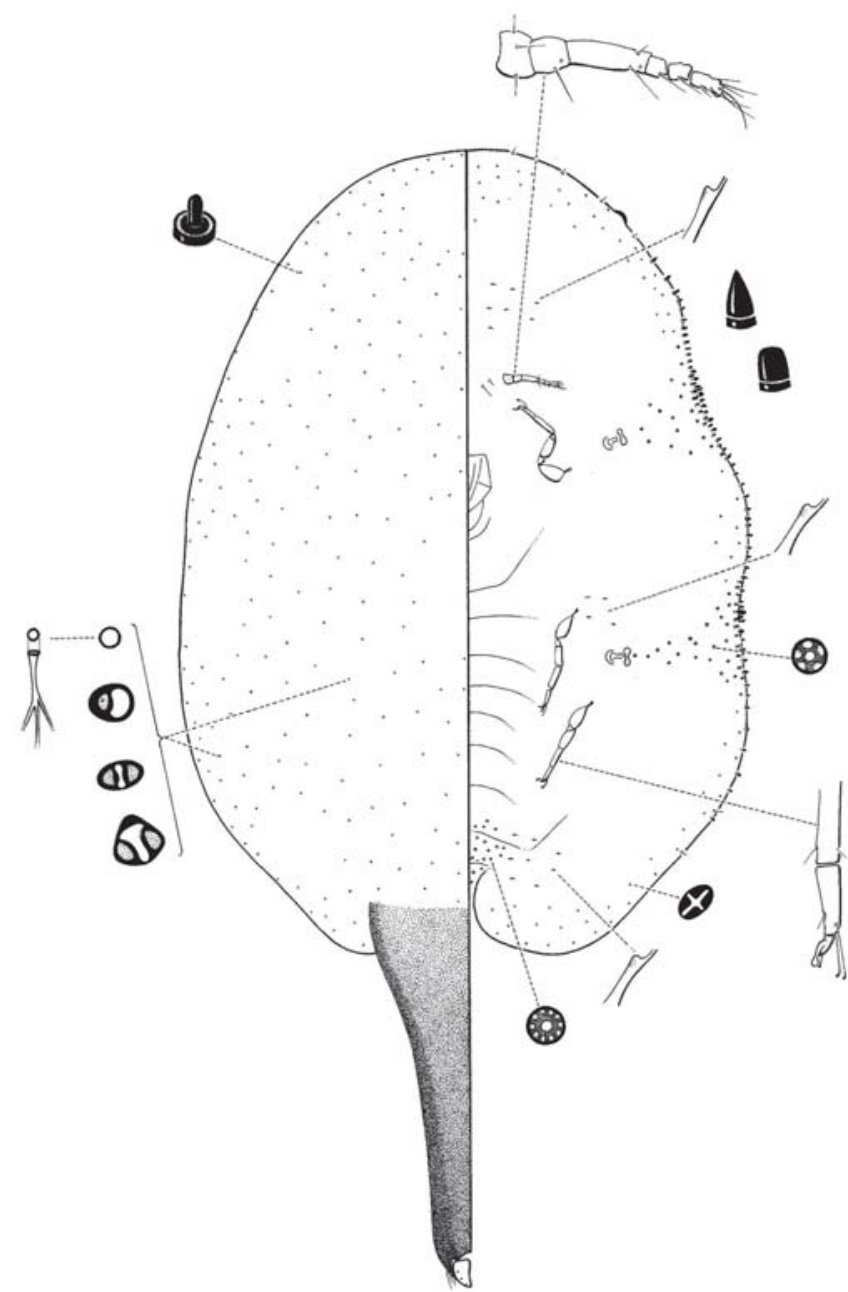

Fig. 80. Ceroplastes acutus sp. nov., sobre Machaerium acutifolium (Fabaceae).

pares laterais. Setas cônicas; poros triloculares, de contorno oval e triangular tipo II em maior número e, escassos biloculares e tetraloculares. Poros pré-operculares crivados. Placas anais com 3 ou 4 setas dorsais, uma ventral e 3 ou 4 na borda; anel anal com 6 setas (Fig. 94).

Margem: com setas estigmáticas cônicas e pontiagudas de diferentes tamanhos, 12,5-30 $\mu \mathrm{m}$ de comprimento, dispostas em 3 ou 4 linhas na margem dos canais estigmáticos, prolongando-se lateralmente em duas linhas nas regiões da

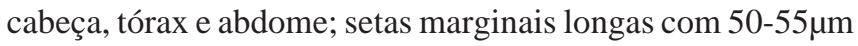
de comprimento alternam-se com as estigmáticas (Fig. 94).

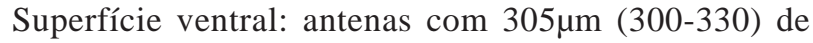

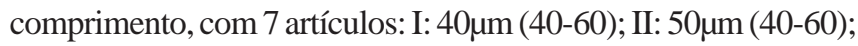

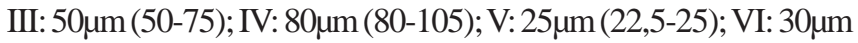
(25-30) e VII: $30 \mu \mathrm{m}$ (30-32,5); o IV pode apresentar-se parcialmente dividido; com três setas próximas da margem da base de cada antena. Pernas com 520-580 $\mu \mathrm{m}$ de comprimento:

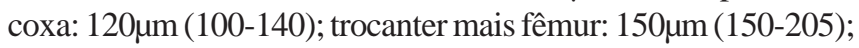
tíbia: $125 \mu \mathrm{m}(120-145)$; tarso: $80 \mu \mathrm{m}$ (75-100); garra: $25 \mu \mathrm{m}$ (2530 ), com dentículo; digítulos tarsais delgados com $57,5 \mu \mathrm{m}$ (55-
$62,5)$ de comprimento, com extremidades distais dilatadas; digítulos da garra iguais e dilatados com 37,5 $\mu \mathrm{m}$ (35-40) de comprimento e extremidades distais espatuladas; esclerotização na articulação tíbio-tarsal presente. Poros dos canais estigmáticos com 5 lóculos; poros cruciformes dispersos na superfície ventral, ainda que mais concentrados na área submarginal; poros genitais com 10 lóculos. Condutos tubulares, com filamento delgado e curto, escassos nos últimos segmentos abdominais (Fig. 94).

Material examinado: BRASIL. São Paulo: Pedreiras (X-1926, hospedeiro indeterminado), 11 exemplares em 2 lâminas (IBSP); "Pirapitinguy" (31-XII-1930, arbusto do campo, A. Hempel col.), 2 exemplares em 2 lâminas; São Carlos (16-VIII-2001, Banisteriopsis oxyclada, A.L.B.G. Peronti col.), 8 exemplares em 2 lâminas; (16VIII-2001, Byrsonima sp. A.L.B.G. Peronti col.), 4 exemplares em 1 lâmina; (18-XI-2001, B. oxyclada, A.T. Fushita col.), 4 exemplares em 2 lâminas, (DCBU); São Paulo (X-1926, hospedeiro indeterminado) 3 exemplares em 1 lâmina; (21-I-1935, planta silvestre, E.J. Hambleton col.), 4 exemplares em 3 lâminas; (19-XI-1934, Casearia sylvestris, D. Braz col.), 8 exemplares em 5 lâminas; (23-X-1937, planta silvestre, R.L. Araújo col.), 2 exemplares em 1 lâmina; Sorocaba, Brigadeiro Tobias: (VI-1932, planta silvestre, J. Deslandes), 7 exemplares em 2 lâminas (IBSP). Material proveniente de outros Estados: Pernambuco (24-X-1928, 24-X-1929, planta silvestre, A. Hempel col.), 3 exemplares em 1 lâmina; Gerivá: (27-VII-1928, planta silvestre, A. Hempel col.), 7 exemplares em 2 lâminas (IBSP).

Distribuição geográfica: Brasil (Amazônia, Pernambuco, São Paulo); Argentina.

Discussão: espécies semelhantes e diferenças entre elas, ver discussão de $C$. coronatus. No presente trabalho $C$. communis Hempel, 1900 é sinonimizado com C. formicarius.

\section{Ceroplastes formosus Hempel}

(Figs. 35-40, 95)

C. formosus Hempel, 1900a: 468; Hempel, 1901b: 64 (redescr.); Vernalha, 1953: 128 (cat.); Silva et al., 1968:138 (cat.); Ben-Dov, 1993: 36 (cat.). Síntipos o. Brasil, Minas Gerais, Poços de Caldas sobre Eugenia sp., ?data, ?coletor. Hempel não designou holótipo na descrição original da espécie. São aqui designados lectótipo (lâmina $\mathrm{N}^{\circ} 37$, DZUP), exemplar preparado por Matile-Ferrero/ 1993 a partir de material série-tipo, presevados a seco e, 2 paralectótipos (tipo 79요/195a, No 95.137, MZSP) [examinado].

Características macroscópicas: (baseado em exemplares vivos).

Cera: rija, branca, com aspecto semitransparente e coloração branco-amarelada nos exemplares mais jovens; retangular a oval em vista dorsal e, semicircular a retangular em vista lateral; dividida em 1 placa dorsal, 4 laterais, 1 anterior e 1 posterior; núcleo dorsal grande e oval; núcleos laterais, anterior e posterior inconspícuos, com mancha branca e retangular acima dos mesmos (Figs. 35-38); comprimento, 3,5mm (2,0-4,0); largura, 3,0mm (2,5-3,5); altura, 2,6mm (2,3-3,0).

Corpo: oval, coloração castanho-amarelada (Fig. 39); comprimento, 2,7mm (1,2-3,9); largura, 1,9mm (0,8-2,5); processo caudal cônico, dirigido para trás, com $0,5-1,1 \mathrm{~mm}$ de comprimento e coloração castanho-escura.

Características microscópicas: Superfície dorsal: com 8 


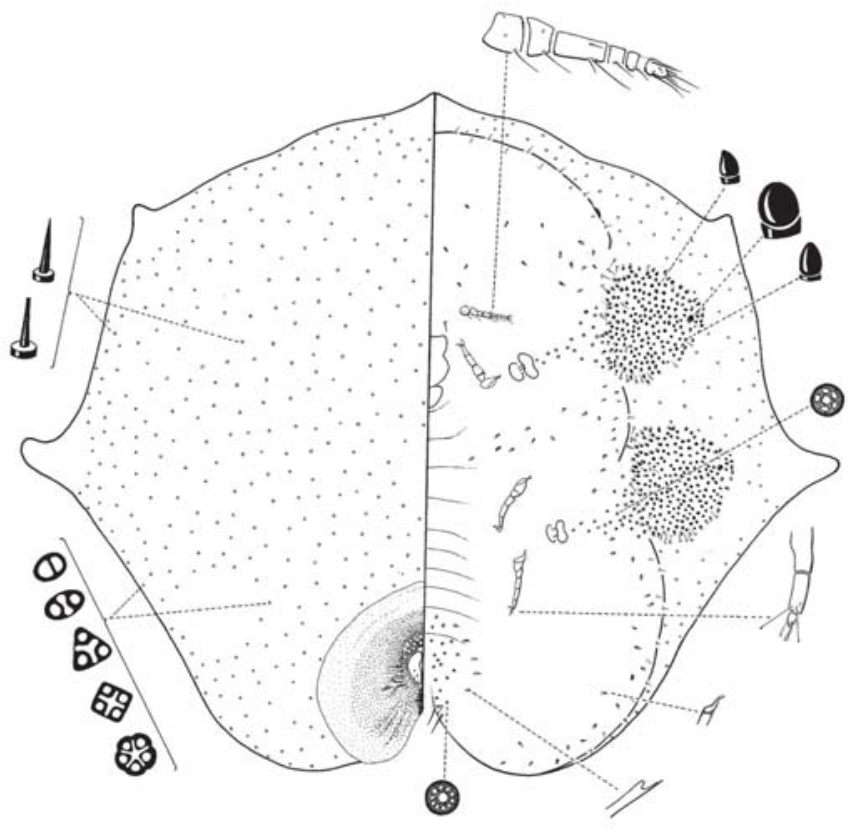

Fig. 81. Ceroplastes agrestis Hempel, esquema do tipo.

áreas claras, uma na região cefálica, uma na médio-dorsal e 3 pares laterais. Setas cilíndricas com ápice arredondado, curtas com cerca de $3 \mu \mathrm{m}$; poros relativamente grandes com condutos filamentosos ramificados; bilocular tipo I com $7 \mu \mathrm{m}$ de diâmetro e triloculares, de contorno oval e triangular tipo I, com $8 \mu \mathrm{m}$ de base. Processo caudal com poros pré-operculares simples e com seis setas em seu ápice, três de cada lado, abaixo das placas anais; placas anais com 3 setas dorsais (Fig. 95).

Margem: com 80-110 setas estigmáticas cônicas estão inseridas na margem do corpo, entre a altura da base da antena até um pouco além da inserção do terceiro par de pernas; no ápice do canal estigmático estão dispostas em duas ou três linhas, com 3 a 4 setas maiores, retangulares ou com ápice arredondado, ao centro; as demais, estão dispostas lateralmente, em uma única linha, além do canal estigmático;

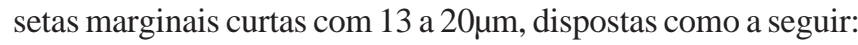
cerca de 8-9 entre os tubérculos dos olhos, 1 entre cada tubérculo do olho e a sutura estigmática anterior, 3-4 entre a suturas estigmáticas anterior e posterior e 4-6 entre a sutura estigmática posterior e a fissura anal (Fig. 95).

Superfície ventral: setas submarginais curtas com cerca de 5 a $6 \mu \mathrm{m}$ de comprimento; antenas com 210 $\mu \mathrm{m}$ (180-240) de

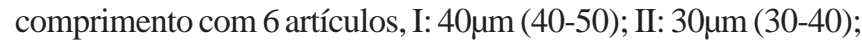

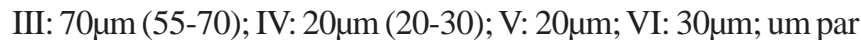
de setas próximas da base de cada antena. Pernas com 372,5 $\mu \mathrm{m}$

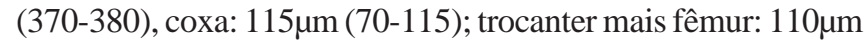

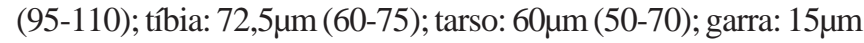

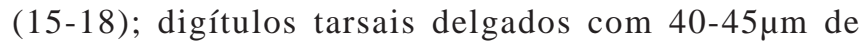
comprimento e extremidades distais dilatadas; digítulos da garra diferentes, um delgado e outro dilatado, com 30-32,7 $\mu \mathrm{m}$ de comprimento e extremidades distais espatuladas; esclerotização na articulação tíbio-tarsal ausente. Poros dos canais estigmáticos com 5 lóculos; poros cruciformes concentrados na região submarginal; poros genitais com 10 lóculos. Condutos tubulares com filamento delgado na região cefálica e nos últimos segmentos abdominais (Fig. 95).

Matérial examinado: BRASIL. São Paulo: Campinas (1926, hospedeiro indeterminado, ?col.), 8 exemplares em 1 lâmina (IBSP); (VII-1939, jaboticabeira, A.O. Martins col.), 4 exemplares em 1 lâmina (DZUP); Santa Rita do Passa Quatro, Parque Estadual de Vassununga (?data, hospedeiro indeterminado, A. Hempel col.), 7 exemplares em 2 lâminas (IBSP); Santos (21-III-2002, Eugenia sprengelli, A.L.B.G. Peronti col.), 3 exemplares em 1 lâmina; São Carlos (04-IX-2001, XI2001, E. sprengelli, A.L.B.G. Peronti col.), 14 exemplares em 6 lâminas; (01-III-2002, Myrciaria cauliflora, A.L.B.G. Peronti col.), 4 exemplares em 1 lâmina (DCBU).

Distribuição geográfica: Brasil (Minas Gerais, São Paulo). Discussão: assemelham-se a $C$. formosus as espécies: $C$. acutus, C. purpureus Hempel, 1900 e C. speciosus Hempel, 1900a registradas para o Estado de São Paulo; C. itatiayensis Hempel, 1938 conhecido para o estado do Rio de Janeiro, Brasil, e C. magnicauda Reyne, 1964 conhecido para Curaçao. Semelhanças e diferenças entre elas, ver discussão de $C$. acutus.

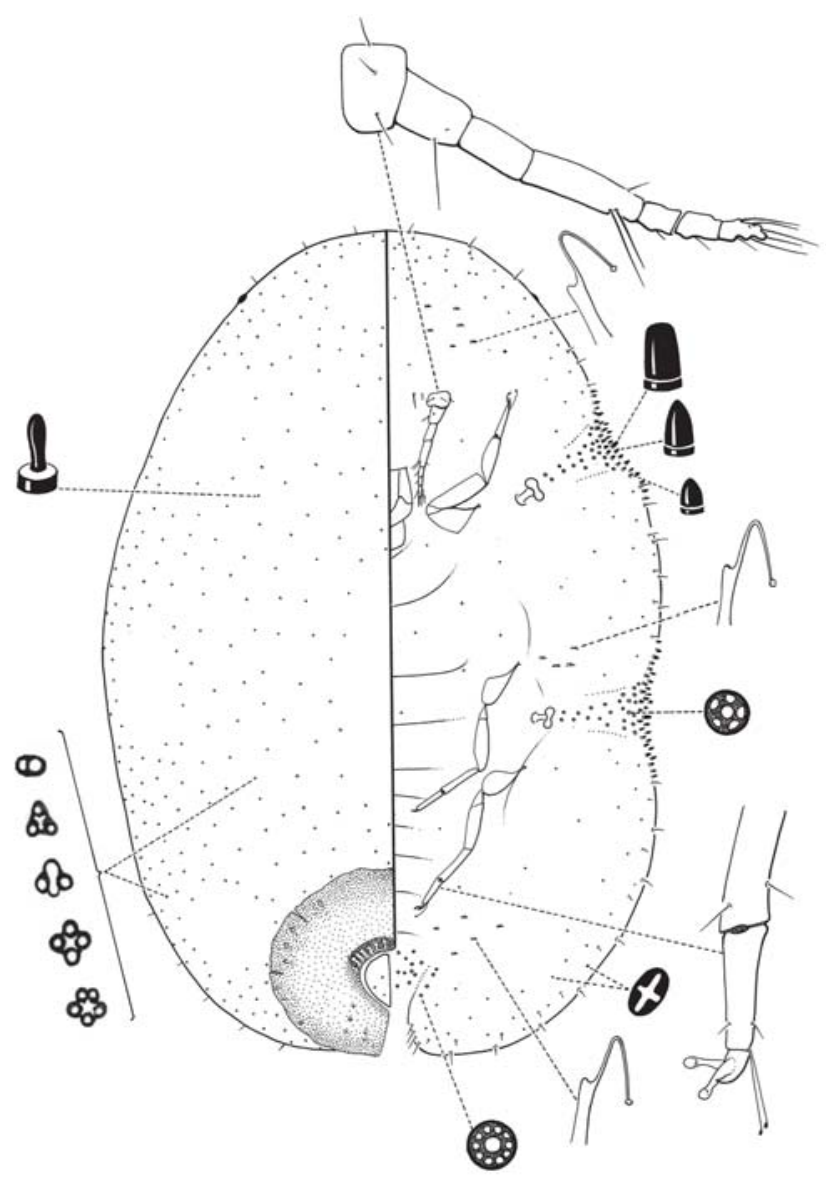

Fig. 82. Ceroplastes bragai sp. nov., sobre hospedeiro indeterminado. 


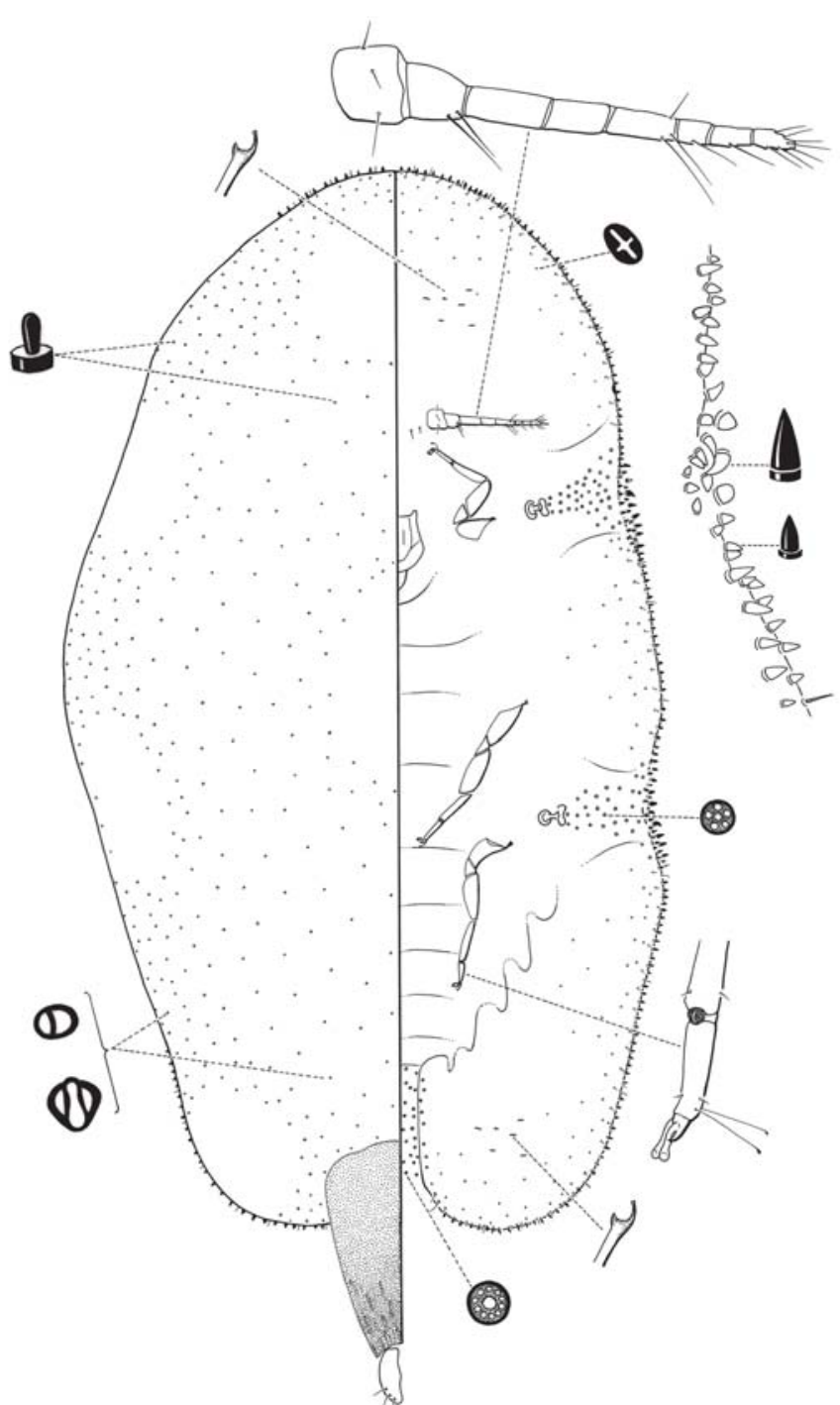

Fig. 83. Ceroplastes cassiae (Chavannes) sobre Ficus citrifolia (Moraceae).

\section{Ceroplastes glomeratus Peronti sp. nov.}

(Figs. 41-44, 96)

Material tipo: holótipo $\odot$, Brasil, Rio Grande do Sul, Santa Maria, $\mathrm{N}^{\circ} 251$ (DCBU), sobre Vernonia brevifolia (Asteraceae), 22-X-2002, D. Link col; 4 parátipos na mesma preparação do holótipo (DCBU).

Etimologia: O nome da espécie é alusivo a forma com que os exemplares fundem-se uns aos outros, formando um grande aglomerado.

Características macroscópicas: (baseado em exemplares vivos).

Cera: rija, coloração branca, com limites indefinidos; um exemplar apresenta-se fundido ao outro, formando um aglomerado, cobertos por uma massa densa de cera. (Figs. 41, 42); sem divisão de placas; núcleo dorsal com oito pequenos núcleos dispostos ao seu redor, localizado ao lado da abertura do processo caudal; bandas estigmáticas estendendo-se até o dorso; comprimento, $3,2 \mathrm{~mm}(3,0-4,5)$; largura, $2,0 \mathrm{~mm}(2,3-$ $3,2)$; altura, $2,0 \mathrm{~mm}(1,5-7,0)$.

Corpo: oval nos mais jovens e retangulares nos exemplares mais velhos; coloração rósea ou branco-amarelada; comprimento, 2,8mm (2,5-3,5); largura, $2 \mathrm{~mm}(1,4-2,5)$ e altura, $1,2 \mathrm{~mm}(1,0-3)$; processo caudal castanho-escuro formando duas corcovas sobre o dorso (Figs. 43, 44).

Características microscópicas: Superfície dorsal: com 6 ou 8 áreas claras, uma na região cefálica, uma médio-dorsal e 2 ou 3 pares laterais. Setas cônicas de dois tipos, com ápice arredondado ou pontiagudo. Poros biloculares tipo II, triloculares, de contorno oval e triangular, tipo I e II, e escassos tetraloculares. Área esclerotizada do processo caudal com base ampla, estendendo-se sobre o dorso, cobrindo a área clara médio-dorsal; nos exemplares mais velhos, cobrindo até a área clara cefálica; placas anais com 4 setas na superfície dorsal (Fig. 96).

Margem: com 100 ou mais setas estigmáticas cônicas, com ápices arredondados ou, cilíndricos com ápices truncados, agrupadas no ápice dos canais estigmáticos (Fig. 96).

Superfície ventral: antenas com $300 \mu \mathrm{m}(280-335)$ de

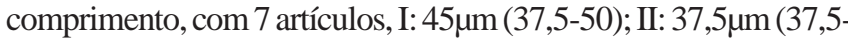

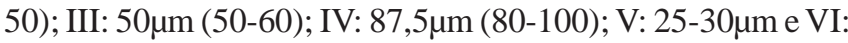
22,5 $\mu \mathrm{m}$ (20-25); VII: $35-40 \mu \mathrm{m}$; o IV segmento geralmente apresenta uma pseudo-segmentação; com duas setas próximas da base de cada antena, a maior com $50 \mu \mathrm{m}$ e a menor com

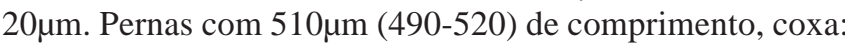

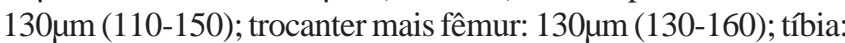

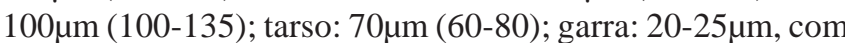
dentículo; digítulos tarsais com 47,7-55 $\mu \mathrm{m}$ de comprimento, com extremidades distais dilatadas; digítulos da garra iguais, dilatados com 25-27,5 $\mu \mathrm{m}$ de comprimento, com extremidades distais espatuladas; esclerotização na articulação tíbio-tarsal presente. Poros dos canais estigmáticos com 5 lóculos; poros cruciformes concentrados na região submarginal; poros genitais com 10 lóculos. Condutos tubulares presentes na região cefálica e nos últimos segmentos abdominais (Fig. 96).

Material examinado: BRASIL. São Paulo: Araraquara (02-V-2002, Schinus therebinthifolius, A.L.B.G. Peronti col.), 4 exemplares em 2 lâminas (DCBU); Gália (X-1935, planta silvestre, O. Costa col.), 2 exemplares em 1 lâmina (IBSP); (31-IV-2002, Acacia plumosa, A.L.B.G. Peronti col.), 2 exemplares em 1 lâmina; (01-V-2002, A. plumosa, A.L.B.G. Peronti col.), 2 exemplares em 1 lâmina (DCBU); Itararé (02-XII-1928, hospedeiro indeterminado, E. Schwebel col.), 4 exemplares em 1 lâmina; (29-V-1928, arbusto, A. Hempel col.), 1 exemplar em 1 lâmina; (26-VIII-1928, planta silvestre, E. Schwebel col.), 1 exemplar em 1 lâmina; (29-IX-1928, árvore silvestre, E. Schwebel col.), 1 exemplar em 1 lâmina (IBSP); Luís Antônio, Reserva Ecológica do Jataí (24-IV-2001, A. plumosa, A.L.B.G. Peronti col.), 1 exemplar em 1 lâmina; Rio Claro (18-VI-2001, Calliandra tweedii, A.L.B.G. Peronti col.), 5 exemplares em 1 lâmina; Santa Rita do Passa Quatro (24-VII-2002, hospedeiro indeterminado, A.L.B.G. Peronti col.), 8 exemplares em 4 lâminas; (24-VII-2002, Dalbergia frutescens, A.L.B.G. Peronti col.), 2 exemplares em 1 lâmina; São Carlos (21-VII2001, Caesalpinia peltophoroides, A.L.B.G. Peronti col.), 4 exemplares em 2 lâminas; (19-XI-2001, Anadenanthera sp., A.L.B.G. Peronti col.), 3 exemplares em 1 lâmina; (23-IV-2002, A. plumosa, A.L.B.G. Peronti col.), 4 exemplares em 1 lâmina, (22-V-2002, A. plumosa, A.L.B.G. Peronti col.), 1exemplar em 1 lâmina; (26-VIII-2002, Anadenanthera pavonina, A.L.B.G. Peronti col.), 2 exemplares, 1 lâmina; Fazenda 


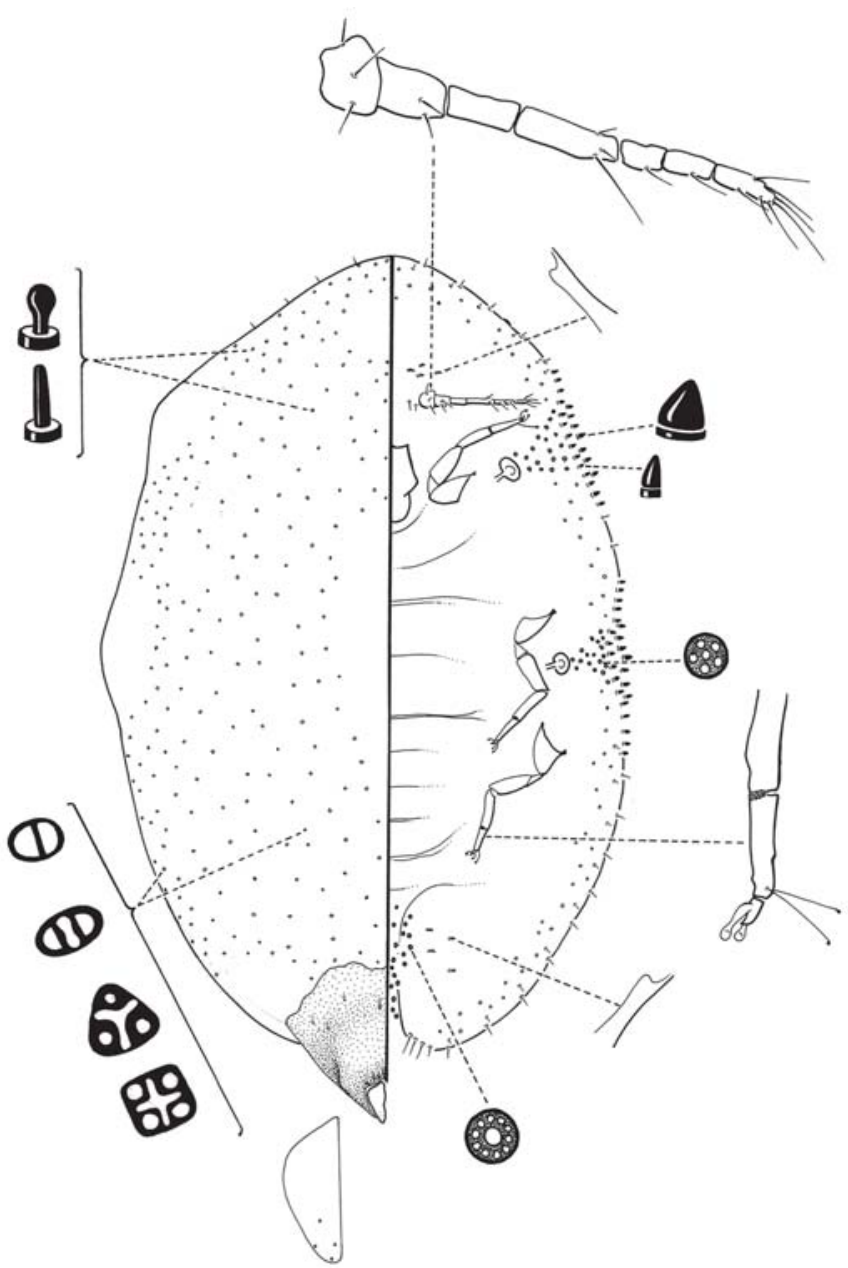

Fig. 84. Ceroplastes cirripediformes Comstock sobre Duranta repens var. aurea (Verbenaceae).

Canchim, Embrapa (14-IX-2000, A. plumosa, A.L.B.G. Peronti col.), 1 exemplar em 1 lâmina; (07-VIII-2001, Mimosaceae, A.L.B.G. Peronti col.), 7 exemplares em 2 lâminas (DCBU); São José do Rio Preto (VII1926, hospedeiro indeterminado, A. Hempel), 1 exemplar em 1 lâmina; São Paulo (13-VII-1936, Piptadenia colubrina, ?col.), 2 exemplares em 1 lâmina; (16-VIII-1898, Inga sp., ?col.), 2 exemplares em 1 lâmina; (23-X-1937, planta silvestre, R.L. Araujo), 2 exemplares em 1 lâmina (IBSP). Material proveniente de outros Estados: Mato Grosso, Barra do Garça, (28.IX.1990, hospedeiro indeterminado, M.T. Tavares col.), 4 exemplares em 3 lâminas; Paraná, Ponta grossa (17-VII-1930, hospedeiro indeterminado, J. Deslandes), 6 exemplares em 2 lâminas (IBSP); (17-VII-1930, hospedeiro indeterminado, J. Deslandes), 1 exemplar em 1 lâmina (MZSP).

Distribuição geográfica: Brasil (Mato Grosso, São Paulo, Paraná e Rio Grande do Sul).

Discussão: em vista macroscópica, assemelham-se a Ceroplastes glomeratus as espécies: C. bruneri Cockerell \& Cockerell, 1902, conhecido para a Argentina, Bolívia e Paraguai; C. lahillei Cockerell, 1910, mencionado para a Argentina; $C$. caesalpiniae Reyne, 1964, conhecida para Curaçao e Gascardia madagascariensis Targioni Tozzetti, 1893, registrada para Madagascar, por ocorrerem em aglomerados, cobertos por uma massa densa de cera. Em vista microscópica, assemelham-se por apresentarem esclerotização tíbio-tarsal; digítulos da garra iguais e dilatados e setas estigmáticas cônicas com ápice arredondado. C. caesalpiniae e C. bruneri assemelham-se ainda por apresentarem antenas com 7 segmentos, esclerotização do processo caudal cobrindo quase toda superfície dorsal do corpo e superfície dorsal da placa anal com 4 setas. C. caesalpiniae difere pela ausência de esclerotização tíbio-tarsal, por não apresentar poros dorsais tetraloculares e por apresentar área esclerotizada do processo caudal contínua, sem estreitamento acima da placa anal. $C$. bruneri difere principalmente por não apresentar na superfície dorsal, poros biloculares e quadriloculares e setas cônicas. $C$. lahillei $\mathrm{e}$ G. madagascariensis diferem por apresentar antenas com 8 segmentos. G. madagascariensis, difere também por apresentar setas estigmáticas em maior número e dispostas em uma longa faixa sobre o dorso, em posição perpendicular ao corpo e por apresentar um grande número de setas na região dorsal da placa anal. As estruturas morfométricas dos exemplares aqui designados como holótipo e parátipos de $C$. glomeratus sp. nov. são coincidentes com aquelas identificadas como C. confluens Cockerell \& Tinsley, 1898, depositadas no IBSP, MZSP e DCBU. Entretanto, os síntipos de C. confluens, depositados no USMN, diferem destas por apresentarem, setas estigmáticas cônicas em pequeno número, processo caudal cônico, ausência de esclerotização acima do processo caudal, setas dorsais cilíndricas com ápice truncado lateralmente e poros do canal estigmático com número de lóculos variáveis. Constatamos, portanto, que $C$. confluens não ocorre no estado de São Paulo.

\section{Ceroplastes grandis Hempel} (Figs: 45-55, 97)

Ceroplastes grandis, Hempel, 1900a: 455; Hempel, 1901a: 62 (redescr.); Gomes Costa, 1949:16 (cit.); Vernalha, 1953: 128 (cat.); Silva et al., 1968: 139 (cat.); Corseuil \& Barbosa, 1971: 237 (cit.); BenDov, 1993: 37 (cat.); Hickel \& Ducroquet. 1995: 667 (cit.); Borges et al., 2003. (cit.); Kussler et. al. 2004: 1231 (cit). Síntipos 우,
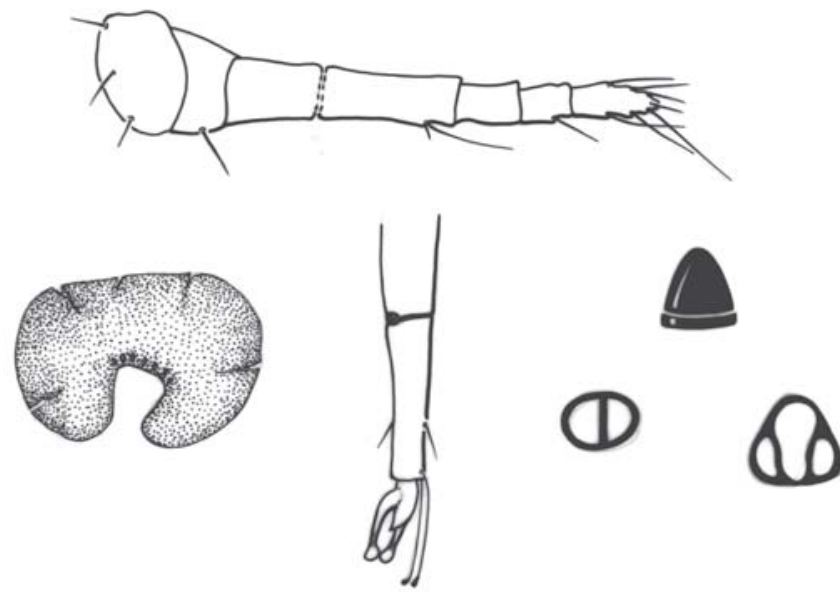

Fig. 85. Ceroplastes cirripediformis (Esquema de partes do tipo de Ceroplastes cultus Hempel). 


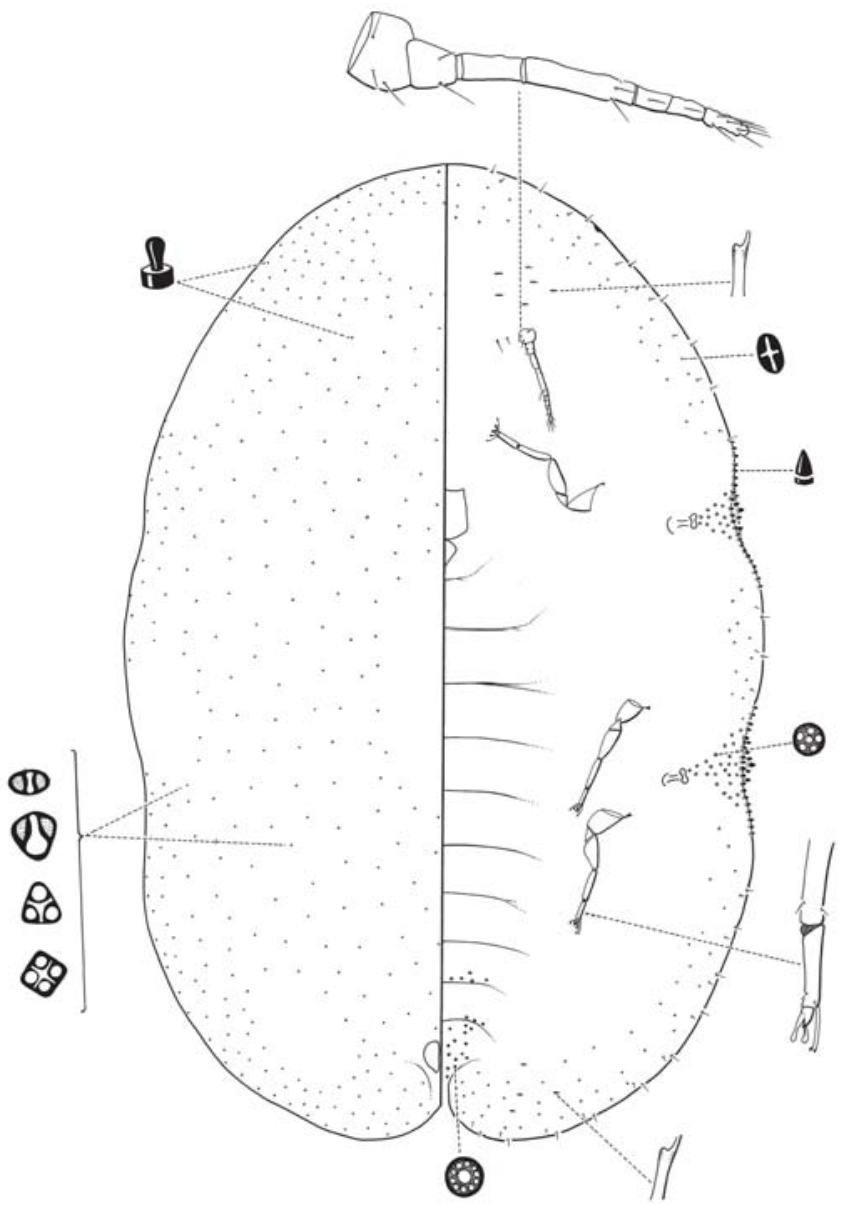

Fig. 86. Ceroplastes cirripediformis (espécie-tipo de Ceroplastes cuneatus Hempel).

Brasil, São Paulo, Ipiranga (84, 271b) sobre Zanthoxylum sp., Ilex sp., Psidium sp., Mechilia flava, Baccharis sp. e várias outras plantas, principalmente Myrtaceae, ?data, H.V. Iheringi; 2 exemplares em 1 lâmina, que apresentam a superfície dorsal e ventral separadas (MZSP) [examinado].

Ceroplastidia grandis (Hempel, 1900a); Granara de Willink, 1999: 66 (comb., redescr.).

Ceroplastes hempeli Lizer \& Trelles, 1919: 381; Granara de Willink, 1999: 66 (desig. de sin.).

Ceroplastes rhizophorae Hempel, 1918: 201; Silva et al., 1968: 140 (cat.); Ben-Dov, 1993: 49 (cat.). Síntipos + , Brasil, Santos, sobre Rhizophora mangle, ?data, ?coletor (MZSP) [não localizado]. n. sin.

Características macroscópicas: (baseado em exemplares vivos).

Cera: úmida, branca com manchas roseas ou inteiramente rósea; oval, circular ou irregular em vista dorsal e, semicircular ou irregular em vista lateral; sem placas distintas; núcleos inconspícuos; bandas estigmáticas espessas (Figs. 45); comprimento, 8mm (5-18); largura, 6mm (3-15); altura, 5mm (313).

Corpo: oval, de coloração rosea ou castanho-clara; com dois ou três tubérculos de cada lado, um anterior e um posterior; comprimento, 5mm (4-10); largura, 3,0mm (3,2-7); processo caudal cônico com ápice dirigido para trás, com 0,65-2mm de comprimento e coloração negra (Figs. 46, 54).

Características microscópicas: Superfície dorsal: com 8 áreas claras, uma na região cefálica, uma na médio-dorsal e 3 pares laterais. Setas cilíndricas de dois tipos, as menores com 7- $9 \mu \mathrm{m}$ de comprimento e ápice truncado e, as maiores com 11 a $15 \mu \mathrm{m}$ de comprimento com ponta ou com ápice truncado lateralmente; poros biloculares tipo II, triloculares, de contorno oval ou triangular do tipo II e tetraloculares, em maior número e, escassos pentaloculares e hexaloculares. Processo caudal com poros pré-operculares simples; placas anais com 4 setas dorsais, 3 ventrais e 4 ou 5 na borda da prega anal (Fig. 97).

Margem: com 46-80 setas estigmáticas cônicas de diferentes tamanhos agrupadas no ápice dos canais estigmáticos e estendendo-se sobre o dorso; setas marginais dispostas como a seguir: cerca de 7 a 8 entre os tubérculos oculares, 1 a 2 entre cada tubérculo ocular e a sutura estigmática anterior, 3-4 entre a suturas estigmáticas anterior e posterior e 13 entre a sutura estigmática posterior e a fissura anal (Fig. 97).

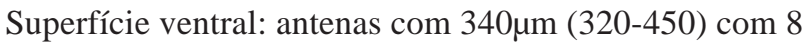

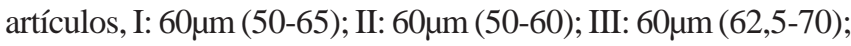

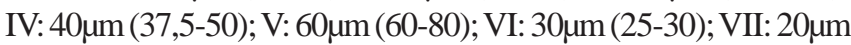

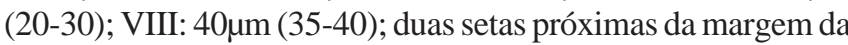

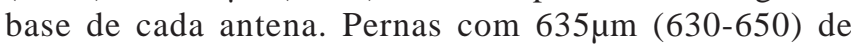
comprimento, coxa: $160 \mu \mathrm{m}$ (150-180); trocanter mais fêmur:

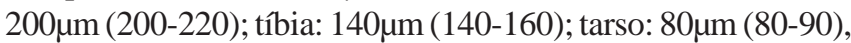

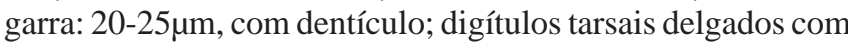
55-60 $\mu \mathrm{m}$ de comprimento e extremidades distais dilatadas;

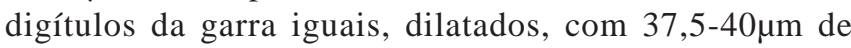
comprimento e extremidades distais espatuladas; esclerotização tíbio-tarsal presente. Poros dos canais estigmáticos, predominantemente com 5 lóculos e, em menor número, com 6 lóculos; poros cruciformes concentrados na superfície submarginal; poros genitais com 10 lóculos. Condutos tubulares de filamento curto nos últimos segmentos abdominais e na região cefálica, próximos das antenas (Fig. 97).
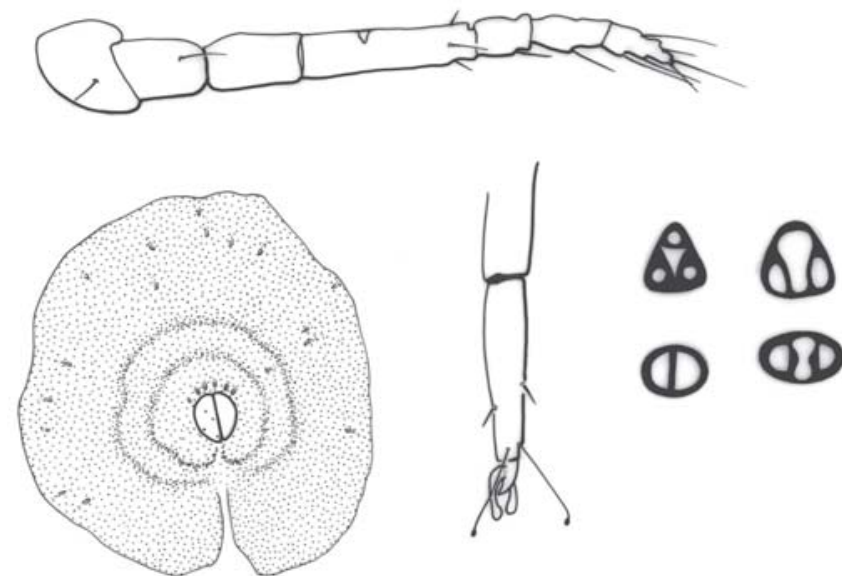

Fig. 87. Ceroplastes cirripediformis (Esquema de partes do tipo de Ceroplastes rarus Hempel). 
Material examinado: BRASIL. São Paulo: Campos do Jordão (25XI-2001, Platanus sp., A.L.B.G. Peronti col.) 5 exemplares em 3 lâminas; Santos (22-III-2002, Avicennia tomentosa, A.L.B.G. Peronti col.), 2 exemplares em 1 lâmina; (22-III-2002, Rhizophora mangle, A.L.B.G. Peronti col.), 2 exemplares em 1 lâmina; São Carlos (06-XII2001, 26-V-2002, 10-IX-2002, Duranta repens var. aurea, A.L.B.G. Peronti col.), 4 exemplares em 2 lâminas; (IV-2002, Schinus molle, A.L.B.G. Peronti col.), 2 exemplares em 2 lâminas (DCBU); São Paulo (19-X-1932, goiabeira, F. Rocha col.), 2 exemplares em 2 lâminas; (12-I-1935, árvore, O. Rocha col.), 2 exemplares em 2 lâminas; (15VIII-1929, árvore de sombra, A. Hempel col.), 4 exemplares em 2 lâminas; (18-V-1931, Platanus sp, G. de O. Castro col.), 4 exemplares em 2 lâminas; (XII, 1908, hospedeiro indeterminado, H. Luederwald col.), 2 exemplares em 2 lâminas; (IX-1909, Platanus sp., H. Luederwald col.), 2 exemplares em 2 lâminas (IBSP); (22-IX-2001, Stenocalyx pitanga, A.L.B.G. Peronti col.), 4 exemplares em 2 lâminas (DCBU); Suzano (27-X-1934, ameixeira, Amaral col.), 1 exemplar em 1 lâmina (IBSP). Material proveniente de outros Estados: Paraná, Rio Negro (03-I-1929, planta silvestre, Borgmeir \& Autuori col.), 4 exemplares em 2 lâminas (IBSP); Rio de Janeiro, Niterói (2002, Schinus sp., C.R.Sousa-Silva col.), 2 exemplares em 2 lâminas (DCBU); Rio Grande do Sul, Santa Maria (22-XII-2002, Tabebuia avellanedae, D. Link col.), 2 exemplares em 2 lâminas); Bento Gonçalves (13-VIII-2001, Delonix regia, I. Teixeira col.), 5 exemplares em 2 lâminas.

Distribuição geográfica: Brasil (Rio de Janeiro, São Paulo, Paraná, Rio Grande do Sul); Argentina.

Discussão: assemelha-se a Ceroplastes grandis Hempel, 1900: Ceroplastes willinkae sp. nov. por apresentar setas estigmáticas cônicas, setas dorsais de dois tipos, cilíndricas com ponta ou com ápice truncado; poros dorsais com 3 a 5 lóculos, sendo o trilocular de contorno triangular do tipo II e setas estigmáticas cônicas. C. grandis, difere principalmente por apresentar setas estigmáticas agrupadas na margem dos canais estigmáticos; poros biloculares; antenas com 8 segmentos e processo caudal mais curto. Na presente revisão C. rhizophorae Hempel, 1918 é sinonimizada com C. grandis. As populações de $C$. grandis coletadas no decorrer desse trabalho apresentaram muitas variações (Figs. 47 -53), principalmente quanto a coloração e formato da cera.

\section{Ceroplastes gregarius Hempel}

Ceroplastes gregarius Hempel, 1932: 323; Silva et al., 1968:139 (cat.); Ben-Dov, 1993: 38 (cat.). Síntipos + , Brasil, São Paulo, Ipiranga, $\mathrm{N}^{\circ} 537$ sobre Gomphrena nagansellarti, VII-1915, H. Luederwaldt col.; 3 exemplares fragmentados, em 1 lâmina (IBSP) [examinado].

Características microscópicas: Superfície dorsal: 6 ou 8 áreas claras, uma na região cefálica, uma na médio-dorsal e 2 ou 3 pares laterais; poros biloculares e triloculares de contorno triangular e oval; processo caudal curto.

Margem: 25 a 30 setas estigmáticas cônicas dispostas em 2 ou 3 linhas no ápice dos canais estigmáticos, prolongandose lateralmente um pouco além destes.

Superfície ventral: cerdas submarginais com $10 \mu \mathrm{m}$; antenas com 302,5-320 $\mu$ m de comprimento com 7 artículos: I: 35-40 $\mu$ m;

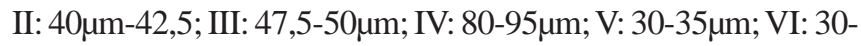

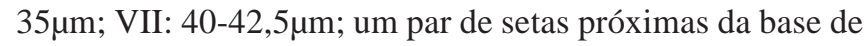

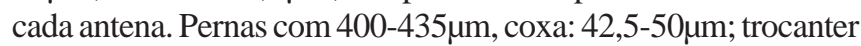

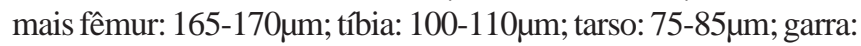
15-20 $\mu \mathrm{m}$, digítulos tarsais delgados e espatulados com 45-

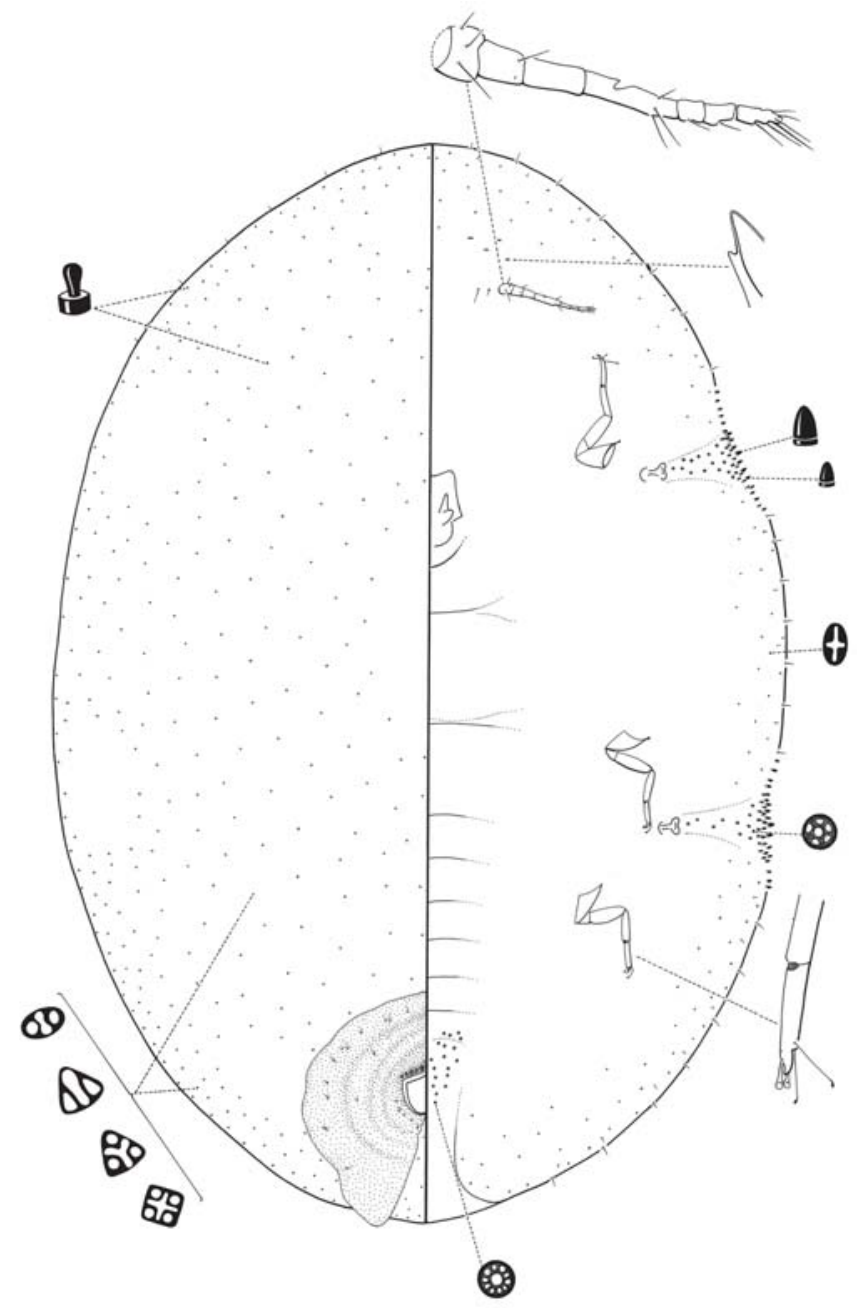

Fig. 88. Ceroplastes cirripediformis (espécie-tipo de Ceroplastes rotundus Hempel).

$50 \mu \mathrm{m}$ de comprimento e extremidades distais dilatadas; digítulos da garra iguais e dilatados, com 30-32,5 $\mu \mathrm{m}$ e extremidades distais espatuladas; esclerotização na articulação tíbio-tarsal presente.

Distribuição geográfica: Brasil (São Paulo).

Discussão: espécies semelhantes e diferenças entre elas, ver discussão de $C$. cirripediformis.

\section{Ceroplastes iheringi Cockerell (Figs. 56-58, 98)}

Ceroplastes iheringi Cockerell, 1895: 100; Gomes Costa, 1949: 17 (cit.); Vernalha, 1953: 128 (cat.); Silva et al., 1968: 139 (cat.); Ben-Dov, 1993: 39 (cat.). Síntipos ㅇ, Brasil, Rio Grande do Sul, sobre Baccharis platensis (USMN) [examinado].

Características macroscópicas: (baseado em exemplares vivos).

Cera: úmida, irregular, com coloração branco-amarelada; sem placas distintas; com bandas estigmáticas espessas (Figs. $56,57)$; comprimento, $2,8 \mathrm{~mm}(2,5-5,0)$; largura, $1,6 \mathrm{~mm}(1,4-4,2)$ e altura: $2 \mathrm{~mm}(1,9-3,0)$. 


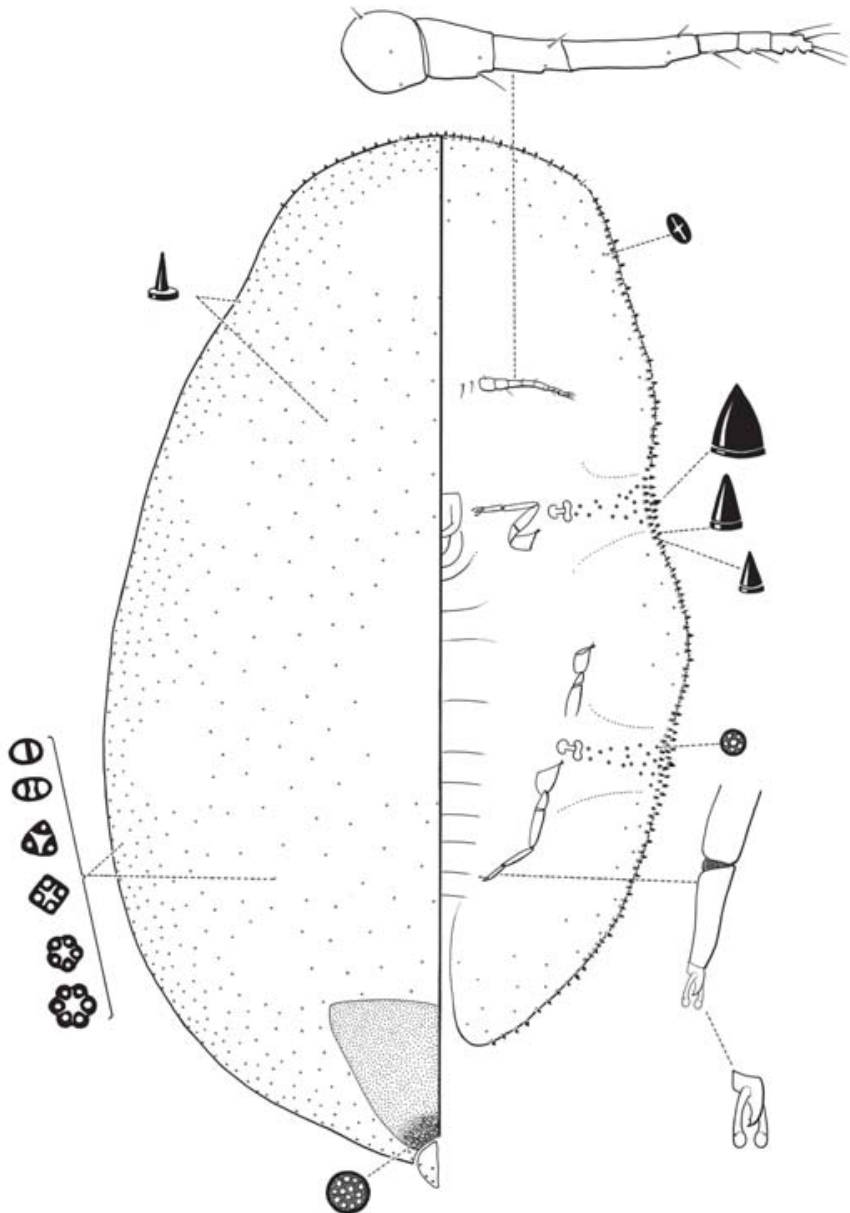

Fig. 89. Ceroplastes coronatus sp. nov. sobre Platanus sp. (Platanaceae).

Corpo: oval, coloração castanho-amarelada; comprimento, 2,1mm (1,6-3,0); largura, 1,7mm (1,5-2,0); Processo caudal curto, dirigido para cima, com ápice mais escuro que a base (Fig. 58).

Características microscópicas: Superfície dorsal: com 6 ou 8 áreas claras, uma na região cefálica, uma na médio-dorsal e 2 ou 3 pares laterais. Setas cônicas, com 7 a $9 \mu \mathrm{m}$ de comprimento; poros triloculares, de contorno oval e triangular tipo II em maior número, biloculares tipo II restritos a região submarginal e escassos tetraloculares. Placas anais com 4 setas dorsais, duas ou três ventrais e 5 na borda da prega anal (Fig. 98).

Margem: setas estigmáticas agrupadas e de dois tipos: o primeiro grupo, mais próximo da superfície ventral, é constituído por 13-16 setas lanceoladas e, o segundo grupo, na superfície dorsal, por 9-12 setas cônicas; setas marginais com 17,5-25 $\mu \mathrm{m}$ de comprimento, dispostas da seguinte forma: 8-9 entre os tubérculos dos olhos; 1 entre cada tubérculo do olho e a sutura estigmática anterior; 3-4 entre a sutura estigmática anterior e posterior e 9-10 entre a sutura estigmática posterior e a fissura anal (Fig. 98).

Superfície ventral: setas submarginais de 7,5 a 12,5 $\mu \mathrm{m}$, dispostas da seguinte forma: 7 a 8 entre os tubérculos dos olhos; 3 a 4 entre cada tubérculo do olho e a sutura estigmática anterior; 3 ou 4 entre a sutura estigmática anterior e posterior e 12-14 entre a sutura estigmática posterior e a fissura anal. Antenas com 250 $\mu \mathrm{m}$ (240-270) de comprimento, com 7 artículos,

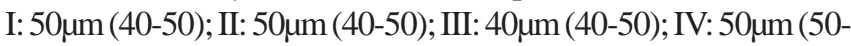

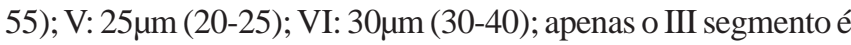

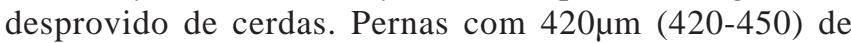
comprimento, coxa: $110 \mu \mathrm{m}$ (110-130); trocanter mais fêmur:

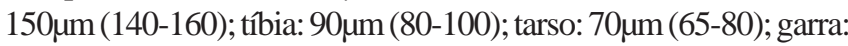
25-27,5 $\mu \mathrm{m}$, com dentículo; esclerotização na articulação tíbiotarsal presente; digítulos tarsais delgados, com 52,5-55 $\mu \mathrm{m}$ de comprimento e extremidades distais dilatadas; digítulos da garra iguais, dilatados e extremidades distais espatuladas com 32,5-37,5. Poros do canal estigmático geralmente com 5 lóculos, alguns com 6 a 8 lóculos; poros cruciformes mais numerosos na região submarginal e em menor número na região central do corpo; poros genitais com 10 lóculos distribuídos na região central do corpo até o mesotórax. Condutos tubulares presentes apenas nos últimos segmentos abdominais (Fig. 98).

Material examinado: BRASIL. São Paulo: Campos do Jordão (23XI-2001, Baccharis sp., A.L.B.G. Peronti col.), 4 exemplares em 1 lâmina; (23-XI-2001, hospedeiro indeterminado, A.L.B.G. Peronti col.), 5 exemplares em 2 lâminas; São Carlos (VIII-2000, 31-10-2000, 16II-2001, 14-IX-2001, 23-XI-2001, Vernonia polyanthes, A.L.B.G. Peronti col.), 28 exemplares em 6 lâminas; (16-II-2001, hospedeiro indeterminado, A.L.B.G. Peronti col.), 9 exemplares em 3 lâminas; (DCBU); São Paulo (31-VIII-1934, assa peixe, R.C. Drummond col.), 4 exemplares em 1 lâmina; (VII-IX-1928, Baccharis sp., A. Gehrt col.), 21 exemplares em 6 lâminas (IBSP).

Distribuição geográfica: Brasil (Minas Gerais, São Paulo, Rio Grande do Sul).

Discussão: assemelham-se a Ceroplastes iheringi, todas as espécies incluídas no gênero Waxiella, por apresentarem dois grupos de setas estigmáticas distintos: lanceoladas, dispostas no ápice do canal estigmático e cônicas, estendendose sobre a superfície dorsal. Waxiella é atualmente constituído por 15 espécies e 5 subspécies, provenientes principalmente da região Afrotropical, exceto por duas espécies, uma mencionada para Israel, Arábia Saudita e outra para o Egito Ben-Dov (1993). Outras características comuns a C. iheringi e a maioria das espécies incluídas no gênero Waxiella são: presença de esclerotização tíbio-tarsal, digítulos da garra iguais e dilatados, garras com dentículo; setas da superfície dorsal cônicas; poros triloculares com contorno triangular "tipo II" em maior número, condutos tubulares ausentes na região cefálica e uma única seta próxima da base de cada antena.

\section{Ceroplastes janeirensis Gray (Figs. 59-64, 99-100)}

Coccus (Ceroplastes) janeirensis Gray, 1828: 7; Hempel, 1900a: 451 (redescr.); Gomes Costa, 1949: 18 (cit., fotografia, hosped.); De Lotto, 1965: 185; Silva et al., 1968: 139 (cat.); Corseuil \& Barbosa, 1971: 238 (cit., hosped.); Vernalha et al., 1974: 128; Ben-Dov, 1993: 40 (cat.), Granara de Willink, 1999: 55 (redescr. e ilustr.); Hodgson, 1994: 161 (redescr., ilustr.); Hickel \& Ducroquet. 1995: 


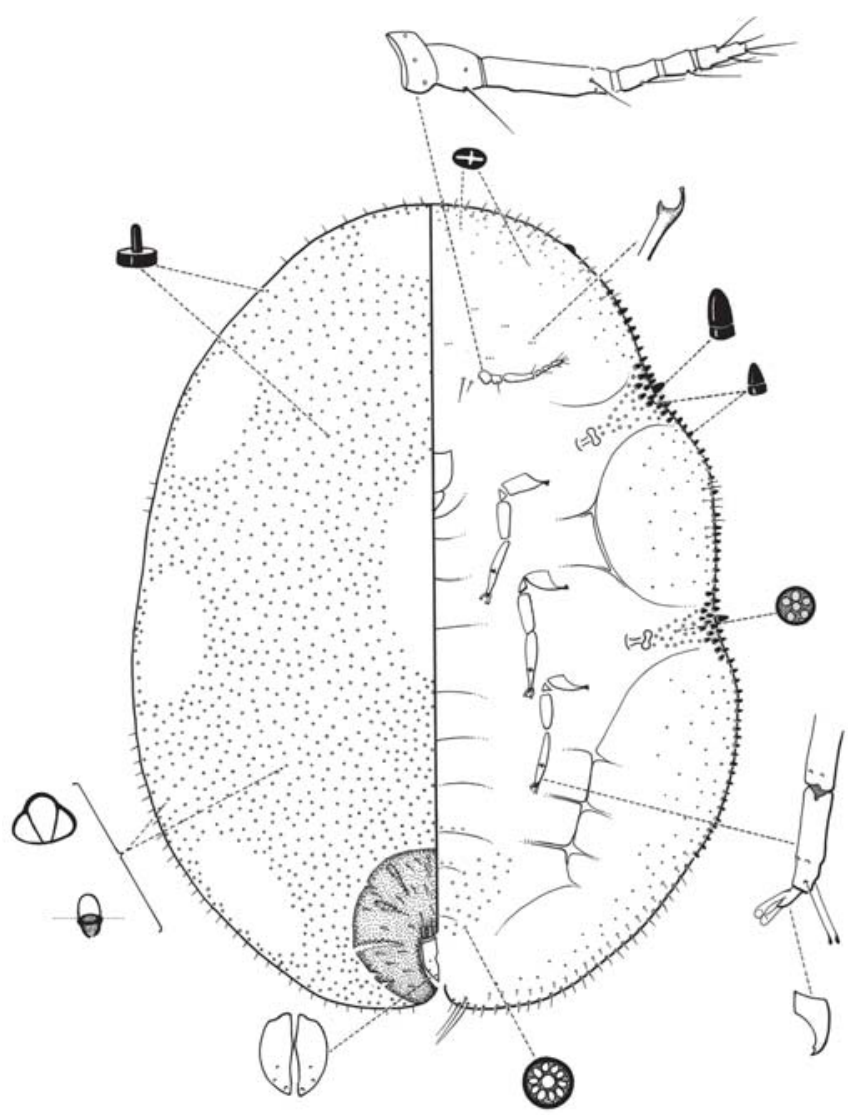

Fig. 90. Ceroplastes deodorensis Hempel sobre Annona squamosa (Annonaceae).

667 (cit.). Síntipo 오, Brasil, sobre Solanum sp. [não localizado]. Columnea ianeirensis Targioni Tozzetti ; Targioni Tozzetti, 1866: 145 (erro de grafia).

Ceroplastes janeirensis Gray; Signoret, 1869: 858. (tax.).

Ceroplastes psidii (Chavannes); Hempel, 1920: 369 (redescr.); Silva et al., 1968: 140 (cat.); Ben-Dov, 1993: 47 (cat.). Sintipos ㅇ, Brasil, Rio de Janeiro, Botafogo, sobre Psidium sp. (MNHM) [não examinado]. n. sin.

Ceroplastes simplex Hempel, 1900a: 475; Hempel, 1901b: 68; Vernalha, 1953: 130 (cat.); Silva et al., 1968: 141 (cat.); Ben-Dov, 1993: 54 (cat.). Sintipos + , Brasil, São Paulo, Ipiranga, sobre Myrtaceae, A. Hempel col., 2 exemplares em 1 lâmina (na etiqueta a direita se lê Ceroplastes simplex tipo N 48 a - 402 e na etiqueta a esquerda se lê, C. variegatus Hempel N 95. 083) [examinado]. n. sin.

Características macroscópicas: (baseado em exemplares vivos).

Cera: rija, com coloração branca; oval a retangular em vista dorsal e semicircular ou retangular em vista lateral; dividida em 7 placas, 1 dorsal, 4 laterais, 1 anterior e 1 posterior, distintas apenas nos exemplares mais jovens; com núcleo dorsal maior e os demais inconspícuos; com superfície, geralmente enrugada e ligeiramente deprimida ao redor dos núcleos (Fig. 59, 60); comprimento, 4,0 $\mathrm{mm}(3,0-8,0)$; largura, $1,9 \mathrm{~mm}(1,8-4,5)$.

Corpo: oval, de coloração castanho-clara, com tubérculos laterais pouco evidentes. Comprimento: 3,0mm (2,1-5); largura: $2,1 \mathrm{~mm}(1,2-3)$; processo caudal cônico dirigido para trás, com 0,98mm $(0,98-1,7)$ de comprimento e mais escuro que o corpo (Fig. 61).

Características microscópicas: Superfície dorsal: com 8 áreas claras, uma na região cefálica, uma na médio-dorsal e 3 pares laterais. Setas cilíndricas com ápice levemente truncado; poros monoloculares, biloculares tipo II e, em maior número, triloculares com contorno oval e triangular tipo I. Placas anais com 4 setas dorsais; anel anal com 6 setas (Fig. 99).

Margem: 32 (32-44) setas estigmáticas cônicas, algumas com ápice truncado; no ápice do canal estigmático estão dispostas em duas a cinco linhas, com 1-3 setas de forma retangular ao centro; os dois grupos de setas, o do canal estigmático anterior e do posterior, estão quase unidos na região mediana do corpo, em geral, são separados apenas por

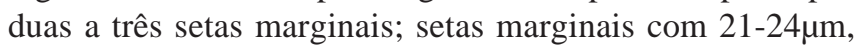
dispostas como a seguir: cerca de 10 (8-10) entre os tubérculos dos olhos, 3 (2-6) entre cada tubérculo do olho e a sutura estigmática anterior, 3 (3-5) entre a suturas estigmáticas anterior e posterior e $8(8-31)$ entre a sutura estigmática posterior e a fissura anal (Fig. 99).

Superfície ventral: antenas com 330

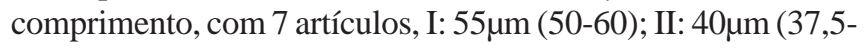

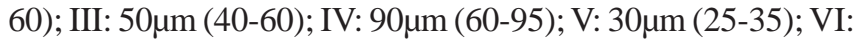

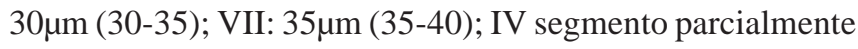
dividido em alguns exemplares; duas setas próximas da base de cada antena. Pernas com 530 $\mu$ m (430-550) de comprimento,

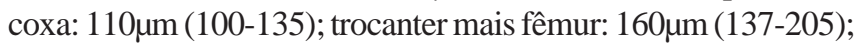
tíbia: $150 \mu \mathrm{m}(120-155)$; tarso: $80 \mu \mathrm{m}$ (70-85), garra: $20 \mu \mathrm{m}$ (2025), com dentículo; digítulos tarsais delgados com $60-65 \mu \mathrm{m}$ de comprimento e extremidades distais dilatadas; digítulos da

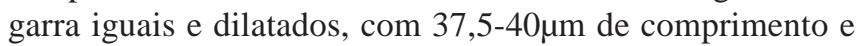

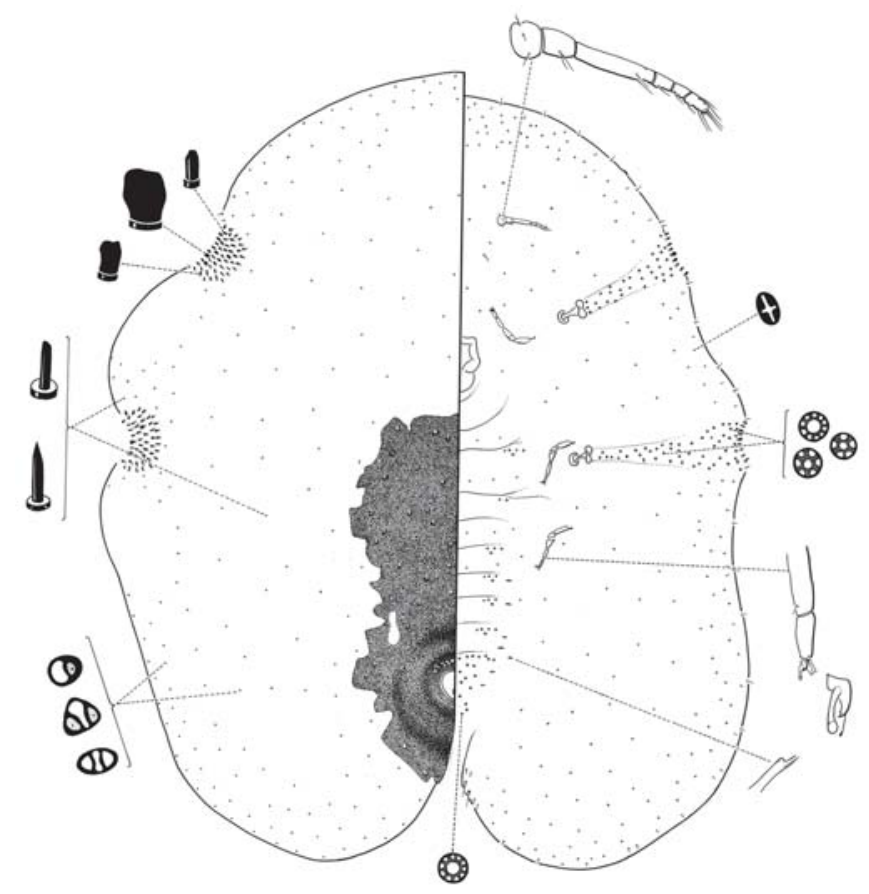

Fig. 91. Ceroplastes diospyros Hempel sobre Diospyros kaki (Ebenaceae). 


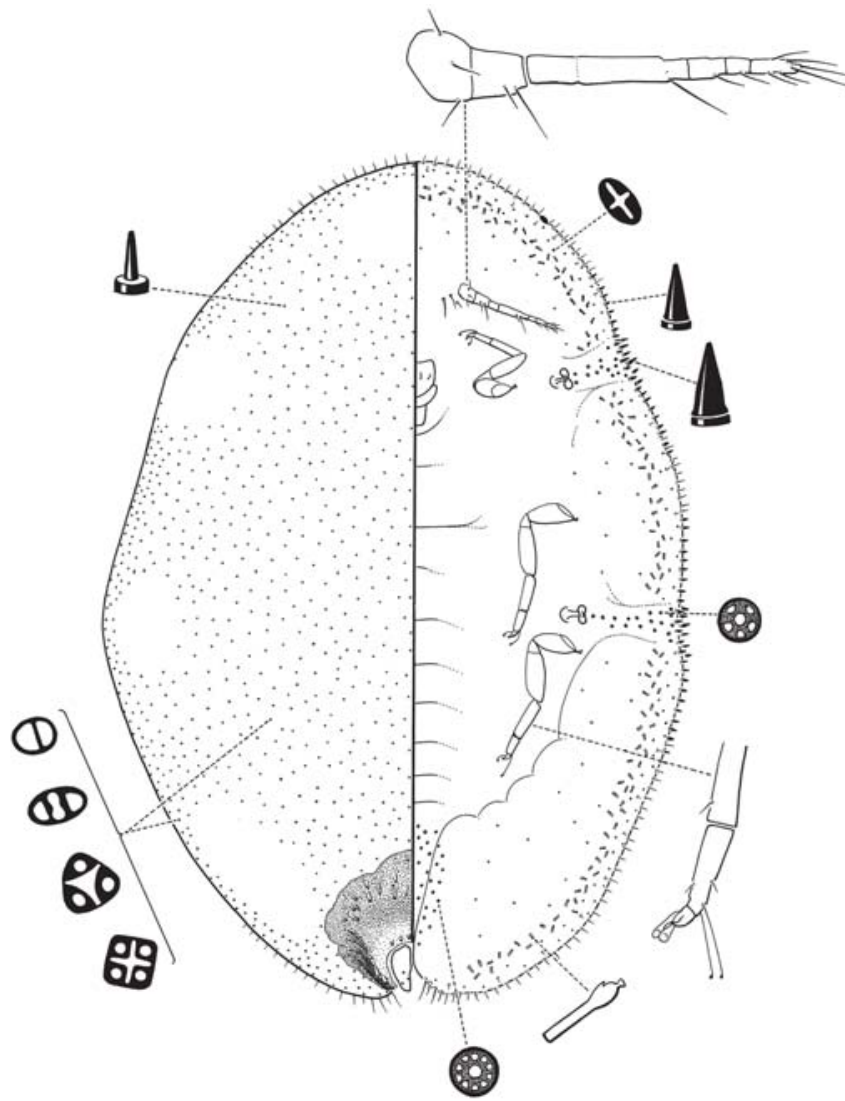

Fig. 92. Ceroplastes floridensis Comstock sobre Schefflera actinophylla (Araliaceae).

extremidades distais espatuladas; esclerotização na articulação tíbio-tarsal presente. Poros dos canais estigmáticos com 5 lóculos em maior número e raros com 6 e 7 lóculos; poros cruciformes concentrados na região submarginal; poros genitais com 10 lóculos. Condutos tubulares, com filamento delgado, na região cefálica, visíveis apenas em boas preparações microscópicas e, nos últimos segmentos abdominais (Fig. 99).

Material examinado: BRASIL. São Paulo: Campinas (18-VII-1930, 21-V-1930, Psidium guajava, A. Hempel col.), 11 exemplares em 4 lâminas; (07-VIII-2001, P. guajava, V.A. Costa col.), 6 exemplares em 3 lâminas; (19-XI-1934, cabeluda, E.J. Hembleton col.), 2 exemplares em 1 lâmina (IBSP); Gália (25-XI-2001, Ficus citrifolia, A.L.B.G. Peronti col.), 2 exemplares em 1 lâmina; (25-XI-2001, Machaerium acutifolium, A.L.B.G. Peronti col.), 3 exemplares em 2 lâmina; Ilha Anchieta (21-III-2001, Psidium sp., A.L.B.G. Peronti col.), 12 exemplares em 4 lâminas; (21-III-2001, Clusiaceae, A.L.B.G. Peronti col.), 4 exemplares em 2 lâminas (DCBU); Itararé (25-V1928, goiabeira do campo, A. Hempel col.), 2 exemplares em 1 lâmina; (29-V-1928, araçaeiro silvestre, A. Hempel col.), 2 exemplares em 1 lâmina; (28-V-1928, arbusto silvestre, A. Hempel col.), 3 exemplares em 6 lâminas; (09-VI-1928, planta do campo, A. Hempel col.), 2 exemplares em 1 lâmina; (09-XI-1928, planta silvestre, A. Hempel col.), 1 exemplar em 1 lâmina (IBSP); Jales (21-V-2001, P. guajava, A.L.B.G. Peronti col.), 2 exemplares em 1 lâmina; Piracicaba (15VIII-2001, hospedeiro indeterminado, H.N. Oliveira col.), 5 exemplares em 1 lâmina; Pirassununga (22-VII-2001, Myrtaceae, A.L.B.G. Peronti col.), 6 exemplares em 2 lâminas (DCBU); Santa Rita do Passa Quatro
(24-VII-1928, 25-VII-1928, arbusto do campo, A. Hempel col.), 3 exemplares em 2 lâminas (IBSP); São Carlos (09-XI-2000, Psidium sp., A.L.B.G. Peronti col.), 2 exemplares em 1 lâmina; (29-X-2000, 09-XI-2000，18-I-2001，12-V-2001，15-VI-2001，27-VIII-2001，05IX-2001, 18-XI-2001, P. guajava, A.L.B.G. Peronti col.), 61 exemplares em 23 lâminas; (05-IV-2002, Psidium sp., A.L.B.G. Peronti col.), 4 exemplares em 1 lâmina; (23-IV-2002, Campomanesia pubescens, A.L.B.G. Peronti col.), 3 exemplares em 1 lâmina; (03-III2002, C. xanthocarpa, A.L.B.G. Peronti col.), 2 exemplares em 1 lâmina; (09-XI-2001, Myrtaceae, A.L.B.G. Peronti col.), 17 exemplares em 6 lâminas; (04-III-2002, Vernonia sp., A.L.B.G. Peronti col.), 2 exemplares em 1 lâminas; (III-2001, Eugenia uvalha, A.L.B.G. Peronti col.), 2 exemplares em 1 lâmina; (22-VI-2001, Stenocalyx pitanga, A.L.B.G. Peronti col.), 6 exemplares em 2 lâminas; (20-X-2001, 05XI-2001, 20-V-2002, 20-VIII-2002, hospedeiro indeterminado, A.L.B.G. Peronti col.), 7 exemplares em 6 lâminas; São José do Rio Preto (VII, 1926, guabiroba, A. Hempel col.), 1 exemplar em 1 lâmina; (VII-1926, hospedeiro indeterminado, A. Hempel col.), 2 exemplares em 1 lâmina; (17-VII-1926, 20-VII-1926, goiabeira, A. Hempel col.), 6 exemplares em 2 lâminas (IBSP); São Paulo (X, 1970, VII, 1981, Myrtaceae, J. P. da Fonseca col.), 15 exemplares em 13 lâminas (MZSP); (22-IV-2001, P. guajava, A.L.B.G. Peronti col.), 11 exemplares em 5 lâminas; (22-IV-2001, Bignoniaceae, A.L.B.G. Peronti col.), 8 exemplares em 6 lâminas, (DCBU), (V-1954, hospedeiro indeterminado, ?coletor), 1 exemplar em 1 lâmina (MZSP); (07-IX-1928, Myrtaceae, A. Gehrt col.), 3 exemplares em 2 lâminas; Taboão da Serra (02-011935, araçá, B. Ribeiro col.), 1 exemplar em 1 lâmina; Alto da Serra: (X-1928, galhos de plantas silvestres, R. Spitz col.), 3 exemplares em 1 lâmina (IBSP); Sorocaba, Brigadeiro Tobias (VI-1932, araçá, J. Deslandes col.), 3 exemplares em 1 lâmina (IBSP); Valinhos (28-I2002, P. guajava, A.L.B.G. Peronti col.), 7 exemplares em 2 lâminas; (28-I-2002, Punica granatum, A.L.B.G. Peronti col.), 2 exemplares em 1 lâmina (DCBU); Votuporanga (21-V-2001, S. pitanga, A.L.B.G. Peronti col.), 4 exemplares em 1 lâmina (DCBU). Material proveniente de outros Estados: Minas Gerais, Delfinópolis (II-2001, P. guajava, C.R. Sousa-Silva col.), 9 exemplares em 2 lâminas (DCBU); Pouso Alegre: (X-1970, IX-1978, hospedeiro indeterminado), 1 exemplar

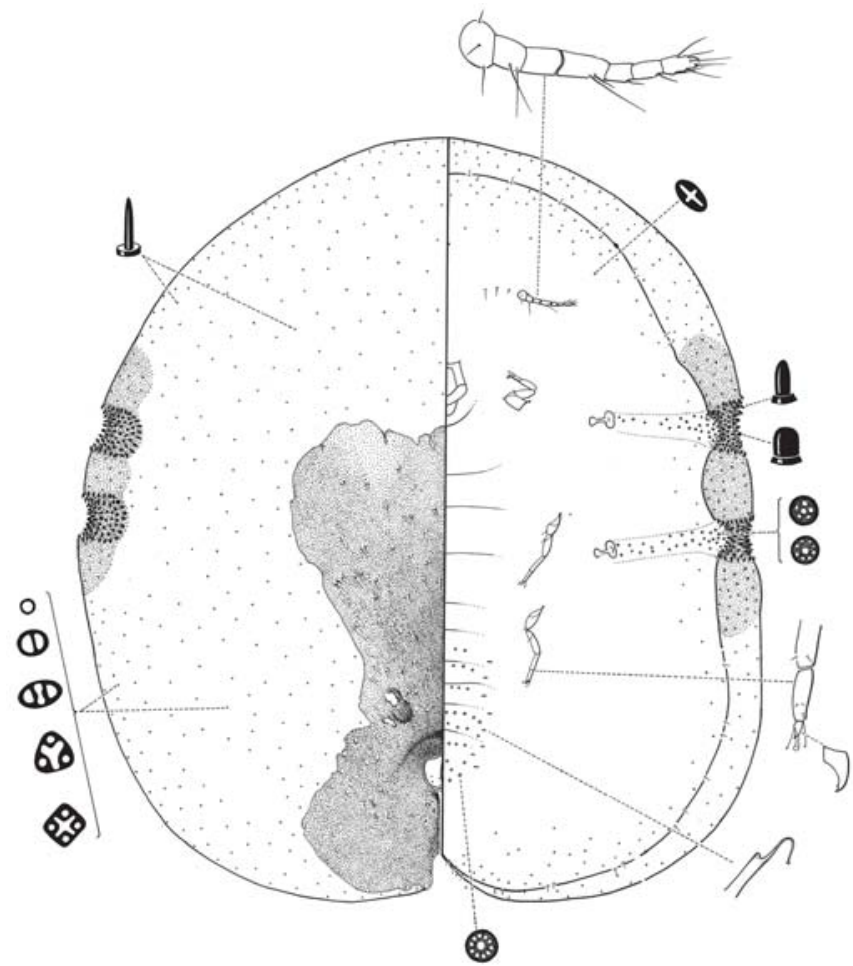

Fig. 93. Ceroplastes flosculoides Matile-Ferrero sobre Psidium guajava (Myrtaceae). 
em 1 lâmina (MZSP); Uberabinha (26-VIII-1928, planta silvestre), 1 exemplar em 1 lâmina; Paraíba, São Gonçalo (VI-1941, goiabeira, M.A. Oliveira col.), 4 exemplares em 1 lâmina (IBSP); (1974, hospedeiro indeterminado, ?coletor), 1 exemplar em 1 lâmina (MZSP); Paraná, Cascavel (07-VIII-1828, planta silvestre, A. Hempel col.), 2 exemplares em 1 lâmina; Pernambuco, Jatobá: (1933, goiabeira, R. von Ihering col.), 3 exemplares em 2 lâminas; Rio Grande do Norte, Cruzeta (II1941, Aspidiosperma pirifolium, M. A. Oliveira col.), 2 exemplares em 1 lâmina (IBSP).

Distribuição geográfica: I. Maurício; Brasil (Rio Grande do Norte, Paraíba, Pernambuco, Rio de Janeiro, Minas Gerais, São Paulo, Paraná, Rio Grande do Sul); Argentina.

Discussão: assemelham-se a $C$. janeirensis as espécies: C. cassiae e espécies afins, por apresentarem poros dorsais predominantemente biloculares tipo II e, triloculares com contorno triangular tipo I; processo caudal dirigido para trás e bastante desenvolvido; condutos tubulares na região cefálica; esclerotização na articulação tíbio-tarsal e digítulos da garra iguais. C. cassiae e espécies afins diferem principalmente por apresentarem as setas estigmáticas distribuídas em toda margem do corpo. Na presente revisão, Ceroplastes psidii (Chavannes), C. simplex Hempel, 1900, mencionadas para o Brasil, são sinonimizadas com a espécie em questão. Os dois únicos exemplares da série-tipo de $C$. simplex encontrados apresentam processo caudal incompleto, provavelmente quebrado ou removido durante o processo de montagem da lâmina permanente (Fig. 100). Ceroplastes janeirensis é a espécie mais comum no Estado de São Paulo, principalmente sobre Myrtaceae, apresentando muitas variações na cor e tamanho da carapaça cerosa (Figs. 59-60, 62-63).

\section{Ceroplastes jordanensis Peronti sp. nov.}

(Fig.101)

Material tipo: holótipo + , Brasil, São Paulo, Campos do Jordão, $\mathrm{N}^{\circ}$ 357 sobre Myrtaceae; 24-XI-2001; A.L.B.G. Peronti col. (DCBU).

Etimologia: o nome da espécie é alusivo ao município onde foi coletada, Campos do Jordão, SP.

Características macroscópicas: (baseado em exemplares vivos).

Cera: pastosa, com coloração branco-amarelada; circular em vista dorsal; sem divisão de placas; comprimento, $4,3 \mathrm{~mm}$ (4,0-5,3); largura, 3,8 $\mathrm{mm}(3-4,5)$ e altura, 3,5mm (3,0-4,0).

Corpo: circular a cordiforme, de coloração castanho-escura; comprimento, 2,45mm (2,4-4); largura, 1,9mm (1,8-2,2); processo caudal de coloração negra com área esclerotizada sobre o dorso.

Características microscópicas: Superfície dorsal: com 8 áreas claras, uma na região cefálica, uma na médio-dorsal e 3 pares laterais. Setas da superfície de dois tipos, ambas cilíndricas, uma com ponta e outra com ápice truncado lateralmente, com 6-7,5 $\mu \mathrm{m}$ de comprimento. Poros biloculares tipo I, triloculares de contorno oval e com contorno triangular tipo I e II (Fig.101).

Margem: com 19-25 setas estigmáticas com formatos irregulares, agrupadas no ápice dos canais estigmáticos e sobre o dorso (Fig.101).

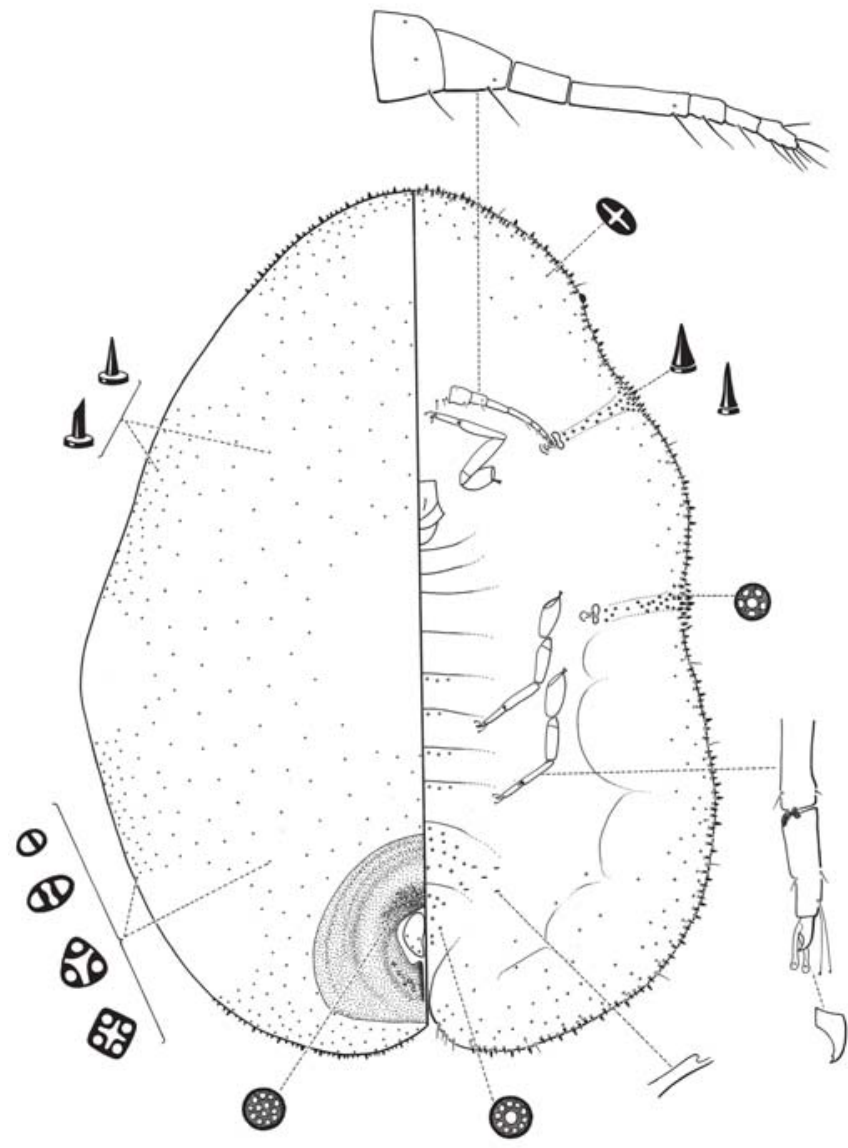

Fig. 94. Ceroplastes formicarius Hempel sobre Banisteriopsis oxyclada (Malpighiaceae).

Superfície ventral: antenas com 242,5 $\mu$ m (230-260) de

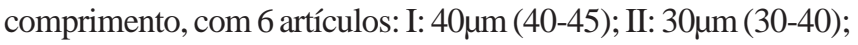

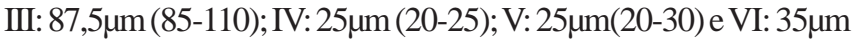

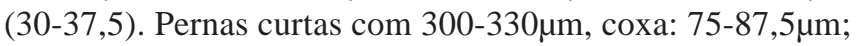

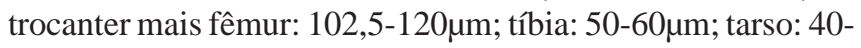

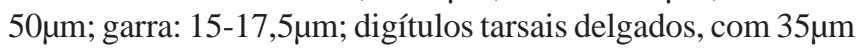
de comprimento e extremidades distais dilatadas; digítulos da garra diferentes, um dilatado e o outro delgado com 22,5-25 $\mu \mathrm{m}$ de comprimento e extremidades distais espatuladas; garras com dentículo; esclerotização na articulação tíbio-tarsal ausente. Poros do canal estigmático com 5 lóculos; poros cruciformes concentrados na região submarginal; poros genitais com 10 lóculos, restritos aos últimos segmentos abdominais. Condutos tubulares presentes na região cefálica e nos últimos segmentos abdominais (Fig.101).

Material examinado: BRASIL, São Paulo: Campos do Jordão (24XI-2001, hospedeiro indeterminado, A.L.B.G. Peronti col.), 1 exemplar em 1 lâmina (DCBU); Guarujá (22-III-2002, Myrtaceae, A.L.B.G. Peronti col.), 1 exemplar em 1 lâmina (DCBU).

Discussão: assemelham-se a $C$. jordanensis as espécies: C. leonardianus Lizer \& Trelles, 1939 conhecida para a Argentina, e C. nakararai Gimpel, 1974 conhecida para Cuba e Flórida (EUA) e C. diospyros e espécies afins como já 


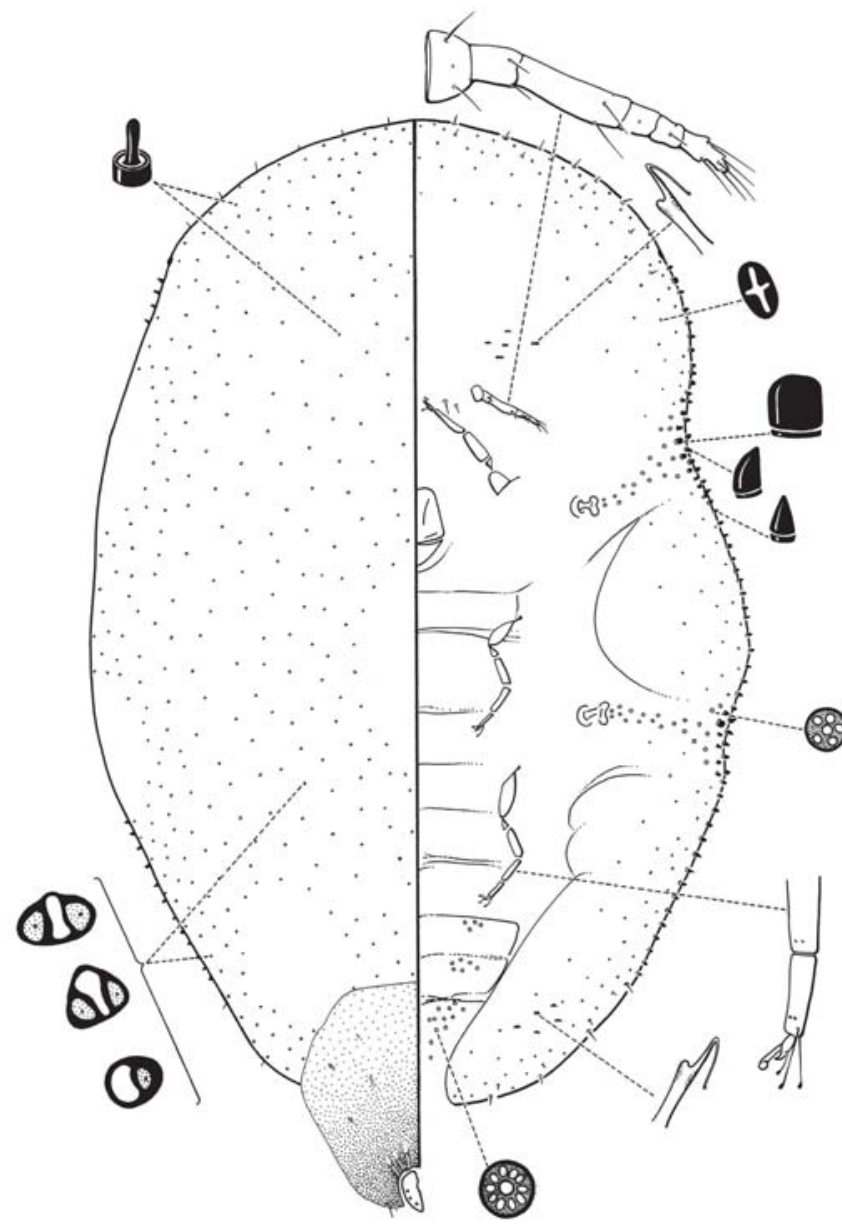

Fig. 95. Ceroplastes formosus Hermpel, esquema da espécie-tipo.

discutido anteriormente. C. nakararai e C. leonardianus aproximam-se de $C$. jordanensis principalmente devido a grande extensão da área esclerotizada do processo caudal, que se estende sobre o dorso até a região mediana do corpo e por apresentar um número reduzido de setas estigmáticas; digítulos da garra desiguais e garras com dentículos. $C$. nakararai, difere por apresentar setas estigmáticas ciíndricas com ápices truncados e denteados e poros dorsais tetraloculares. C. leonardianus difere por apresentar antenas com 7 segmentos; esclerotização tíbio-tarsal presente; ausência de condutos tubulares na região cefálica; poros monoloculares na superfície dorsal e setas dorsais de um único tipo.

\section{Ceroplastes lucidus Hempel}

(Figs. 65-67, 102)

Ceroplastes lucidus Hempel, 1900a: 465; Silva et al., 1968: 140 (cat.); Vernalha et al., 1974: 129 (cat.); Ben-Dov, 1993: 42 (cat.). Síntipos ㅇ, Brasil, São Paulo, Ipiranga, sobre Baccharis dracunculifolia (MZSP) [não localizado]. Cótipo sobre $B$. dracunculifolia, Brasil (INTA) Granara de Willink, 1999: 71 (redescr.) [examinado].

Ceroplastidia lucida (Hempel); Granara de Willink, 1999: 71 (comb.).
Ceroplastes novaesi Hempe1, 1900: 457; Silva et al., 1968: 140 (cat.).Corseuil \& Barbosa, 1971: 238 (cit., cit.); Vernalha et al., 1974: 129 (cat.); Ben-Dov, 1993: 45 (cat.); Granara de Willink, 1999: 75 (redescr. tax.). Síntipos ㅇ, Brasil, São Paulo, Campinas, Capoeira Grande sobre Abutilon sp. e Baccharis dracunculifolia e Vernonia riedelli ?data, ?coletor, (2 exemplares em 1 lâmina) (MZSP) [examinado]. n. sin.

Ceroplastes novaesi var. mendozae Cockerell, 1902. Granara de Willink, 1999: 75 (desig. de $\sin$.).

Características macroscópicas: (baseado em exemplares vivos).

Cera: rija e nodosa; com coloração branca, amarelada ou ocrácea, com aspecto translúcido; retangular, em vista dorsal e lateral; sem divisão de placas; placa posterior geralmente retraída; placa dorsal deprimida ao redor do núcleo; núcleo dorsal visível, geralmente coberto por uma secreção branca, laterais localizados nos centros das depressões, indicados pelas bandas estigmáticas (Figs. 65, 66); comprimento, 4,5mm (3-7); largura, 4,2 mm (2,5-6,0) e altura, 3,5mm (2,0-4,5).

Corpo: oval a circular; coloração castanho-escura com tubérculos laterais pouco evidentes; tubérculo dorsal e áreas estigmáticas mais claras que o corpo; comprimento, $3,5 \mathrm{~mm}$ (2,5-4,5); largura, 2,5mm (1,2-3,0); processo caudal curto, dirigido para cima e mais escuro que o corpo (Fig. 67).

Características microscópicas: Superfície dorsal: com 8 áreas claras, uma na região cefálica, uma na médio-dorsal e 3 pares laterais. Setas cilíndricas com ápice truncado. Poros monoloculares com condutos filamentosos simples; poros biloculares tipo II e triloculares, com contorno triangular, tipo I. Placas anais com ápices arredondados, com 4 setas dorsais (Fig.102).

Margem: com setas estigmáticas de diferentes tamanhos, arredondadas e, cônicas com ápices truncados ou denteados, 21-25 no ápice do canal estigmático inferior e 40-48 no ápice do canal estigmático superior (Fig.102).

Superfície ventral: antenas com $220 \mu \mathrm{m}(190-240)$ de

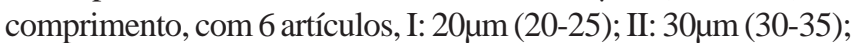
III: 70 $\mu \mathrm{m}$ (62,5-75); IV: $25 \mu \mathrm{m}$ (22,5-25); V: $25 \mu \mathrm{m}$ (22,5-35); VI: $35 \mu \mathrm{m}(32,5-37,5)$; com duas setas próximas da margem da base de cada antena, a maior com $25-42,5 \mu \mathrm{m}$ e a menor com 7,5-

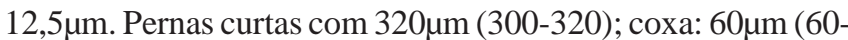

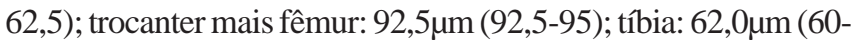
62,5); tarso: 50 $\mu \mathrm{m}$ (47,5-50); garra: $22,5 \mu \mathrm{m}$ (20-22,5); digítulos tarsais delgados com 52,5-55 $\mu \mathrm{m}$ de comprimento e extremidades distais dilatadas; digítulos da garra diferentes, um dilatado e o outro delgado, ambos com 30-35 $\mu \mathrm{m}$ de comprimento e extremidades distais espatuladas; esclerotização na articulação tíbio-tarsal ausente. Poros do canal estigmático estigmáticos com 5 lóculos; poros cruciformes dispersos em toda superfície, mais concentrados na região submarginal. Poros genitais com 10 lóculos, restritos aos últimos segmentos abdominais. Condutos tubulares na região cefálica, próximos das antenas, nos últimos segmentos abdominais e na região submarginal (Fig.102).

Material examinado: BRASIL. São Paulo: Campos do Jordão (23XI-2001, 24-XI-2001, hospedeiro indeterminado, A.L.B.G. Peronti 


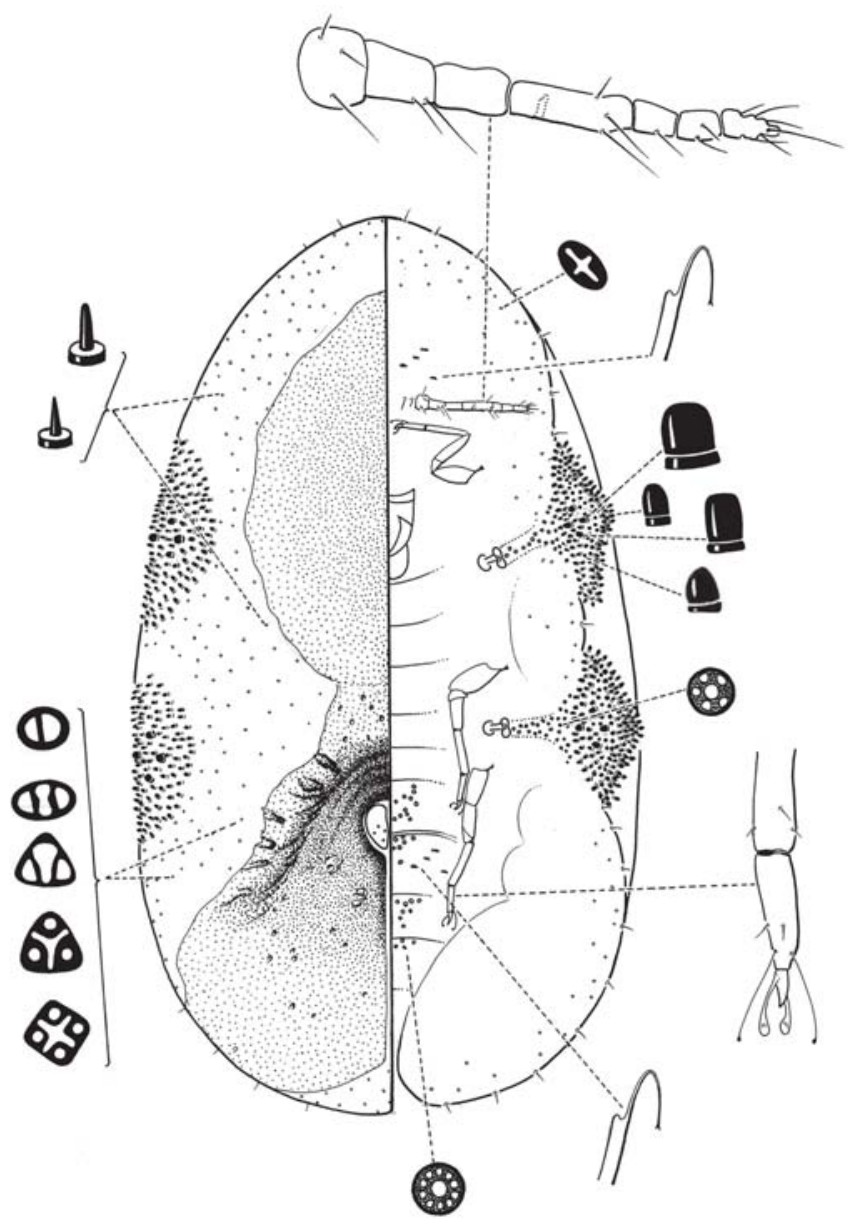

Fig. 96. Ceroplastes glomeratus sp. nov. sobre Vernonia brevifolia (Asteraceae).

col.), 10 exemplares em 6 lâminas; (23-XI-2001, Mimosa sp., A.L.B.G. Peronti col.), 8 exemplares em 2 lâminas; (24-XI-2001, Baccharis sp., A.L.B.G. Peronti col.), 8 exemplares, 2 lâminas; Gália, (01-V-2002, hospedeiro indeterminado, A.L.B.G. Peronti col.), 6 exemplares em 3 lâminas (DCBU); Itararé (26-V-1928, planta do campo, A. Hempel col.), 3 exemplares em 2 lâminas; (28-VIII-1928, Eupatorium sp. A. Hempel col.), 4 exemplares em 2 lâminas; (29-V-1928, Baccharis, A. Hempel col.), 2 exemplares em 1 lâmina; (20-VIII-1928, planta silvestre, A. Hempel col.), 2 exemplares em 1 lâmina; Leme (10-IX1930, planta do campo, A. Hempel col.), 6 exemplares em 2 lâminas; Santa Rita do Passa Quatro (?data, planta do campo, A. Hempel col.), 4 exemplares em 2 lâminas; (24-VII-1928, Baccharis sp., A. Hempel col.), 2 exemplares em 1 lâmina (IBSP); São Carlos (09-XI-2000, 23XI-2001, Myrtaceae, A.L.B.G. Peronti col.), 4 exemplares em 2 lâminas; (28-VIII-2001, 05-XI-2001, 23-XI-2001, B. dracunculifolia, A.L.B.G. Peronti col.), 8 exemplares em 4 lâminas; (07-VIII-2001, Solanaceae, A.L.B.G. Peronti col.), 4 exemplares em 2 lâminas; (23XI-2001, Vernonia sp., A.L.B.G. Peronti col.), 4 exemplares em 2 lâminas (DCBU).

Distribuição geográfica: Brasil (São Paulo, Rio Grande do Sul); Argentina.

Discussão: assemelham-se a $C$. lucidus as espécies: $C$. boyacensis Mosquera, 1979, conhecida para a Colômbia e $C$. parvus Green, 1935 registrada para o Uruguai, por apresentarem setas estigmáticas arredondadas, retangulares ou denteadas agrupadas nos ápices dos canais estigmáticos; antenas com 6 segmentos, ausencia de esclerotização tíbio-tarsal; digítulos da garra diferentes e processo caudal curto. C. boyacensis difere, de acordo com a descrição de Mosquera (1979), por apresentar setas dorsais em forma de cerda; poros dorsais monoloculares e biloculares ausentes e condutos tubulares ausentes. C. parvus difere por apresentar um menor número de setas estigmáticas. C. novaesi Hempel, 1900 é aqui sinonimizado com C. lucidus.

\section{Ceroplastes minimus Peronti sp. nov.}

(Fig. 103)

Material tipo: holótipo + , Brasil, São Paulo, Campos do Jordão, $\mathrm{N}^{\circ}$ 340, hospedeiro indeterminado; 24-XI-2001; A.L.B.G. Peronti col. (DCBU).

Etimologia: o nome da espécie é alusivo ao tamanho dos exemplares encontrados.

Características macroscópicas: (baseado em exemplares vivos).

Cera: pastosa, de coloração branca ou branco-amarelada; oval em vista dorsal e semicircular em vista lateral; sem placas definidas; núcleo dorsal maior e, placa posterior com dois núcleos, um de cada lado da fenda do processo caudal; comprimento, 3,5mm (2,6-4); largura, 1,9mm (1,7-2,6) e altura, $2 \mathrm{~mm}(2,0-2,2)$.

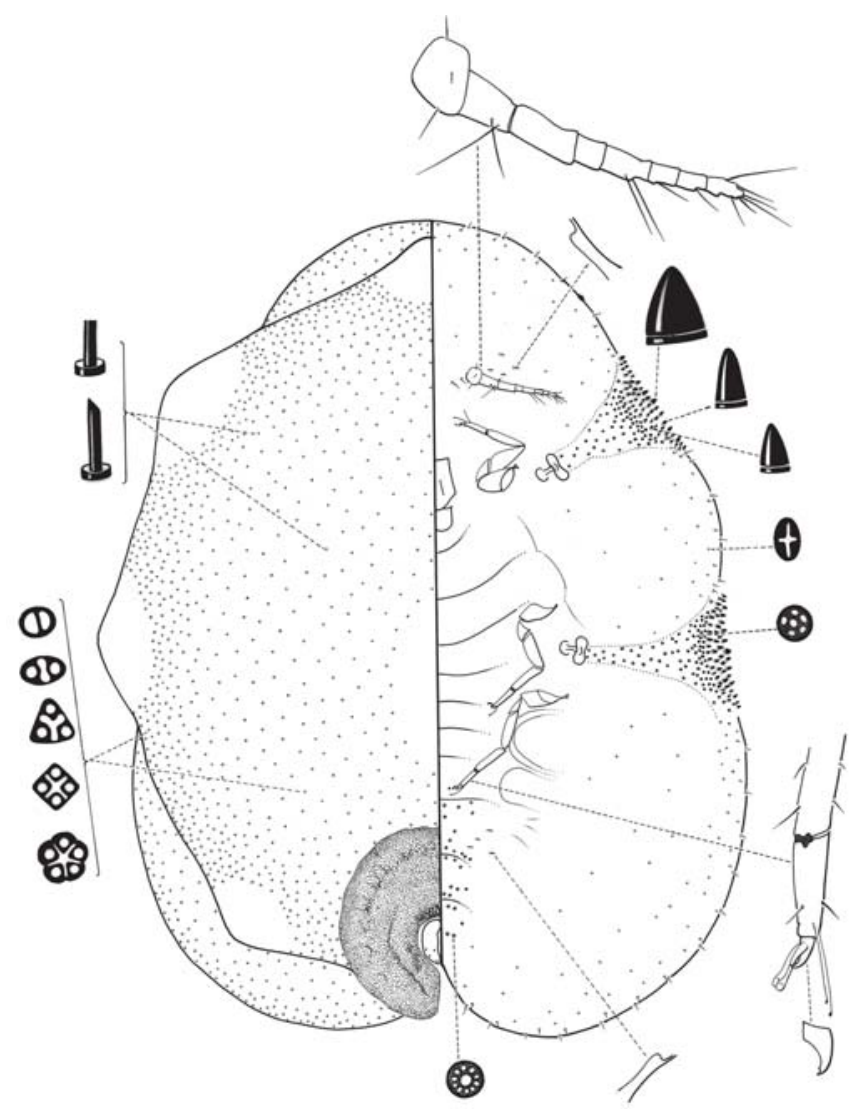

Fig. 97. Ceroplastes grandis Hempel sobre Duranta repens var. aurea (Verbenaceae). 


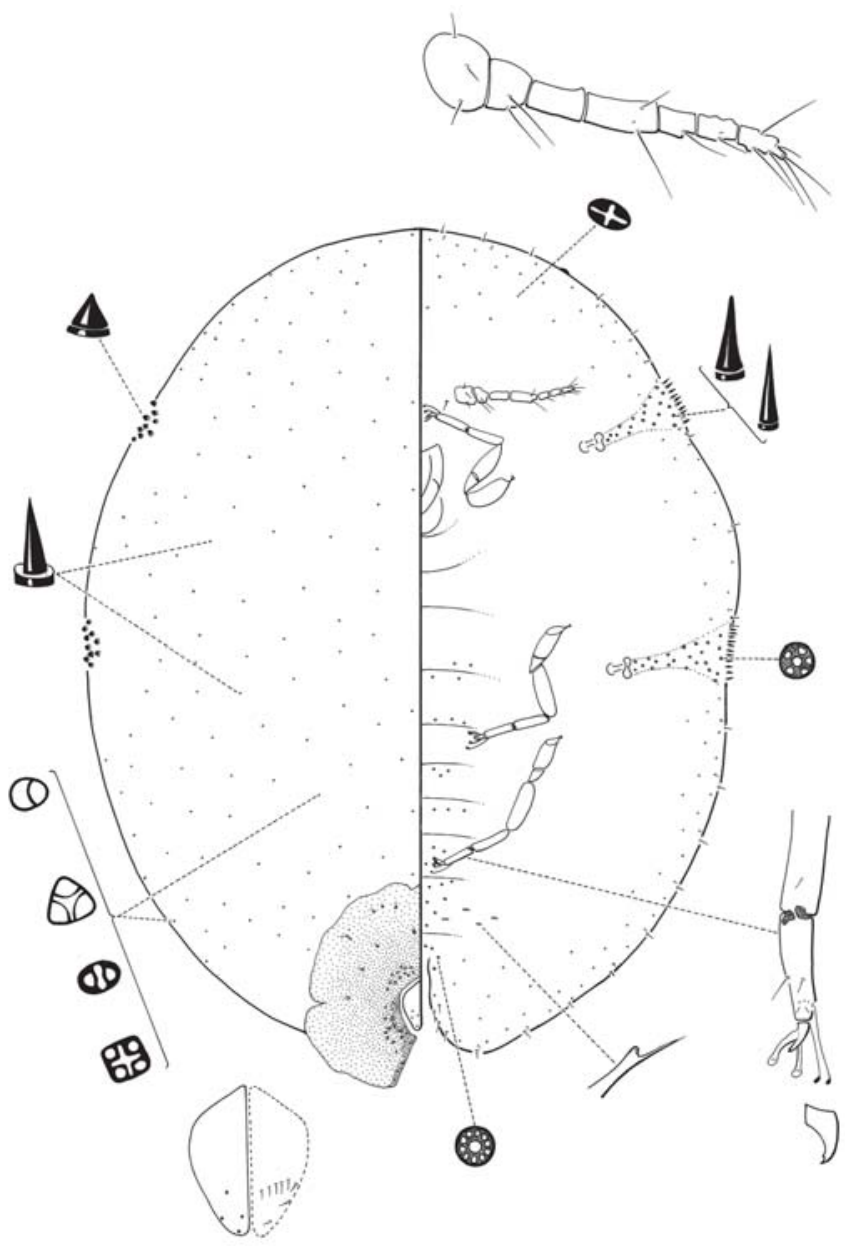

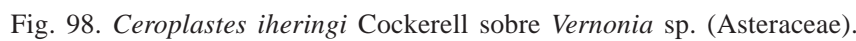

Corpo: oval com tubérculos reduzidos; comprimento, $1,9 \mathrm{~mm}$ $(1,8-2,0)$; largura, $1,4 \mathrm{~mm}(1,4-1,7)$. Processo caudal curto.

Características microscópicas: Superfície dorsal: com 6 ou 8 áreas claras, uma na região cefálica, uma médio dorsal e 2 ou 3 pares laterais. Setas cônicas com ápice truncado, com 5-6um de comprimento; poros triloculares ovais e triangulares tipo I e II e, escassos tetraloculares. Placas anais aparentemente com 4 cerdas dorsais e 1 ventral (Fig.103).

Margem: com 23 a 36 setas cônicas, dispostas em 3 linhas na margem do canal estigmático, e prolongando-se um pouco além destes em uma única linha; setas marginais longas com 35-50 $\mu \mathrm{m}$ de comprimento (Fig.103).

Superfície ventral: antenas com 270um (270-290) de

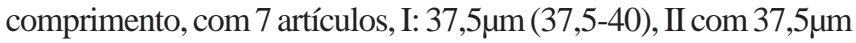

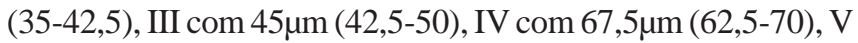

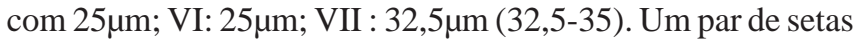

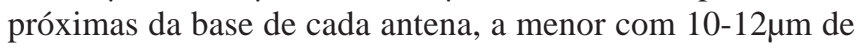

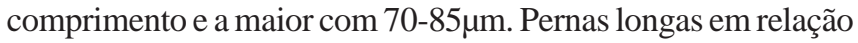

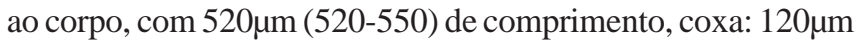
(100-120); trocanter mais fêmur com 170 $\mu \mathrm{m}$ (150-170); tíbia com

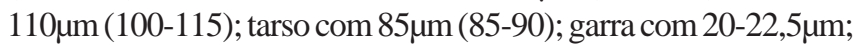
digítulos tarsais delgados, com $60 \mu \mathrm{m}$ e extremidades distais

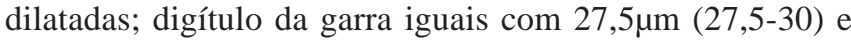
extremidades distais espatuladas; presença de esclerotização na articulação tíbio-tarsal. Poros genitais com 10 lóculos, e com 5 lóculos nos canais estigmáticos; poros cruciformes concentrados na região submarginal; condutos tubulares com filamento curto e dilatado presentes nas regiões cefálica e adjacentes ao processo caudal (Fig.103).

Material examinado: BRASIL. São Paulo: Campos do Jordão (24XI-2001, Myrtaceae, A.L.B.G. Peronti col.), 2 exemplares em 2 lâminas; (24-XI-2001, Miconia minutiflora, A.L.B.G. Peronti col.), 3 exemplares em 3 lâminas; 24-XI-2001, hospedeiro indeterminado, A.L.B.G. Peronti col.), 2 exemplares em 2 lâminas (DCBU).

Distribuição geográfica: Brasil (São Paulo).

Discussão: assemelham-se a $C$. minimus as espécies: $C$. cirripediformis e espécies afins por apresentarem antenas com 7 segmentos, presença de esclerotização tíbio-tarsal, digítulos da garra iguais e dilatados, setas estigmáticas predominantemente cônicas; poros da superfície dorsal predominantemente triloculares, de contornos ovais e triangulares tipo II. C. cirripediformis e espécies afins

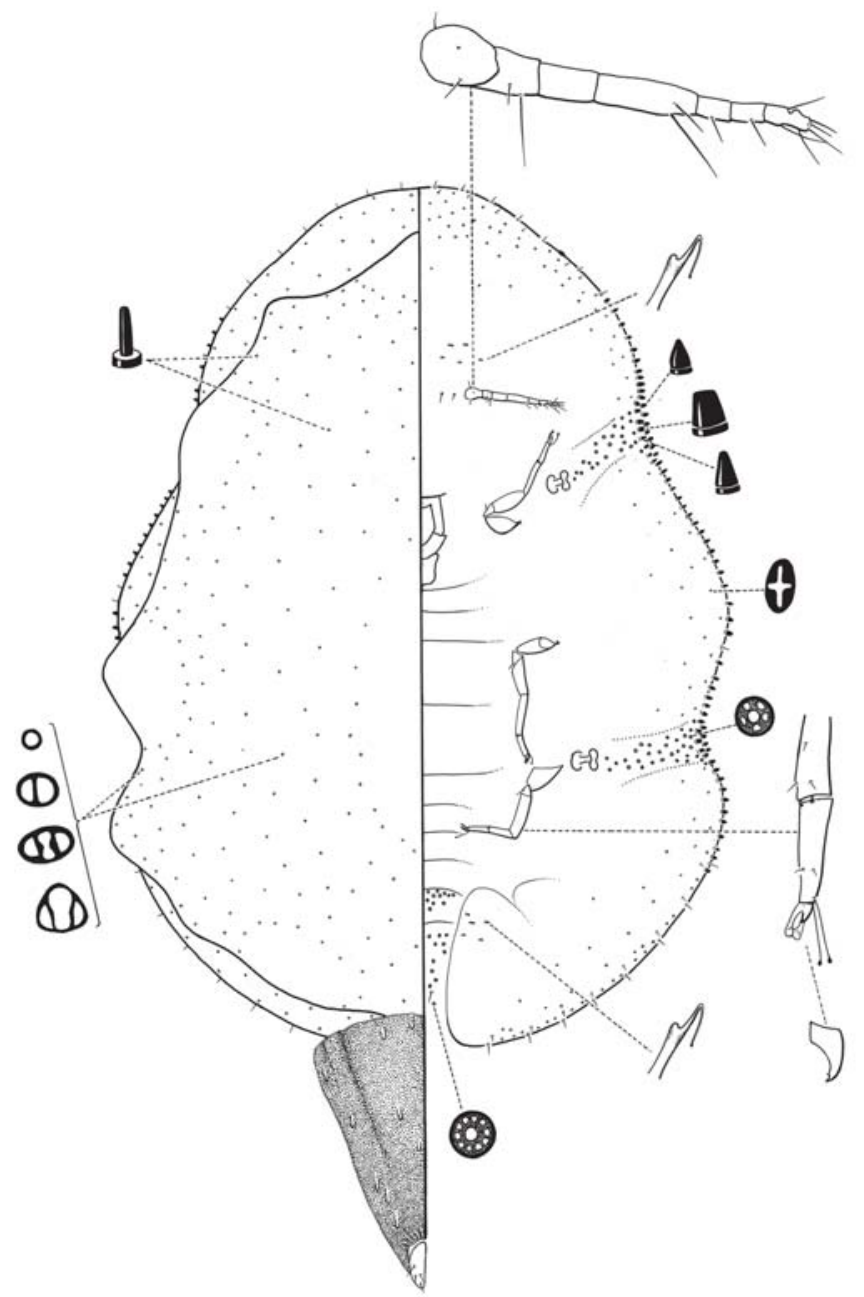

Fig. 99. Ceroplastes janeirensis Gray, sobre Psidium guajava (Myrtaceae). 
diferenciam-se principalmente por apresentarem setas da superfície dorsal capitada e condutos tubulares com filamentos delgados.

\section{Ceroplastes purpureus Hempel} (Figs. 68-70, 104)

Ceroplastes purpureus Hempel, 1900a: 466; Hempel, 1901b: 63 (redescr.); Vernalha, 1953: 129 (cat.); Silva et al., 1968:140 (cat.); Ben-Dov, 1993: 48 (cat.). Síntipos + , Brasil, São Paulo, Ipiranga sobre Miconia sp., ?data, ?coletor. Hempel não designou holótipo na descrição original da espécie. São aqui designados lectótipo (lâmina $\mathrm{N}^{\circ} 161$, DZPU) e 4 paralectótipos ( 2 exemplares da lâmina $\mathrm{N}^{\circ} 161$ e 2 exemplares em 1 lâmina, MZSP) [examinado].

Características macroscópicas: (baseado em exemplares vivos).

Cera: fina, rija de coloração branco-amarelada ou brancoarroxeada e aspecto semitranslucido; retangular em vista dorsal e, semicircular a retangular em vista lateral; dividida em 1 placa dorsal, 4 laterais, 1 anterior e 1 posterior, distintas apenas nos exemplares mais jovens; com núcleo dorsal maior e os laterais indicados apenas por uma depressão; com uma mancha branca de formato retangular, ou em formato de "u" entre as depressões que correspondem aos núcleos e as bordas laterais (Figs. 68, 69); comprimento, 2,3mm (1-2,5); largura, $1,5 \mathrm{~mm}(0,75-2)$; altura, $1,5 \mathrm{~mm}(1-2)$.

Corpo: oval, de coloração castanho-clara; comprimento, $1,55 \mathrm{~mm}(1-1,85)$; largura, $1 \mathrm{~mm}(0,95-1,4)$; processo caudal curto, geralmente mais claro que o corpo, que se escurece no ápice; apresenta-se inserido em uma base retangular de coloração castanho-clara (Fig. 70).

Características microscópicas: Superfície dorsal: com 8 áreas claras, uma na região cefálica, uma na médio-dorsal e 3 pares laterais. Setas cilíndricas curtas com ápice arredondado; poros biloculares tipo II, triloculares, de contorno oval e triangular tipo I. Processo caudal com poros pré-operculares simples e, com quatro setas em seu ápice, duas de cada lado, abaixo das placas anais. Placas anais com 3 setas dorsais (Fig.104).

Margem: com 38 a 40 setas estigmáticas retangulares, de diferentes tamanhos, dispostas em uma só linha, aproximadamente, entre a altura da inserção do primeiro e do terceiro par de coxas; 3 ou 4 setas maiores, semelhantes ao formato de um dente, formam uma segunda linha no centro do ápice do canal estigmático; setas marginais com 12,5-15 $\mu$ m, dispostas como a seguir: 11-12 entre as suturas estigmáticas anteriores, 2-3 entre a suturas estigmáticas anterior e posterior e 5-7 entre a sutura estigmática posterior e a fissura anal; nos lóbulos anais estão inseridas 4 setas (Fig.104).

Superfície ventral: setas submarginais curtas com cerca de $5 \mu \mathrm{m}$; antenas com $165 \mu \mathrm{m}$ (160-180) de comprimento, com 6

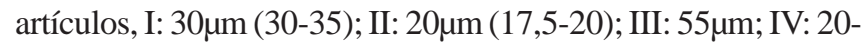

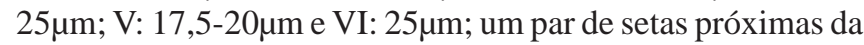

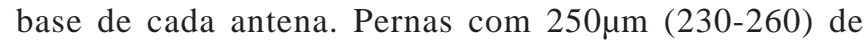

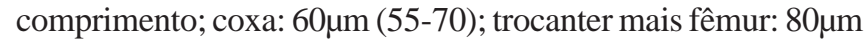

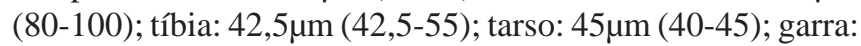
$15 \mu \mathrm{m}$, digítulos tarsais delgados com 50 $\mu \mathrm{m}$ de comprimento e

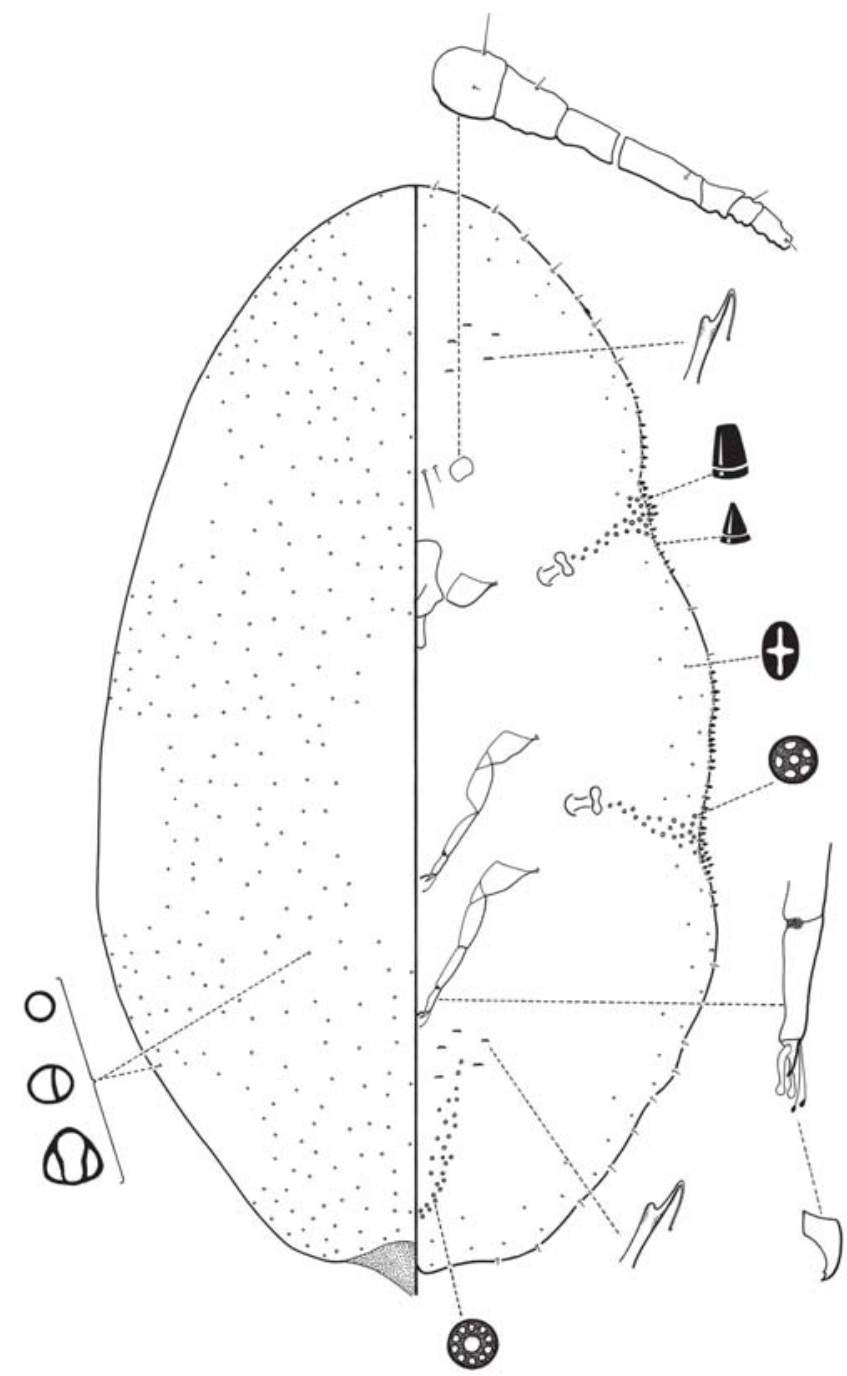

Fig. 100. Ceroplastes janeirensis (espécie-tipo de Ceroplastes simplex Hempel).

extremidades distais dilatadas; digítulos da garra diferentes entre si com $20 \mu \mathrm{m}$ de comprimento, sendo um apenas um pouco mais dilatado que o outro e extremidades distais espatuladas; esclerotização tíbio-tarsal ausente. Poros dos canais estigmáticos com 5 lóculos; poros cruciformes dispersos em toda a superfície ventral, mais concentrados na área submarginal; poros genitais com 10 lóculos. Condutos tubulares com filamento curto e delgado presentes na região cefálica e nos últimos segmentos abdominais (Fig.104).

Material examinado: BRASIL. São Paulo: Campos do Jordão (24XI-2001, hospedeiro indeterminado, A.L.B.G. Peronti col.), 4 exemplares em 2 lâminas; (24-XI-2001, Myrtaceae, A.L.B.G. Peronti col.), 4 exemplares em 1 lâmina; (24-XI-2001, Miconia sp. A.L.B.G. Peronti col.), 12 exemplares em 3 lâminas (DCBU).

Distribuição geográfica: Brasil (São Paulo).

Discussão: espécies semelhantes e diferenças entre elas, ver discussão de Ceroplastes acutus. 


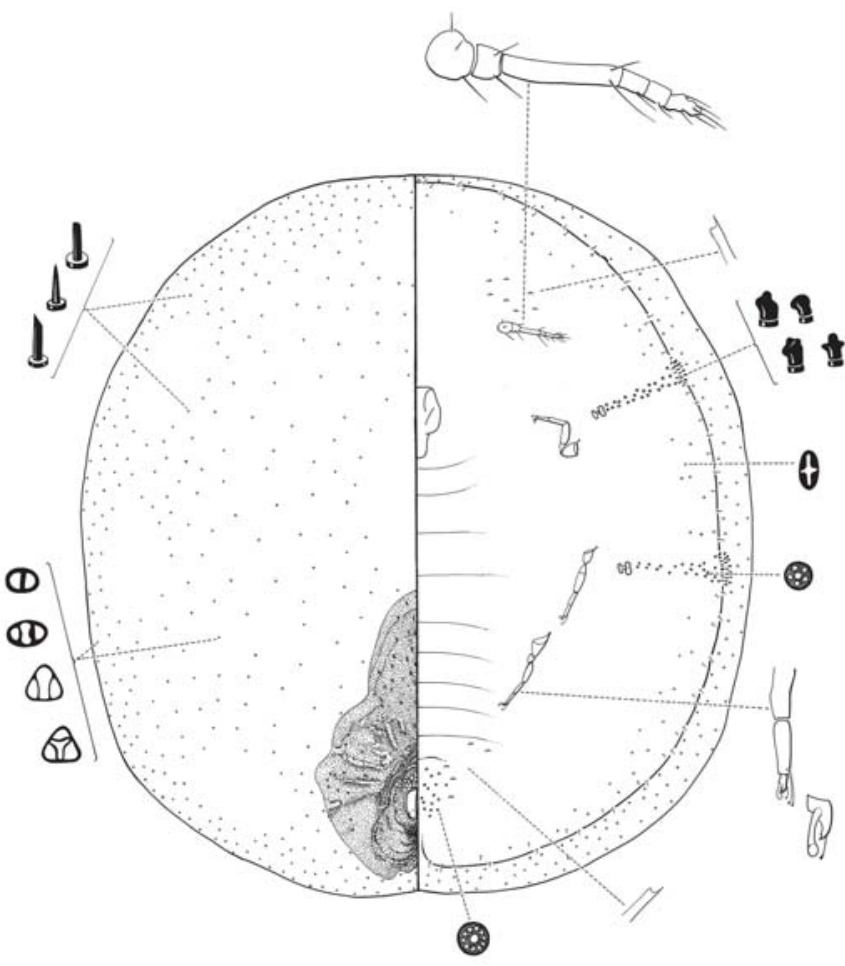

Fig. 101. Ceroplastes jordanensis sp. nov., sobre hospedeiro indeterminado.

\section{Ceroplastes quadratus Green} (Figs. 71-74, 105)

Ceroplastes quadratus Green, 1935: 274; Ben-Dov, 1993: 48 (cat). Sintipos + , Brasil, Goiás, hospedeiro indeterminado, 24-XI-1933, R. Spitz col. (BMNH) [examinado].

Características macroscópicas: (baseado em material vivo).

Cera: rija, de coloração amarelo-vivo; com aspecto semitranslúcido nos exemplares mais velhos; amarelo-clara ou olivácea (Fig. 71-72); retangular a hexagonal em vista dorsal; com borda posterior da placa dorsal formando um "v", com o vértice dirigido para o núcleo da placa dorsal; retangular em vista lateral; dividida em 7 placas, 1 dorsal, 4 laterais, 1 anterior e 1 posterior; núcleo dorsal com coloração castanho-escura ou negra ou ainda apresentando-se coberto por uma secreção branca, presente também nos núcleos laterais; comprimento, 3-5mm; largura, 3-5mm e altura, $1,5-2 \mathrm{~mm}$.

Corpo: oval a retangular, coloraçãoamarela; comprimento, $3,2 \mathrm{~mm}(3,2-4,4)$; largura, $2,3 \mathrm{~mm}(2,3-3,4)$; processo caudal cônico, curto, dirigido para trás e coloração castanho-escura (Fig. 73).

Características microscópicas: Superfície dorsal: com 8 áreas claras, uma na região cefálica, uma na médio-dorsal e 3 pares laterais. Setas cilíndricas com ápice arredondado ou truncado lateralmente. Poros biloculares tipo I e triloculares com contorno oval e triangular dos tipos I e II. Processo caudal com poros pré-operculares simples; placa anal com 4 setas dorsais e 2 ventrais; borda da prega anal com 4 setas (Fig.105).
Margem: com 90 setas estigmáticas cilíndricas com ápices truncados ou arredondados, agrupadas no ápice dos canais estigmáticos e estendendo-se sobre o dorso (Fig.105).

Superfície ventral: antenas com $242,5 \mu \mathrm{m}(212-250)$ de

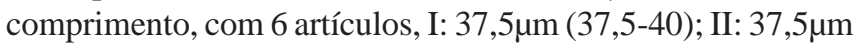

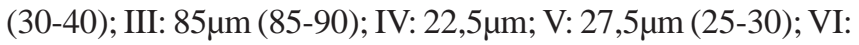
32,5 $\mu \mathrm{m}$ (30-35); com duas setas próximas da margem da base de cada antena. Pernas com 367,5 $\mu \mathrm{m}$ (350-370); coxa: $85 \mu \mathrm{m}$ (85-100); trocanter mais fêmur: $125 \mu \mathrm{m}(112,5-120)$; tíbia: $75 \mu \mathrm{m}$

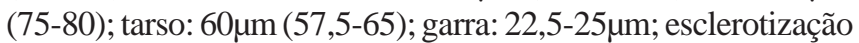
na articulação tíbio-tarsal ausente; digítulos tarsais delgados com $45-50 \mu \mathrm{m}$ de comprimento, com extremidades distais dilatadas; digítulos da garra diferentes, um dilatado e o outro delgado, ambos com $30 \mu \mathrm{m}$ de comprimento e extremidades distais espatuladas. Poros dos canais estigmáticos com 5 lóculos; poros cruciformes concentrados na região submarginal; poros genitais com 10 lóculos, restritos aos últimos segmentos abdominais. Condutos tubulares com filamentos curtos na região cefálica e nos últimos segmentos abdominais (Fig.105).

Material examinado: BRASIL. São Paulo: "Pirapitinguy" (10-VIII1931, planta silventre, A. Hempel col.), 2 exemplares em 1 lâmina; (6III-1931, Miconia sp., A. Hempel col.), 2 exemplares em 1 lâmina (IBSP); São Carlos (24-VII-2001, Psidium guajava, A.L.B.G. Peronti col.), 4 exemplares em 2 lâminas; (20-VI-2002, Miconia albicans, A.L.B.G. Peronti col.), 4 exemplares em 2 lâminas; Santa Rita do Passa Quatro, Parque Estadual de Vassununga (24-VII-2002, M. minutiflora, A.L.B.G. Peronti col.), 8 exemplares em 4 lâminas; (24-VII-2002, hospedeiro indeterminado, A.L.B.G. Peronti col.), 4 exemplares em 2

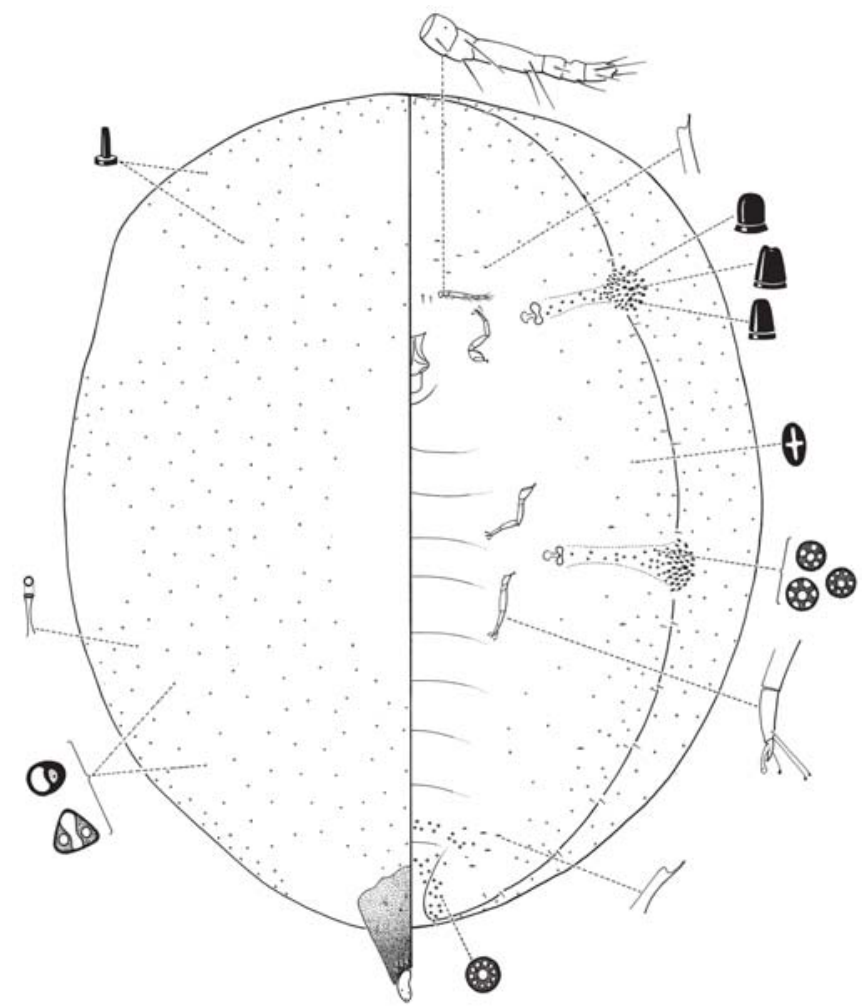

Fig. 102. Ceroplastes lucidus Hempel sobre Baccharis dracunculifolia (Asteraceae). 


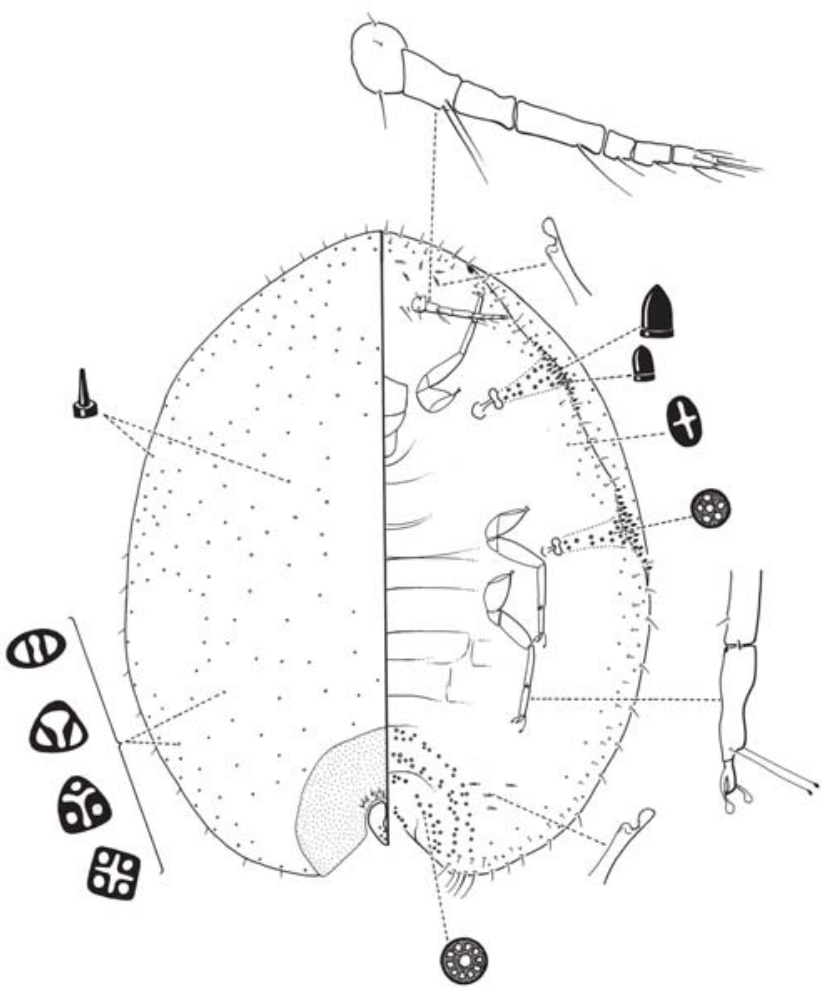

Fig. 103. Ceroplastes minimus sp. nov., sobre Myrtaceae.

lâminas (DCBU). Material proveniente de outros Estados: Minas Gerais, Lagoa Grande (27-VIII-1934, Myrtaceae, J.G.Kuhlmam col.), 3 exemplares em 1 lâmina. Paulo).

Distribuição geográfica: Brasil (Goiás, Minas Gerais, São

Discussão: assemelham-se a $C$. quadratus as espécies: $C$. lucidus por apresentar setas estigmáticas agrupadas no ápice dos canais estigmáticos e sobre o dorso; antenas com 6 segmentos, esclerotização tíbio-tarsal ausente; digítulos da garra diferentes e processo caudal curto. C. lucidus difere de C. quadratus por apresentar um menor número de setas estigmáticas (21-48) arredondadas ou cônicas com ápices truncados; setas dorsais cilíndricas com ápices truncados; poros dorsais monoloculares, além dos biloculares e triloculares comum as duas espécies e condutos tubulares presentes também na região submarginal da superfície ventral.

\section{Ceroplastes solanaceus Peronti sp. nov.}

(Fig. 106)

Material tipo: holótipo + , Brasil, São Paulo, Santa Rita do Passa Quatro, Parque Estadual de Vassununga, $N^{\circ} 405$ coletado sobre Solanum sp., 24-VII-2002, A.L.B.G. Peronti col. (DCBU). holótipo \&, Brasil, São Paulo, Campos do Jordão, sobre hospedeiro indeterminado, 24-XI2001, A.L.B.G. Peronti col. (DCBU).

Etmologia: o nome da espécie é alusivo ao gênero da planta hospedeira, Solanum (Solanaceae).

Características macroscópicas: (baseado em exemplares vivos).
Cera: pastosa, branca ou branco-amarelada, com linhas castanhas entre as placas; oval em vista dorsal e, semicircular em vista lateral; dividida em 7 placas, 1 dorsal, 4 laterais, 1 anterior e 1 posterior; núcleo dorsal oval e laterais retangulares; placa posterior com dois núcleos, um de cada lado do processo caudal; comprimento, 6mm (6-7); largura, $5 \mathrm{~mm}$ (5-6) e altura, $4,5 \mathrm{~mm}(4,5-5,0)$.

Corpo: oval, com 6 tubérculos bem evidentes, 2 em cada lateral, um anterior e um dorsal; comprimento, $4,5 \mathrm{~mm}(4,5-5,8)$; largura, 3,4mm (3,4-3,6); processo caudal cônico dirigido para trás, com $1 \mathrm{~mm}(1-1,3)$ de comprimento.

Características microscópicas: Superfície dorsal: com 6 ou 8 áreas claras, uma na região cefálica, uma médio dorsal e 2 ou 3 pares laterais. Setas capitadas com $6 \mu \mathrm{m}$ de comprimento. Poros com 2 a 8 lóculos sendo os triloculares triangulares, tipo I e II, e tetraloculares em maior número. Placas anais com 3 setas dorsais (Fig.106).

Margem: com 30 a 32 setas cônicas com ápice obtuso na região dos estigmas, dispostas em 3 linhas no ápice dos canais estigmáticos e estendendo-se em uma única linha, um pouco além destes; setas menores com 10 a $12 \mu \mathrm{m}$ de comprimento e as maiores cerca de 19 a $22 \mu \mathrm{m}$. Setas marginais com 35-40 $\mu \mathrm{m}$ de comprimento (Fig.106).

Superfície ventral: esclerotizada; setas submarginais com 10 a $12 \mu \mathrm{m}$ de comprimento; antenas com 302,5 $\mu \mathrm{m}$ (300-320) de comprimento, com 7 artículos, sendo o IV parcialmente

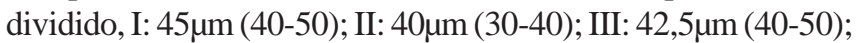

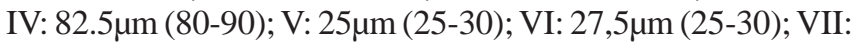
$40 \mu \mathrm{m}$; um par de setas próximas da base de cada antena. Pernas

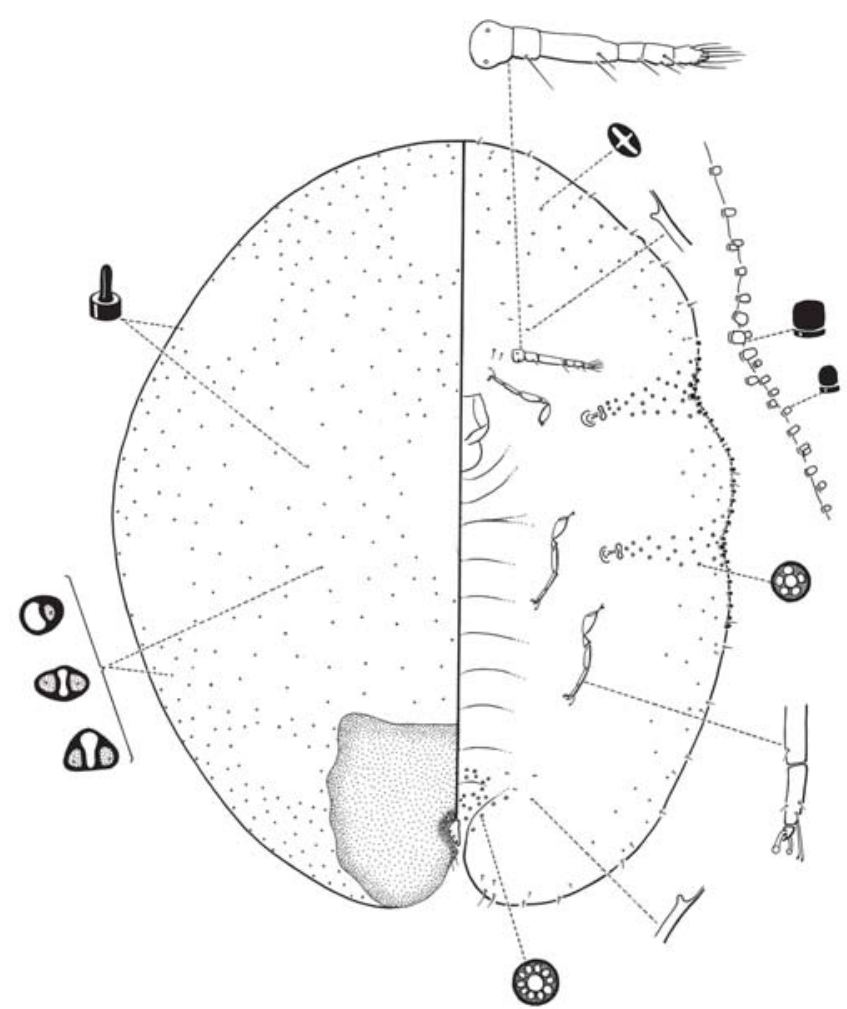

Fig. 104. Ceroplastes purpureus Hempel, esquema da espécie-tipo. 


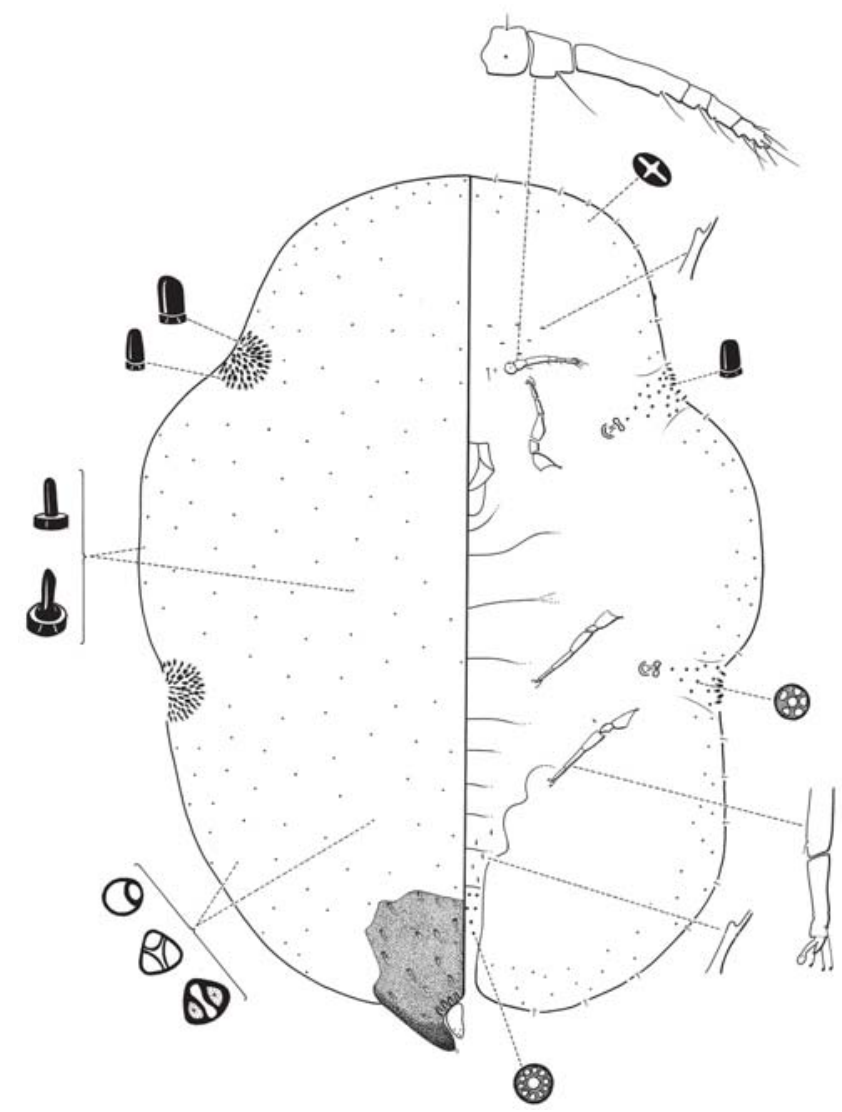

Fig. 105. Ceroplastes quadratus Green sobre Psidium guajava (Myrtaceae).

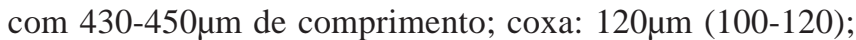

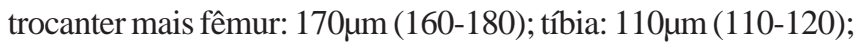

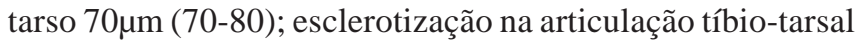
presente; digítulos tarsais delgados, com $50 \mu \mathrm{m}$ de comprimento e extremidades distais dilatadas; digítulos da garra iguais, dilatados, com 27,5-30 $\mu$ m de comprimento e

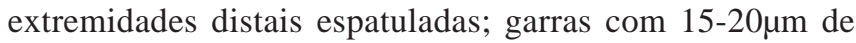
comprimento. Poros genitais com 10 lóculos; poros do canal estigmático com 5 lóculos; poros cruciformes concentrados na região submarginal. Condutos tubulares com filamento aparentemente delgados, distribuídos em tono da vulva, acima do processo caudal (Fig.106).

Material examinado: BRASIL. São Paulo: São Carlos (16-VIII, 2001, Solanum sp., A.L.B.G. Peronti col.), 2 exemplares em 1 lâmina (DCBU).

Distribuição geográfica: Brasil (São Paulo).

Comentários: espécies semelhantes e diferenças entre elas, ver discussão de $C$. cirripediformis.

\section{Ceroplastes speciosus Hempel}

(Figs. 75, 76, 107)

Ceroplastes speciosus Hempel, 1900a: 464; Vernalha, 1953: 131; Silva et al., 1968: 141; Ben-Dov, 1993: 57. Síntipos + , Brasil, São Paulo, Ipiranga, sobre ramos de diversos arbustos de Myrtaceae, ?data, ?coletor. Hempel não designou holótipo na descrição original da espécie. São aqui designados lectótipo (exemplar da lâmina $\mathrm{N}^{\circ} 82 \mathrm{a} /$ 171-2/ DZPU) e 3 paralectótipos (1 exemplar na lâmina $\mathrm{N}^{\circ} 82 \mathrm{~b} /$ 171-1/ DZPU e 2 exemplares na lâmina $\mathrm{N}^{\circ}$ 95.148/ tipo + 297b/ MZSP) [examinado].

Características macroscópicas: (baseado em material preservado a seco).

Cera: rija, coloração castanho-escura e com uma mancha branco-amarelada no centro da placa dorsal; com aspecto semitranslucido; retangular, em vista dorsal, (Fig. 75) e deprimida dorso-ventralmente (Fig. 76); placas indefinidas, com mancha retangular branco-amarelada na placa dorsal; comprimento 4,5mm; largura, $4 \mathrm{~mm}$; altura, $2,5 \mathrm{~mm}$.

Corpo: oval a retangular, com tubérculos laterais pouco evidentes; comprimento, 2,25-3 mm; largura, 1,5-1,6mm. Processo caudal curto e dirigido para trás.

Características microscópicas: Superfície dorsal: com 6 ou 8 áreas claras, uma na região cefálica, uma médio-dorsal e 2 ou 3 pares laterais. Setas de dois tipos, ambas curtas, uma cilíndrica com cerca de $5 \mu \mathrm{m}$ de comprimento e ápice arredondado e outra com ponta, com $6 \mu \mathrm{m}$ de comprimento; poros monoloculares, biloculares tipo I, triloculares ovais e triloculares tipo II, com contorno circular e triangular, com 5$7 \mu \mathrm{m}$. Todos os poros são providos de filamentos diversamente ramificados. Processo caudal com poros pré-operculares simples e quatro setas em seu ápice, duas de cada lado, abaixo das placas anais; placas anais com 3 setas dorsais (Fig.107).

Margem: com 20-28 setas estigmáticas cônicas ou retangulares, dispostas em duas linhas no ápice dos canais estigmáticos e prolongando-se lateralmente, em uma só linha, um pouco além destes (Fig.107).

Superfície ventral: antenas com $190 \mu \mathrm{m}(180-190)$ de

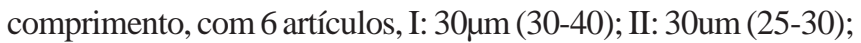

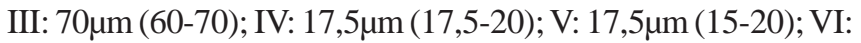
25 $\mu \mathrm{m}$ (25-30); um par de setas próximos da base de cada antena.

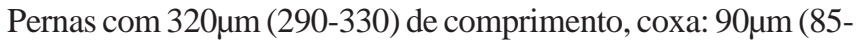

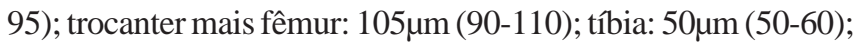
tarso: $60 \mu \mathrm{m}$ (50-60); garra: $15 \mu \mathrm{m}$ (15-17,5); digítulos tarsais delgados, com extremidades distais dilatadas; digítulos da garra diferentes entre si, um dilatado e o outro delgado, com $25 \mu \mathrm{m}$ de comprimento e extremidades distais espatuladas. Poros dos canais estigmáticos com 5 lóculos; poros cruciformes concentrados na região submarginal; poros genitais com 10 lóculos. Condutos tubulares com filamento delgado e ápice dilatado presentes na região cefálica e nos últimos segmentos abdominais (Fig.107).

Material examinado: BRASIL. São Paulo: Santo Amaro (08-X1929, Myrtaceae, J. P. da Fonseca col.); 2 exemplares em 1 lâmina (IBSP).

Distribuição geográfica: Brasil (São Paulo).

Discussão: espécies semelhantes e diferenças entre elas, ver discussão de $C$. acutus. 


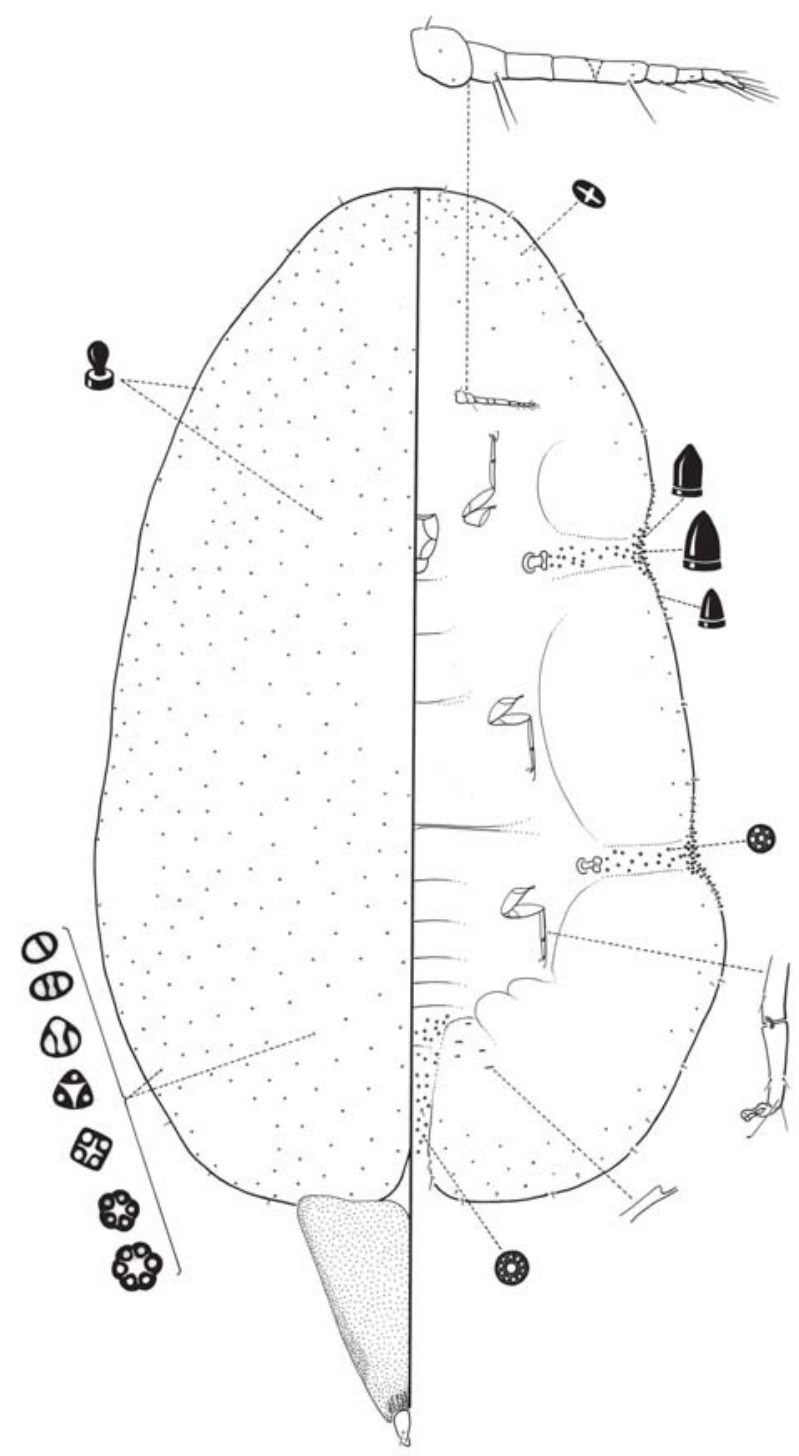

Fig. 106. Ceroplastes solanaceus sp. nov., sobre Solanum sp. (Solanaceae).

\section{Ceroplastes stellifer (Westwood) n. comb.}

(Figs. 77-79, 108)

Coccus stellifer Westwood, 1871: iii. Sintipos + , Ilha reunião, sobre Mangifera indica, ?data, ?col.; Vienna Museum of Natural History, Viena (VMNH). [não examinado]

Vinsonia pulchella Signoret, 1872b: 34; Douglas, 1888: 152 (sin). Vinsonia stellifera (Westwood); Vernalha, 1953: 149 (cat.); Silva et al., 1968: 157 (cat.); Ben-Dov, 1993: (cat.); Hodgson, 1994: 591 (redescr. e ilustr.)

Características macroscópicas: (baseado em exemplares vivos).

Cera: rija, branca ou rósea, de aspecto semitranslúcido, deprimida dorso-ventralmente, com sete raios marginais que lhe dão uma aparência de estrela; sem placas definidas; apenas o núcleo dorsal é visível; diâmetro, 3,2mm (3,0-4,0) (Figs. 77, 79).
Corpo: globoso, de coloração castanho-clara; comprimento, 0,85mm (0,8-1,2); largura, $0,72 \mathrm{~mm}(0,6-1,0)$; processo caudal curto, dirigido para trás e coloração castanho-escura (Fig. 78).

Características microscópicas: Superfície dorsal: derme esclerotizada; com 8 áreas claras, uma na região cefálica, uma médio dorsal e 3 pares laterais. Setas cônicas, escassas, com cerca de $2 \mu \mathrm{m}$ de comprimento; poros monoloculares com filamento ramificado, biloculares e triloculares de contorno triangular tipo I. Placas anais com 3 setas dorsais e 1 ventral; anel anal com 6 setas (Fig.108).

Margem:com 7-10 setas cônicas no ápice dos canais estigmáticos, sendo 4-5 alongadas e com ápices obtusos (Fig.108).

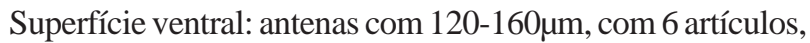

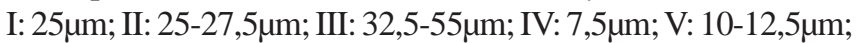
VI: $27,5 \mu \mathrm{m}$; setas interantenais numerosas, $15-19$. Pernas curtas

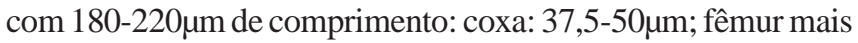
trocanter: $65-75 \mu \mathrm{m}$; tíbia mais tarso (fundidos): $65-80 \mu \mathrm{m}$; digítulos tarsais delgados, com $12,5 \mu \mathrm{m}$ de comprimento e extremidades distais dilatadas; digítulos da garra iguais, dilatadas, com $25 \mu \mathrm{m}$ de comprimento e extremidades distais espatuladas. Poros dos canais estigmáticos com 5 lóculos; poros cruciformes concentrados na área submarginal; poros genitais multiloculares com 10 lóculos. Condutos tubulares ausentes (Fig.108).

Material examinado: BRASIL. São Paulo: Santos (22-III-2002, Ixora coccinea; Schefflera arboricola, A.L.B.G. Peronti col.), 8 exemplares em 2 lâminas (DCBU).

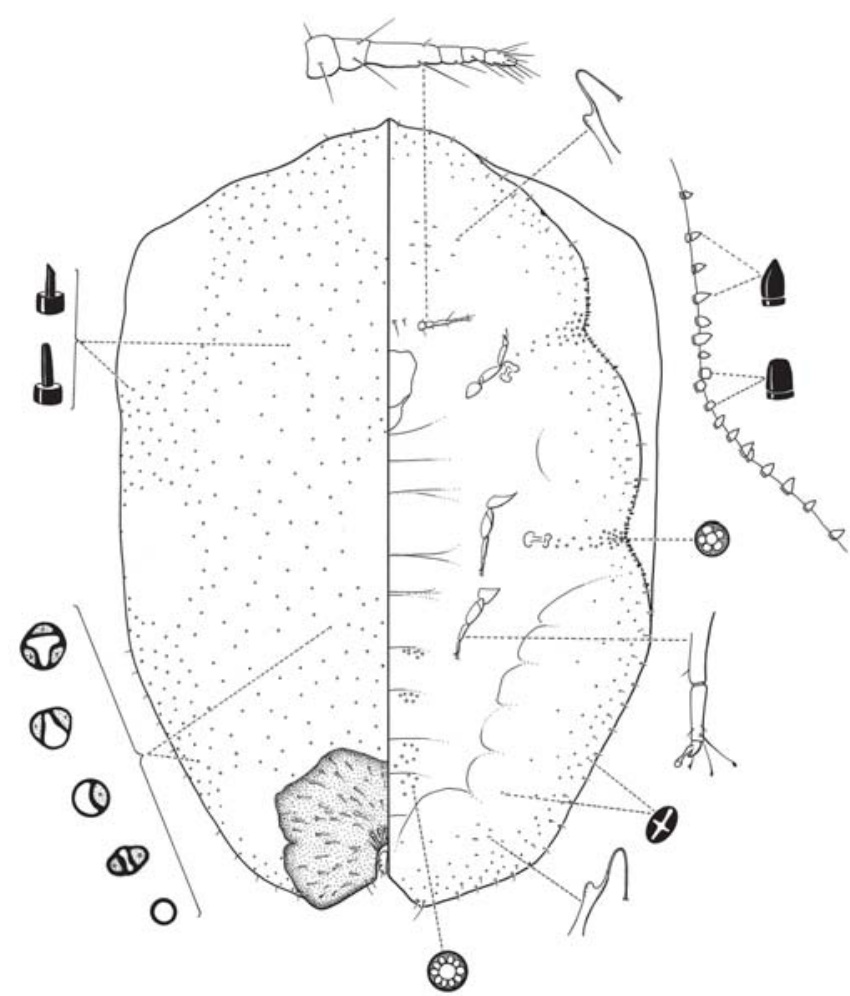

Fig. 107. Ceroplastes speciosus Hempel, esquema da espécie-tipo. 


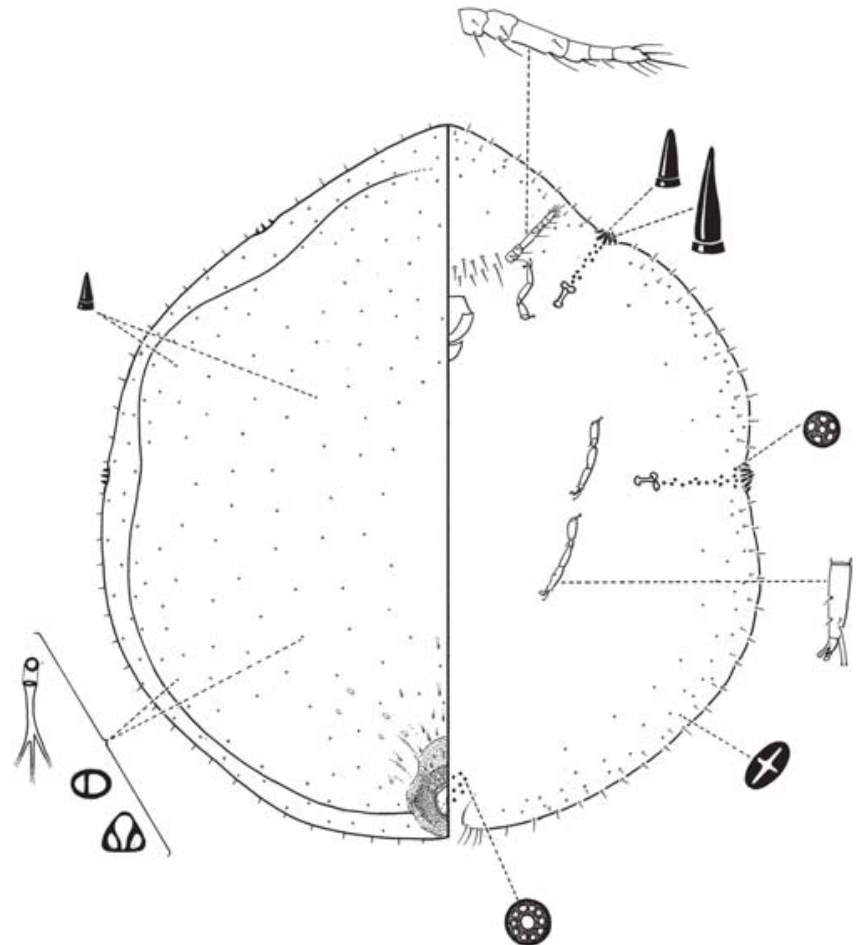

Fig. 108. Ceroplastes stellifer (Westwood) sobre Ixora coccinea (Rubiaceae).

Distribuição geográfica: EUA; Bermudas; Holanda, Paquistão, Índia, Filipinas, Tailândia, Sri Lanka, Malásia, Indonésia, Vietnã, Taiwan, Cabo Verde, Quênia, Angola, São Tomé e Príncipe, I. Seichelles, I. Maurício, I. Reunião, Barbados, Cuba, I Virgens, Jamaica, Porto Rico Trinidad e Tobago, Granada, Guiana, Brasil (Pará, Pernambuco, Rio de Janeiro, São Paulo, Rio Grande do Sul); I. Vieques, Austrália, Fiji, Micronesia, Niue, Palau, Papua Nova Guiné, I. Salomão, Tonga.

Discussão: na região Neotropical, Ceroplastes stellifer é separada de todas as outras espécies por apresentar cera horizontalmente achatada, com sete raios marginais que lhe dão aparência de estrela. Microscopicamente difere, principalmente por apresentar tíbia e tarso fundidos e, 15 a 19 setas interantenais. C. rufus De Lotto, 1966, conhecido para a África do Sul e C. rubens Maskell, 1893, amplamente distribuído, embora apresentem tíbia e tarso fundidos, como em $C$. stellifer, são muito diferentes com relação aos outros caracteres.

\section{Ceroplastes variegatus Hempel} (Fig. 109)

Ceroplastes variegatus Hempel, 1900a: 462; Silva et al., 1968: 141 (cat.); Ben-Dov, 1993: 59 (cat.). Sintipos ㅇ, Brasil, São Paulo, Ipiranga, sobre ramos de Miconia sp. (Melastomataceae) e várias espécies de Myrtaceae, 1 exemplar em 1 lâmina (MZSP) (é aqui designado lectótipo) [examinado]

Características macroscópicas: (baseado em material preservado a seco).
Cera: oval em vista dorsal a cera e, lateralmente piramidal com dorso elevado; dividida em 1 placa dorsal, 4 laterais, 1 anterior e 1 posterior, mais larga.

Corpo: comprimento, 4,2mm; largura; 2,5mm. Processo caudal curto

Características microscópicas: Superfície dorsal: setas cilíndricas com ápice arredondado ou capitado; poros biloculares tipo II, triloculares de contorno oval, triangular tipo I e II em maior número e, escassos tetraloculares (Fig. 109).

Margem: 50 setas estigmáticas cônicas de diferentes tamanhos, dispostas em duas linhas no ápice dos canais estigmáticos e, prolongando-se lateralmente um pouco além destes; e, uma seta central com ápice obtuso e comprimento duas vezes maior que as demais (Fig. 109).

Superfície ventral: antenas com 330-385 $\mu \mathrm{m}$ de comprimento,

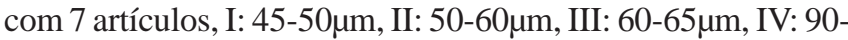
$105 \mu \mathrm{m}$, V: $25-30 \mu \mathrm{m}$, VI: $30-35 \mu \mathrm{m}$, VII: $42,5-50 \mu \mathrm{m}$; todas as

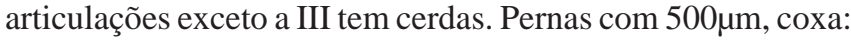
$170 \mu \mathrm{m}$, trocanter mais fêmur: $220 \mu \mathrm{m}$, tíbia: $140 \mu \mathrm{m}$, tarso: $100 \mu \mathrm{m}$, garra: $25-30 \mu \mathrm{m}$; digítulos tarsais delgados, com 55-60 $\mu \mathrm{m}$ de comprimento e extremidades distais dilatadas; digítulos da

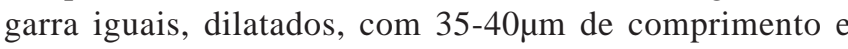

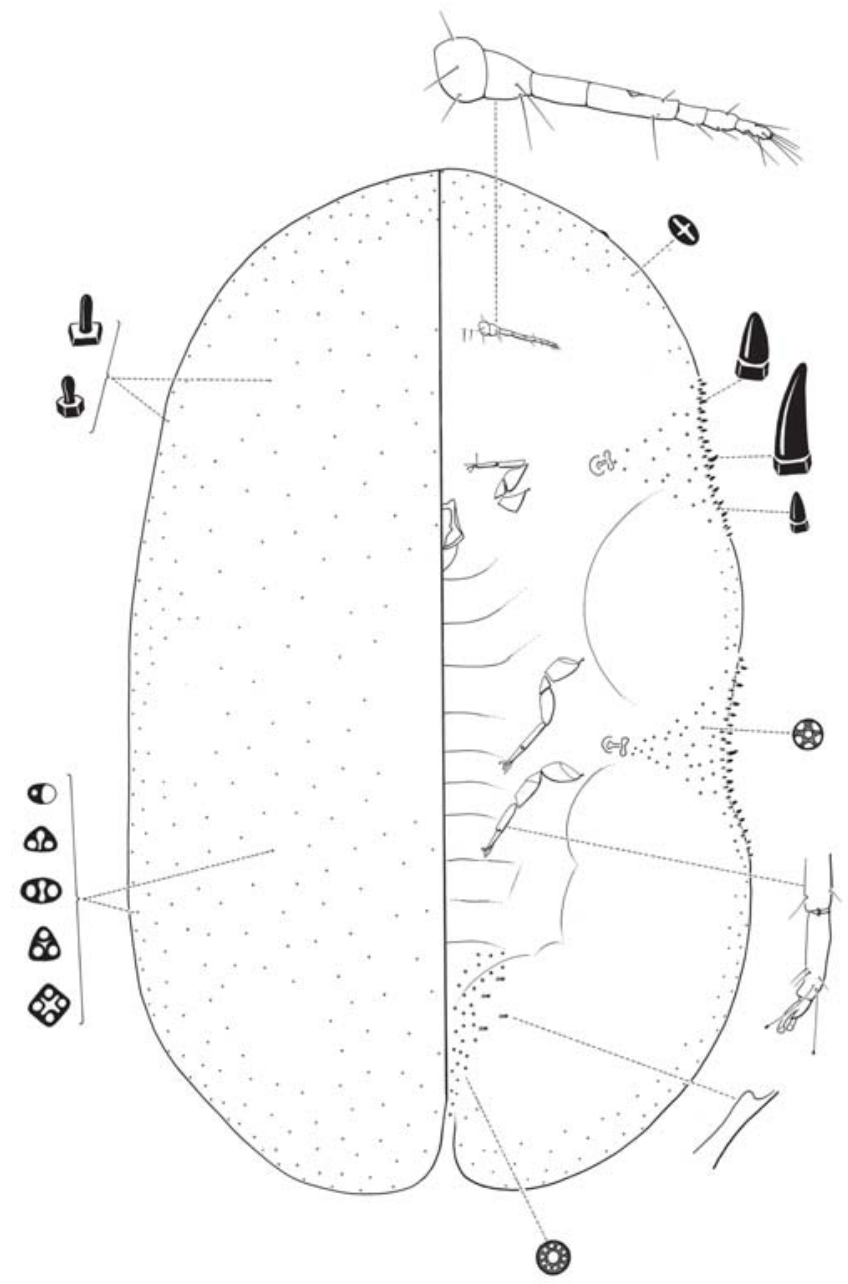

Fig. 109. Ceroplastes variegatus Hempel, material tipo. 


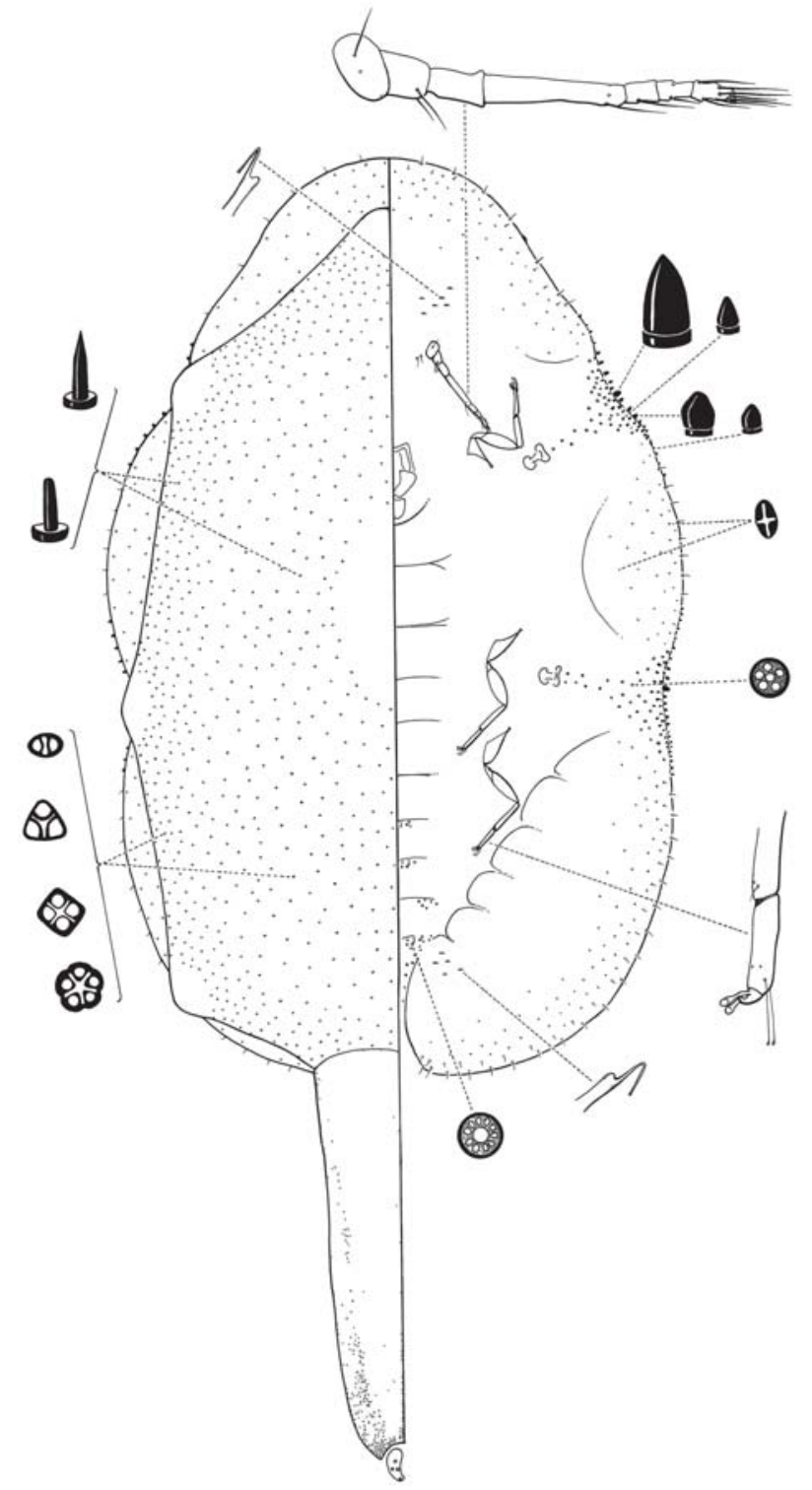

Fig. 110. Ceroplastes willinkae, sp. nov., sobre hospedeiro indeterminado.

extremidades distais espatuladas; esclerotização na articulação tíbio-tarsal presente. Poros dos canais estigmáticos com 5 lóculos; poros cruciformes concentrados na área submarginal; poros genitais multiloculares com 10 lóculos. Condutos tubulares ausentes (Fig. 109).

Material examinado: BRASIL. São Paulo: Itararé (09-VI-1928, planta silvestre, A. Hempel col.), 1 exemplar em 1 lâmina (IBSP).

Distribuição geográfica: Brasil (São Paulo).

Discussão: espécies semelhantes e diferenças entre elas, ver discussão de $C$. cirripediformis. O exemplar aqui designado lectótipo (Fig. 109) provavelmente teve o processo caudal removido durante o processo de montagem da lâmina permanente.

\section{Ceroplastes willinkae Peronti sp. nov.}

(Fig. 110)

Material tipo: holótipo + , Brasil, São Paulo, Araçatuba, (exemplar a direita na lâmina $\mathrm{N}^{\circ}$ 94/ Gav.7./Div.7, IBSP) sobre hospedeiro indefinido, VI-1928, A. Hempel col.

Etmologia: o nome da espécie é uma homenagem a Dra. Maria Cristina Granara de Willink.

Características macroscópicas: Corpo: oval; comprimento, 2,8mm (2,5-3); largura, $1,9 \mathrm{~mm}(1,8-2,5)$; processo caudal longo e afilado, com 1,4mm (1,3-1,5) de comprimento.

Características microscópicas: Superfície dorsal: com 8 áreas claras, uma na região cefálica, uma na médio dorsal e 3 pares laterais. Setas de dois tipos, cilíndricas com ponta ou ápice truncado, com 6-8 $\mu \mathrm{m}$ de comprimento; poros triloculares, ovais e triangulares tipo II, tetraloculares e escassos pentaloculares. Poros pré-operculares simples; placas anais com 3 ou 4 setas dorsais (Fig. 110).

Margem: com 40 a 46 setas cônicas e pentagonais, de diferentes tamanhos, dispostas em 3 a 4 linhas na borda dos canais estigmáticos e, prolongando-se lateralmente, em uma só linha, um pouco além destes; setas marginais de 27,5 a $30 \mu \mathrm{m}$, dispostas como a seguir: 8 a 9 entre os tubérculos dos olhos, 3 a 4 entre tubérculo do olho e a sutura estigmática anterior, 5 a 7 entre as suturas estigmáticas anterior e posterior e 15 a 20 entre a sutura estigmática posterior e a fissura anal; nos lóbulos anais estão inseridas 4 cerdas de 15 a $40 \mu \mathrm{m}$ de comprimento (Fig. 110).

Superfície ventral: setas submarginais dispostas da seguinte forma: 8-9 entre os tubérculos dos olhos, 4 a 6 entre tubérculo do olho e a sutura estigmática anterior, 13 entre as suturas estigmáticas anterior e posterior e 19-20 entre a sutura estigmática posterior e a fissura anal; antenas com cerca de 330 $\mu \mathrm{m}$ (320-340) de comprimento, com 7 artículos, I: $50 \mu \mathrm{m}$; II:

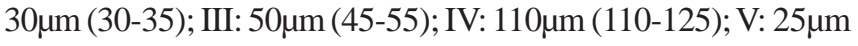

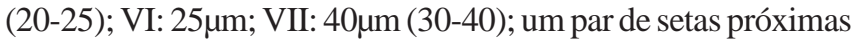
da base de cada antena. Pernas com 595 $\mu$ m (580-600) de comprimento, coxa: $90 \mu \mathrm{m}$ (90-100); trocanter mais fêmur com

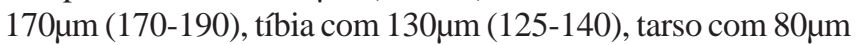
(75-85), garra com 20 $\mu \mathrm{m}$; digítulos tarsais delgados, com $55 \mu \mathrm{m}$ de comprimento e extremidades distais dilatadas; digítulo da garra iguais, com $35 \mu \mathrm{m}$ de comprimento e extremidades distais espatuladas; esclerotização na articulação tíbio-tarsal presente; Poros dos canais estigmáticos com 5 lóculos; poros cruciformes concentrados na região submarginal; poros genitais com 10 lóculos presentes até o V segmento abdominal. Condutos tubulares presentes na região cefálica e nos últimos segmentos abdominais (Fig. 110).

Discussão: espécies semelhantes e diferenças entre elas, ver discussão de $C$. grandis.

Agradecimentos. À Fundação de Amparo à Pesquisa do Estado de São Paulo (FAPESP) pelo auxílio financeiro concedido através de bolsa de estudo. Aos curadores dos museus: Dr. Sérgio Ide (IBSP); Sônia Aparecida Casari (MZSP); Dra. Kéti Maria da Rocha Zanol (DZUP); Dr. Sebastião José de Oliveira "in memorian" (FIOCRUZ); Dr. Willen Hogenes (ZMAN); Dr. Douglass R. Miller (USNM) e ao Dr. Jon Martin 
$(\mathrm{BMNH})$, pelo empréstimo de material. A Dra. Maria Inês Salgueiro Lima e Dr. João Juares Soares (Departamento de Botânica da Universidade Federal de São Carlos) pela identificação de algumas espécies botânicas e ao Dr. Takumasa Demian Kondo, da "Corporación Colombiana de Investigación Agropecuaria" Palmira, pelas valiosas críticas e sugestões.

\section{REFERÊNCIAS}

Amante, E. \& E. Almeida. 1962. Insetos que ocorrem no Ficus retusa e F. benjamina. Arquivos do Instituto Biológico 29: 94-101.

Atkinson, E. T. 1886. Insect-pests belonging to the Homopterous family Coccidae. Journal of the Asiatic Society of Bengal. Natural History 55: 267-298.

Ben-Dov, Y. 1993. A systematic catalogue of soft scales of the world. Sandhill Crane Press, Inc., Florida, USA, Flora \& Fauna Handbook 9: $563 \mathrm{p}$.

Ben-Dov, Y.; D. Matile-Ferrero \& R. Gafny, 2000. Taxonomy of Ceroplastes rubens Maskell with description of a related new species (Hemiptera: Coccoidea: Coccidae) from Reunion, including DNA polymorphism analysis. Annales de la Société Entomologique de France 36: 423-433.

Bodenheimer, F. S. 1952. The Coccoidea of Turkey. I. Revue de la Faculté des Sciences de l'Université d'Instanbul (Series B) 17: 315-351.

Borges, L. R.; S. M. N. Lázzari \& F. A. Lázzari. 2003. Comparação dos sistemas de cultivo nativo e adensado de erva mate, Ilex paraguariensis St. Hil., quanto à ocorrência e flutuação populacional de insetos. Revista Brasileira de Entomologia 47: 563-568.

Caloba, J. \& N. M. Silva. 1995. Insetos associados a graviola, Annona muricata L. e biribá, Rollinia mucosa (Jacq.) Bail no estado do Amazonas. Anais da Sociedade Entomológica do Brasil 24: $179-182$.

Chavannes, P. M. A. 1848. Sur deux Coccus Cérifères du Brésil. Annales de la Société Entomologique 141: 139-145.

Cockerell, T. D. A. 1893. A new subspecies of Ceroplastes from México. Zoe 4: 104-105.

1895. Three new species of Coccidae. The entomologist 28: $100-101$.

1896. New species of insects taken on a trip from the Mesilla Valley to the Sacramento Mts., New Mexico. Journal of the New York Entomological Society 4: 104-105.

1902. A catalogue of the Coccidae of South America. Revista Chilena de História Natural 6: 250-257.

Comstock, J. H. 1881. Report of the entomologist. Part II. Report on scale insects. Report of the entomologist of the USDA for the year 1880: 276-349.

Corseuil, E. \& V. M. B. Barbosa. 1971. A família Coccidae no Rio Grande do Sul (Homoptera: Coccoidea). Arquivos do Museu Nacional 54: 237-241.

Costa Lima, A. 1940. Um novo Ceroplastes gigante (Coccoidea: Coccidae). Papéis avulsos do Departamento de Zoologia, Secretaria de Agricultura - São Paulo. 1: 9-12.

De Lotto, G. 1965. On some Coccidae (Homoptera), chiefly from Africa. Bulletin of the British Museum (Natural History) Entomolgy 16: 174-239.

1969. A new genus of wax scales (Homoptera: Coccidae). Bolletino del Laboratorio di Entomologia Agraria "Filippo Silvestri” 27: 210-218.

1970. On status of two genera of soft scales (Homoptera: Coccoidea: Coccidae). Bollettino del Laboratorio di Entomologia Agraria "Filippo Silvestri” 28: 257-261.

1971. On some genera and species wax scales (Homoptera: Coccidae). Journal of Natural History 5: 133-153.

Douglas, J. W. 1888. Notes on some British and exotic Coccidae $\left(\mathrm{N}^{\circ}\right.$ 12). Entomologist's Monthly Magazine 25: 150-153.

Dozier, H. L. 1931. A new giant wax scale from Haiti. American Museum Novitates 495: 1-2.
Fernald, M. E. 1903. A catalogue of the Coccidae of the world. Bulletin of the Hatch Experimental Station of the Massachusetts Agricultural College 88: 1-360.

Foldi, I. 1988. Nouvelle contribution a l'étude des cochonilles de 1’Amazonie Brésilienne (Homoptera: Coccoidea). Annales de la Societe Entomologique de France 24: 78-87.

Giliomee, J. H. 1967. Morphology and taxonomy of adult males of the family Coccidae (Homoptera: Coccidae). Bulletin of the British Museum (Natural History), Entomology Supplement 7: 168p.

Gill, R. 1988. The Scales Insects of California Part 1. The Soft Scales (Homoptera. Coccoidea: Coccidae). Technical Services in Agricultural Biosystematics and Plant Pathology, California Department of Food and Agriculture, 132 p.

Gimpel, W. F. Jr.; D. R. Miller \& J. A. Davidson. 1974. A systematic revision of the scale genus Ceroplastes, in the United States (Homoptera: Coccoidea: Coccidae). University of Maryland, Agricultural Experiment Station, Miscellaneous Publication 841: $1-85$.

Gomes Costa, R. 1949. Cochonilhas ou coccideas do Rio Grande do Sul. Secretaria de Estado e de Negócios da Agricultura, Indústria e Comércio, Secção de Informações de Publicidade Agrícola, Porto Alegre, $107 \mathrm{p}$.

Granara De Willink, M. C. 1990. Conociendo nuestra fauna I. Superfamilia Coccoidea (Homoptera: Sternorrhyncha). Facultad de Ciencias Naturales e Instituto Miguel Lillo, Universidade Nacional de Tucumán, Argentina, Serie Monográfica y Didáctica. 6: $43 \mathrm{p}$.

1995. Conociendo nuestra fauna VI Família Coccidae (Homoptera: Coccoidea). Facultad de Ciências Naturales e Instituto Miguel Lillo, Universidade Nacional de Tucumán Argentina, Serie Monográfica y Didáctica. 24: $31 \mathrm{p}$.

1999. Las cochinilhas blandas de la República Argentina (Homoptera: Coccoidea: Coccidae). Contributions on Entomology, International 3: $183 \mathrm{p}$.

Gray, J. E. 1828. Spicilegia Zoologica; original figures and short systematic descriptions of new and unfigured animals. Treüttel, Würtz and Co., London. Part. I. 12 p.

Green, E. E. 1935. On three new species of Ceroplastes, from South America. Arbeiten über Morphologische u. Taxonomische Entomologie. Berlin-Dahlem 2: 272-275.

Hempel, A. 1900a. As coccidas Brazileiras. Revista do Museo Paulista 4: $365-537$.

.1900b. Descriptions of Brazilian Coccidae. Annals and Magazine of Natural History 6: 389-398.

1901a. Descriptions of Brazilian Coccidae. Annals and Magazine of Natural History 8: 62-72.

1901b. On some new Brazilian Hemiptera. Coccidae. Annals and Magazine of Natural History 8: 388-391.

1912. Catalogos da fauna Brazileira editados pelo Museu Paulista S. Paulo - Brazil. Diario Official, São Paulo. $77 \mathrm{p}$.

1918. Descripção de sete novas especies de Coccidas. Revista do Museu Paulista 10: 195-208.

1920. Descripções de coccidas novas e pouco conhecidas. Revista do Museu Paulista 12: 231-377

1928. Descripções de novas especies de pulgões (Homoptera:

Coccidae). Archivos do Instituto Biológico 1: 235-237.

1932. Descripção de vinte e duas espécies novas de coccideos

(Hemiptera - Homoptera). Revista de Entomologia 2: 310-339. 1937. Novas espécies de coccideos (Homoptera) do Brasil. Archivos do Instituto Biológico 8: 5-36.

1938. Descripção de uma nova espécie de Ceroplastes (Hom. Coccidae). Revista de Entomologia 8: 263-264.

Hickel, E. R. \& J. P. Ducroquet. 1995. Pragas da goiabeira serrana: Cochonilhas (Homoptera: Coccoidea). Anais da Sociedade Entomológica do Brasil 24: 665-669.

Hodgson, C. J. 1969. Notes on Rhodesian Coccidae (Homoptera: Coccidea). Part. II: The genera Ceroplastes and Gascardia. Arnoldia (Rhodesia) 4: 1-43

1994. The scale insect family Coccidae: an 
identification manual to genera. $\mathrm{CAB}$ International, Wallingford, Oxon, U. K., 639 p.

Hodgson, C. J. \& R. C. Henderson. 2000. Coccidae (Insecta: Hemiptera: Coccoidea). Fauna of New Zealand 41: 264 p.

Houser, J. S. 1918. The Coccidae of Cuba. Annals of the Entomological Society of America 11: 157-172.

Ihering, H. V. 1897. Os piolhos vegetaes (Phytophthires). Revista do Museu Paulista 2: 385-420.

Johnson, W. T. \& H. H. Lion. 1988. Insects that feed on trees and shrubs. Comstock Pub. Associates, Ithaca, N. Y. 556 p.

Kussler, A. L.; S. M. Sabedot; F. R. M. Garcia \& A. L. B. G. Peronti. 2004. Primeiro registro de Pendularia paraguariensis Granara de Willink, 1999 (Hemiptera: Coccidae) no Brasil. Ciência Rural 34: $1231-1233$.

Lizer y Trelles, C. A. 1919. Principales cóccidos que atacam a las plantas cultivadas em la República Argentina. Revista del Centro de Estudiantes de Agronômica y Vet. 12: 15-52.

Lorenzi, H. 1994. Manual de identificação e controle de plantas daninhas. Editora Plantarum LTDA. 300 p. 1997. Palmeiras no Brasil. Nativas e Exóticas. Editora Plantarum LTDA. 320 p. 1998. Árvores Brasileiras. Volume I. Editora Plantarum LTDA. 368 p. 2000. Árvores Brasileiras. Volume II. Editora Plantarum LTDA. 384 p.

Lorenzi, H. \& H. M. Souza. 1999. Plantas ornamentais no Brasil: arbustivas, herbáceas e trepadeiras. Editora Plantarum LTDA. $730 \mathrm{p}$.

Marín-Loayza, R \& F. Cisneros-Vera. 1994. El género Ceroplastes Gray (Homoptera: Coccidae) en el Perú: estudio toxonómico. Revista Peruana de Entomologia 38: 45-54.

1995. Ciclo de desarrollo de Ceroplastes floridensis y $C$. cirripediformis (Homoptera: Coccidae). Revista Peruana de Entomologia 37: 41-54.

Matile-Ferrero, D. \& Couturier, G. 1993. Les cochenilles des Myrtaceae en Amazonie péruvienne. I. Description de deux nouveaux ravageurs de Myrciaria dubia (Homoptera, Coccidae, Kerridae). Bulletin de la Société Entomologique de France 98: 441-448.

Mosquera, P. F. 1979. El género Ceroplastes (Hom. Coccidae) en Colombia. Caldasia XII: 595-627.

1984. El género Ceroplastes (Hom. Coccidae) en Colombia II. Caldasia XIV: 125-147.

Pellizzari, G. \& P. Camporese. 1994. The Ceroplastes species (Homoptera: Coccoidea) of the Mediterranea basin with emphasis on C. japonicus Green. Annales de la Societe Entomologique de France 30: 175-192.
Peña, J. E. \& Bennett., F. D. 1995. Arthropods associated with Annona spp. in the Neotropics. Florida Entomologist 78: 329-349.

Peronti, A. L. B. G; D. R. Miller \& C. R. Sousa-Silva. 2001. Scale insects (Hemiptera: Coccoidea) of ornamental plants from São Carlos, São Paulo, Brazil. Insecta Mundi 15: 247-255.

Qin, T. K. \& P. J. Gullan. 1994. Taxonomy of the wax scales (Hemiptera: Coccoidea: Coccidae: Ceroplastinae). Systematic Entomology 20: 289-308.

1995. A cladistic analysis of wax scales (Hemiptea: Coccoidea: Coccidae: Ceroplastinae). Systematic Entomology 20: 289-308.

Reyne, A. 1964. Scale insects from the Netherlands Antilles. Beaufortia 11: 95-130.

Signoret, V. 1869. Essai sur les cochonilles (Homoptères - Coccides), $2^{\mathrm{a}}$ partie. Annales de la Société Entomologique de France 8: $829-876$

1872. Essai sur les cochonilles (Homoptères - Coccides), $9^{\mathrm{a}}$ partie. Annales de la Société Entomologique de France 2: 33-46.

Silva, A. G. A.; C. R. Gonçalves; D. M. Galvão; A. J. L. Gonçalves; J. Gomes; M. N. Silva \& L. Simoni. 1968. Quarto catálogo dos insetos que vivem nas plantas do Brasil, seus parasitos e predadores. Rio de Janeiro, Ministério da Agricultura. Parte II, $1^{\circ}$ tomo, $622 \mathrm{p}$.

Tang, F. T. 1991. The Coccidae of China. Shanxi United Universities Press, Taiyuan, R. R. China. 378 p.

Targioni Tozzetti, A. 1866. Come certe cocciniglie sieno cagione di alcune melate delle piante, e di alcune ruggini; e come la cocciniglia del fico dia in abbondanza una specie di cera. Atti della $\mathbf{R}$. Accademia dei Georgofli (N.S.) 13: 115-137; App. 138-146. 1868. Introduzioni alla seconda memoria per gli studj sulle Coccinigle, e catalogo dei generi e della specie delle famiglia dei Coccidi. Atti della Società Italiana di Scienze Naturali e del Museo Civico de Storia Naturale de Milano 11: 694-758.

Vernalha, M. M. 1953. Coccídeos da coleção I.B.T.P. Arquivos de Biologia e Tecnologia 8: 11-304.

Vernalha, M. M; J. C. Gabardo, \& Da Silva, R. P. 1974. Coccideos do Brasil. V Coccidae. Ceroplastes (Octoceroplastes) hempeli Lizer, 1919. Acta Biológica Paranaense 3: 12-131.

Westwood, J. O. 1853. Wax insects. Gardeners' Chronicle Agricultural Gazette 31: 484.

1871. [Exhibitions]. Proccedings of the Entomological Society of London, p. iii.

Zucchi, R. A.; S. S. Neto \& O. Nakano.1993. Guia de Identificação de Pragas Agrícolas. FEALQ, Piracicaba. 139 p. 